\title{
Development of a Remote External Repair Tool for Damaged or Defective Polyethylene Pipe
}

\author{
Final Report
}

Reporting Period:

October 1, 2003 - June 30, 2006

\author{
Principal Authors: \\ Kenneth H. Green, Willie E. Rochefort, \\ Nick Wannenmacher, John A. Clark, Kevin Harris
}

February 2007

Contract/Grant No.

DE-FC26-03NT41879

\author{
Submitted by: \\ Timberline Tool \\ 2594 Montana Highway 35 \\ Kalispell, MT 59901 \\ Significant Subcontractor: \\ Oregon State University \\ Chemical Engineering Department \\ Corvallis, OR
}




\section{Disclaimer}

This report was prepared as an account of work sponsored by an agency of the United States Government. Neither the United States Government nor any agency thereof, nor any of their employees, makes any warranty, express or implied, or assumes any legal liability or responsibility for the accuracy, completeness, or usefulness of any information, apparatus, product, or process disclosed, or represents that its use would not infringe privately owned rights. Reference herein to any specific commercial product, process, or service by trade name, trademark, manufacturer, or otherwise does not necessarily constitute or imply its endorsement, recommendation, or favoring by the United States Government or any agency thereof. The views and opinions of authors expressed herein do not necessarily state or reflect those of the United States Government or any agency thereof. 


\section{Abstract}

Current procedures for repairing polyethylene (PE) gas pipe require excavation, isolation, and removal of the damaged section of pipe followed by fusing a new section of pipe into place. These techniques are costly and very disruptive. An alternative repair method was developed at Timberline Tool with support from Oregon State University (OSU) and funding by the U. S. Department of Energy National Energy Technology Laboratory (DOE/NETL).

This project was undertaken to design, develop and test a tool and method for repairing damaged PE pipe remotely and externally in situ without squeezing off the flow of gas, eliminating the need for large-scale excavations. Through an iterative design and development approach, a final engineered prototype was developed that utilizes a unique thermo-chemical and mechanical process to apply a permanent external patch to repair small nicks, gouges and punctures under line pressure.

The project identified several technical challenges during the design and development process. The repair tool must be capable of being installed under live conditions and operate in an 18-inch keyhole. This would eliminate the need for extensive excavations thus reducing the cost of the repair. Initially, the tool must be able to control the leak by encapsulating the pipe and apply slight pressure at the site of damage. Finally, the repair method must be permanent at typical operating pressures.

The overall results of the project have established a permanent external repair method for use on damaged PE gas pipe in a safe and cost-effective manner. The engineered prototype was subjected to comprehensive testing and evaluation to validate the performance. Using the new repair tool, samples of 4-inch PE pipe with simulated damage were successfully repaired under line pressure to the satisfaction of DOE/NETL and the following natural gas companies: Northwest Natural; Sempra Energy, Southwest Gas Corporation, Questar, and Nicor. However, initial results of accelerated age testing on repaired pipe samples showed that the high density polyethylene (HDPE) pipe patch material developed a small crack at the high stress areas surrounding the patched hole within the first 48 hours of hot water testing, indicating that the patch material has a 25-year lifespan. Based on these results, further research is continuing to develop a stronger repair patch for a satisfactory 50-year patch system. Additional tests were also conducted to evaluate whether any of the critical performance properties of the PE pipe were reduced or compromised by the repair technique. This testing validated a satisfactory 50 -year patch system for the pipe. 


\section{Table of Contents}

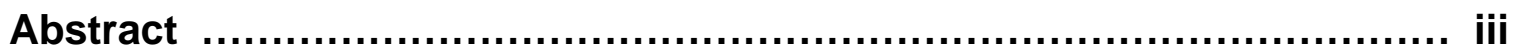

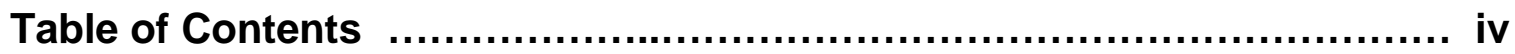

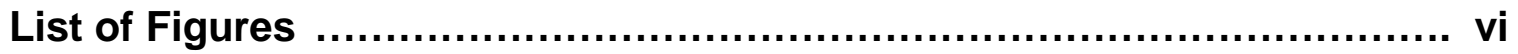

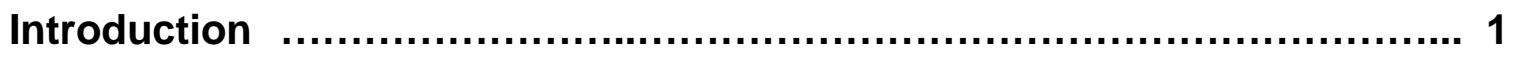

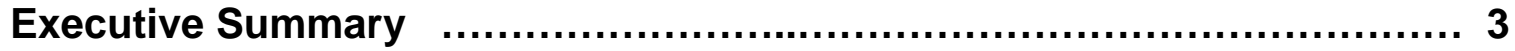

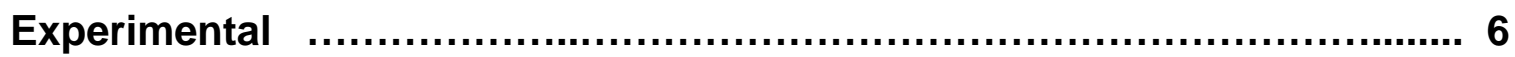

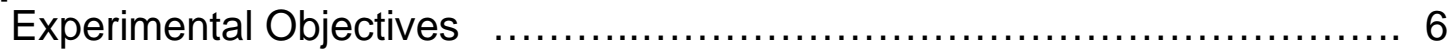

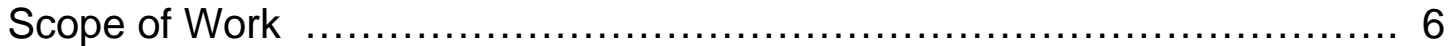

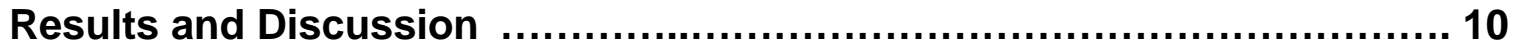

Task 1 Research Management Plan .................................... 10

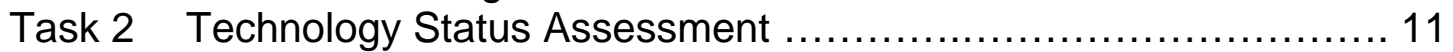

Task 3 Development of the Test Tool................................. 11

3.1 Safety Considerations for Repairing Pressurized Pipe....... 12

3.2 Test Tool Conceptual Design \& Development................... 13

3.3 Detailed Test Tool Design …........................... 17

3.4 Test Tool Construction and In-house Testing ............... 18

Task 4 R\&D of Chemical Bonding Process for Repair Patch $\ldots \ldots \ldots \ldots 19$

4.1 Chemical Bonding Process ................................ 20

4.2 Polymer Hot Weld ....................................... 25

4.3 Material \& Thickness of the Repair Patch ................. 25

4.4 Test Tool Performance Tests …........................ 28

Task 5 Laboratory Testing on Repaired PE Pipe Sections $\ldots \ldots \ldots \ldots \ldots . \ldots 28$

5.1 Pressure Testing .......................................... 28

5.2 Accelerated Age Testing …........................... 31

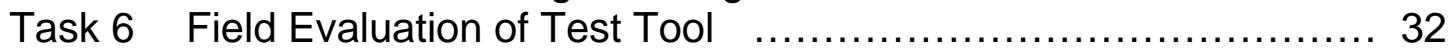

Task $7 \quad$ Technical Feasibility of the Test Tool ............................. 34

Task 8 Design \& Construction of Engineered prototype ................... 35

8.1 Mechanical Design \& Construction of Engineered

Prototype .............................................. 35

8.2 R\&D of Chemical Bonding Process for Repair Patch ........ 37

Task 9 Laboratory Testing on Repaired PE Pipe Sections.................. 43

9.1 Pressure Testing ........................................... 43

9.2 Accelerated Age Testing ................................. 45

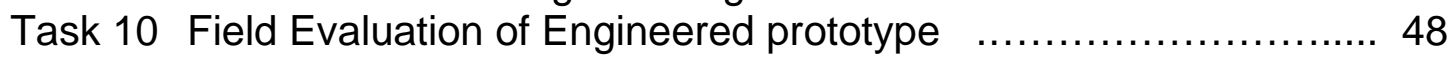

Task 11 Performance \& Design Assessment of Engineered Prototype...... 52 


\section{Table of Contents (continued)}

Conclusion

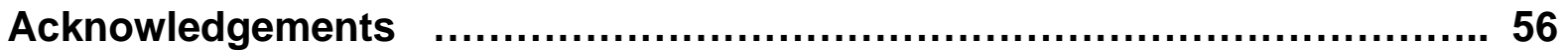

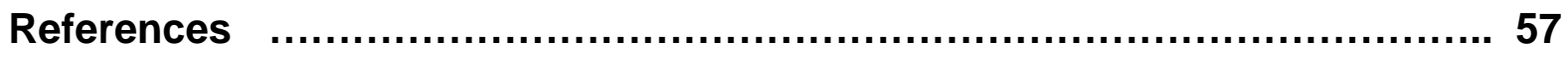

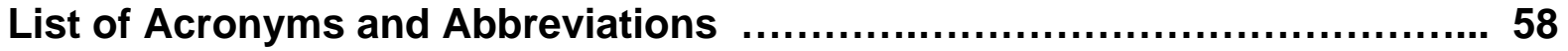

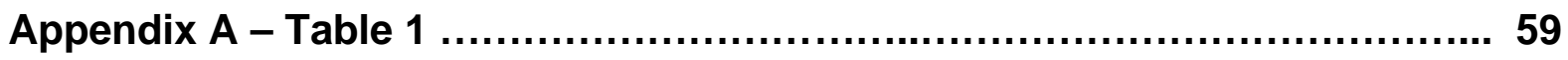

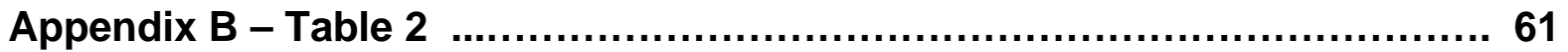




\section{List of Figures}

Figure 1. Keyhole Excavation

Figure 2. SolidWorks ${ }^{\circledR}$ 3D modeling of the mechanical tool design

Figure 3. Final Test Tool Design

Figure 4. Overlap Shear Test using an Instron Machine

Figure 5. Final design of engineered prototype for PE pipe repair

Figure 6. Phase 1 Timeline

Figure 7. Phase 2 Timeline

Figure 8. Repair Tool Design Concept 1

Figure 9. Repair Tool Design Concept 2

Figure 10. Repair Tool Design Concept 3

Figure 11. Final Test Tool Design

Figure 12. Computer numerically controlled (CNC) machining center

Figure 13. Final Test Tool with Repair Patch

Figure 14. Test tool successful in bonding the repair patch to 4-inch PE pipe

Figure 15. UHMWPE powder dissolved in heated solvent

Figure 16. Dissolved UHMWPE pressed into a sheet

Figure 17. Pressed Gel Sheet

Figure 18. UHMWPE gel sheet prior to being sandwiched between HDPE substrates

Figure 19. Carver press equipped with heated platens

Figure 20. Graph of cohesive vs. adhesive failures during lap shear tests

Figure 21. Overlapping Half-wrap Patch Design Concept

Figure 22. Overlapping Full-wrap Patch Design Concept

Figure 23. Preformed Overlapping Full-wrap Patch

Figure 24. Successful bond of PE gel patch to 4-inch MDPE pipe at 600 psi during quick burst testing

Figure 25. Failure of adhesive patch during quick burst testing at $450 \mathrm{psi}$

Figure 26. Quick burst test shows pipe failure below PE gel film patch indicative of successful bonding

Figure 27. Pipe sample with half patch showing hoop stress reinforcement

Figure 28. Overlapping full-wrap patch applied to 4-inch MDPE pipe during demonstrations for Northwest Natural

Figure 29. Completed bonding of overlapping full-wrap patch on 4" MDPE pipe

Figure 30. Test tool and PE gel film repair process successfully demonstrated to DOE/NETL project managers at Timberline Tool facilities

Figure 31. Quick burst test for DOE/NETL demonstrates successful bonding of PE gel film patch on 4-inch MDPE pipe

Figure 32. Engineered prototype design shown with 12-inch jaws

Figure 33. Differential scanning calorimetry curves of virgin PE vs. PE with solvent shows the effect of solvent on lowering the melting point of PE

Figure 34. SEM micrograph showing uniform PE bond interface

Figure 35. Diagram of Lap Shear Sample Design

Figure 36. Graph of bond strength as a function of bonding temperature

Figure 37. Swelling process used to fabricate a large PE gel film patch 
Figure 38. Photo of the final large PE gel film patch after the swelling process

Figure 39. Diagram of PE gel film patch design

Figure 40. Temperature vs. Heating Time for $257^{\circ} \mathrm{F} / 125^{\circ} \mathrm{C}$ platen temperature

Figure 41. Quick burst test with overlapping full-wrap gel film patch shows successful bond at $500 \mathrm{psi}$

Figure 42. Quick burst test with overlapping full-wrap gel film patch shows successful bond \& pipe failure below the patch at 600 psi

Figure 43. Closed system overlapping full-wrap gel film patch held at room temperature \& 200 psi for $>5$ months without any loss in pressure

Figure 44. Photo of HDPE patch material failure at the 25-year mark during accelerated age testing

Figure 45. Graph of HDPE patch material strength loss vs. time in days

Figure 46. Graph of HDPE patch material strength loss at $5,15, \& 18$ days

Figure 47. Broken embrittled HDPE material compared to typical necking in HDPE control sample

Figure 48. PE gel film repair patch being loaded into the engineered prototype for Nicor Gas demonstration in Naperville, IL

Figure 49. Engineered prototype with PE gel film repair patch being applied to damaged 4-inch MDPE pipe

Figure 50. PE gel film patch successfully repaired a damaged 4-inch MDPE pipe

Figure 51. Overlapping full-wrap PE gel film patch successfully bonded to oxidized 4-inch IPS Aldyl-A pipe during demonstration for Sempra Energy

Figure 52. Final engineered prototype applying a PE gel film patch on 4-inch MDPE pipe 
This page left intentionally blank 


\section{Introduction}

The use of polyethylene (PE) pipe for natural gas transmission and distribution within the United States has been steadily growing over the past decade and currently accounts for a majority of America's natural gas distribution network. It is very important that the natural gas delivery system remain safe, reliable, and operate efficiently. In the near future, the number of miles of distribution and transmission PE pipe is projected to increase, ${ }^{1}$ warranting the need for improved construction tools, maintenance, and repair methods to keep up with the expected growth. ${ }^{2}$

If a pipeline of greater than $3 / 4$-inch diameter has damage to more than 10 percent of the wall thickness, or if the pipe wall has been fully penetrated, current procedures for repairing buried natural gas pipe require excavations upstream and downstream from the rupture point and isolation of the damaged section of pipe by "squeezing off" the flow of gas on both sides of the damage. The damaged section of pipe is then excavated and repaired with a mechanical repair fitting or cut out and replaced with a new pipe segment using either two couplings or a fusion joint and a coupling. These repair procedures are costly and very disruptive. ${ }^{2}$

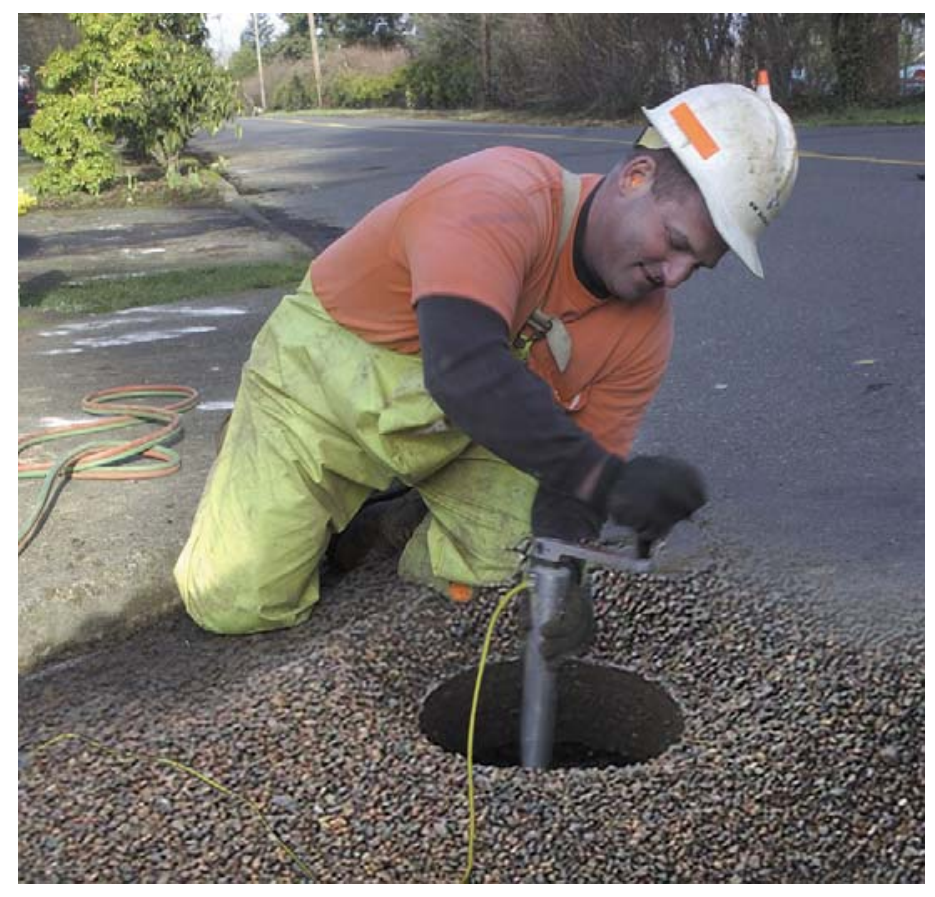

Figure 1: Keyhole Excavation

The portable and lightweight repair tool developed in this project operates from the top-down, without the need to fasten the device under the pipe. This dramatically improves the safety and repair procedures because one person conducts a single 
repair operation and a single excavation. It operates in difficult and keyhole access situations (Figure 1) without the need for pipe squeeze-off.

The new repair tool operates remotely from the ground surface keeping the operator out of the trench, away from the danger of cave-in and flowing natural gas. The safety of the utility operator is the most important benefit of this repair tool. Another key benefit of the repair tool is its ability to operate in "keyhole" excavations. This type of excavation minimizes the impact to the surrounding environment and disruption to the neighborhood. Time and labor savings due to reduced excavation and ease of application are expected to be significant. Maintenance and repair costs will be significantly lowered by the increased efficiency of the new repair method developed by this project. This repair tool gives operators the ability to repair the PE pipe at the site of the damage without additional excavation, and without shutting off the gas supply and interrupting the natural gas distribution to homes and businesses. It is estimated that the natural gas industry spends 3.5 billion dollars on repairs within the continental United States per year. ${ }^{3}$ By perfecting this repair process, thousands of pipe leaks will be repaired at a fraction of the current remediation cost, saving on average, $\$ 2250$ per repair. $^{4}$ 


\section{Executive Summary}

Timberline Tool with support from Oregon State University (OSU) and funding by the U. S. Department of Energy National Energy Technology Laboratory (DOE/NETL) developed a tool and thermo-chemical process for the external repair of damaged or defective polyethylene (PE) pipe. The objectives of this project were to design and develop a mechanical tool that would apply a thermo-chemical patch to fully encapsulate a 4-inch PE pipe at the site of the damage or defect, accomplishing this under line pressure and varying environmental conditions.

Safety of the operator was the foremost criteria in the development of this process and tool. This repair tool technology operates remotely from the ground surface keeping the operator out of the trench, away from the danger of cave-in and flowing natural gas. Another key design criteria of the repair tool was the ability of the tool to operate in keyhole excavations. This repair tool allows the natural gas operator to repair the PE pipe at the site of the damage without additional excavation, and without shutting off the gas supply and interrupting the natural gas distribution to homes and businesses. This repair process allows the natural gas distribution industry to repair defective or damaged PE pipe at a fraction of the current remediation costs.

The repair tool was designed for mechanical operation by one person. The tool is lightweight (constructed of aluminum alloy) and easy to operate. The process to apply the thermo-chemical patch is very straightforward. First, the patch is inserted in the application tool. Then the tool is centered over the damaged area and lowered onto the pipe. Finally, the tool is operated (jaws are closed) until it reaches a mechanical stop. When the tool is completely closed the thermo-chemical patch fully encapsulates the pipe sealing off the leak and covering the area of damage. At this point, the tool and patch are ready for activation. The jaws of the tool transfer heat to the patch, activating the chemical patch. Once the appropriate "soak" time for heating has been reached, the tool is deactivated and allowed to cool. When the jaws of the tool reach the optimum cool-down temperature, the tool is removed from the pipe. Backfilling operations can be commenced immediately.

The thermo-chemical patch was developed so the utility operator would not need to prepare the surface of the pipe prior to application. The patch was designed to work over dirt, grit, oxidized pipe, etc. This attribute makes it ideal for applying the patch remotely. The chemical patch is similar to a sandwich. The outside layer of the patch is composed of high density polyethylene (HDPE) (PE 3408) and the inner surface is a swollen gel film made from a sheet of HDPE (10 mils thick). The swollen gel film is held in place on the patch by means of another layer of HDPE ( 2 to 5 mils thick). When heat is applied to the swollen gel film, the solvent in the gel lowers the melting point of the surface (the first 2 millimeters) of the PE pipe and the patch. This allows fusion welding to take place at the surface of the PE pipe. This bond is formed at a temperature of $230^{\circ} \mathrm{F} / 110^{\circ} \mathrm{C}$, well below the melting point of 
polyethylene $\left(275^{\circ} \mathrm{F} / 135^{\circ} \mathrm{C}\right)$. This allows for fusion welding to take place at the substrate (patch)-film-substrate (pipe) interface without appreciably lowering the overall strength of the bulk of the substrate (pipe/patch) polymers during the bonding process. This creates a very strong seamless bond and maintains the integrity of the pipe.

Laboratory testing of the repaired pipe samples confirmed that the shear strength of the bond formed with the chemical patch approached 1600 psi and quick burst tests on the repaired pipe samples resulted in the pipe material rupturing at 600 psi with the repair patch remaining intact.

Using the new repair tool, pressurized (60 psi) samples of 4-inch PE pipe with simulated damage were successfully repaired to the satisfaction of DOE/NETL and the following natural gas companies: Northwest Natural; Sempra Energy, Southwest Gas Corporation, Questar, and Nicor. After the repair tool was clamped on the damaged area, the escaping airflow was shut off completely. The tool was then activated and the chemical patch was applied to the pipe. Upon completion of the process, the tool was removed and the patch was leak tested under pressure. No leaks were present.

At the conclusion of the field demonstrations, the repaired pipe sections were either sectioned to assess completeness of the bond or subjected to accelerated age testing. The dissected sections of pipe revealed that the bond between the pipe and patch was nearly seamless. Results of accelerated age testing showed no degradation of the pipe or repair patch bond at the 50-year mark. The HDPE patch material, however, showed embrittlement at the 25-year mark. Further research is being conducted to determine the optimum patch material for a 50-year lifespan.

The DOE/NETL sponsored phase of development for a remote external repair tool is complete. This project successfully developed the following:

1. Thermo-chemical patch to bond PE to PE

2. Mechanical tool to apply the thermo-chemical patch under line pressure

3. Remote, external repair tool for use in open trench or keyhole excavations

4. Permanent repair method for PE pipe to provide substantial cost savings

5. New method for quick, safe repair at the site of damage

This thermo-chemical process will allow the natural gas industry to reduce their operating costs to maintain and repair their PE service and distribution pipelines while making the jobsite safer for their employees and the public. It is estimated that the use of this system will save the industry between $\$ 1000$ and $\$ 3500$ per incident in operating costs depending on the size and complexity of the maintenance/repair project. The natural gas industry estimates that they have 150,000 damage and/or repair incidents per year. 
On-going research is being conducted on the repair patch material and the engineered prototype to optimize the repair process in preparation for commercialization. 


\section{Experimental}

\section{Experimental Objectives}

The overall objective of this work was to develop a remote repair tool with unique chemical and mechanical processes to apply a permanent external repair patch to damaged or defective buried PE natural gas pipe.

\section{Scope of Work}

The research effort consisted of experimental and analytical studies conducted in two phases to develop new technology for repairing damaged PE pipe using a repair process comprised of two components: (1) a mechanical tool and (2) a thermochemical repair patch composed of either (a) PE gel film or (b) PE adhesive.

\section{PHASE 1}

\section{Development of the Test Tool}

Three mechanical tool configurations were designed. The optimum design was developed using SolidWorks ${ }^{\circledR}$ 3D modeling (Figure 2) to ensure remote operation, keyhole application, and compliance with natural gas industry operating practices. ${ }^{6}$

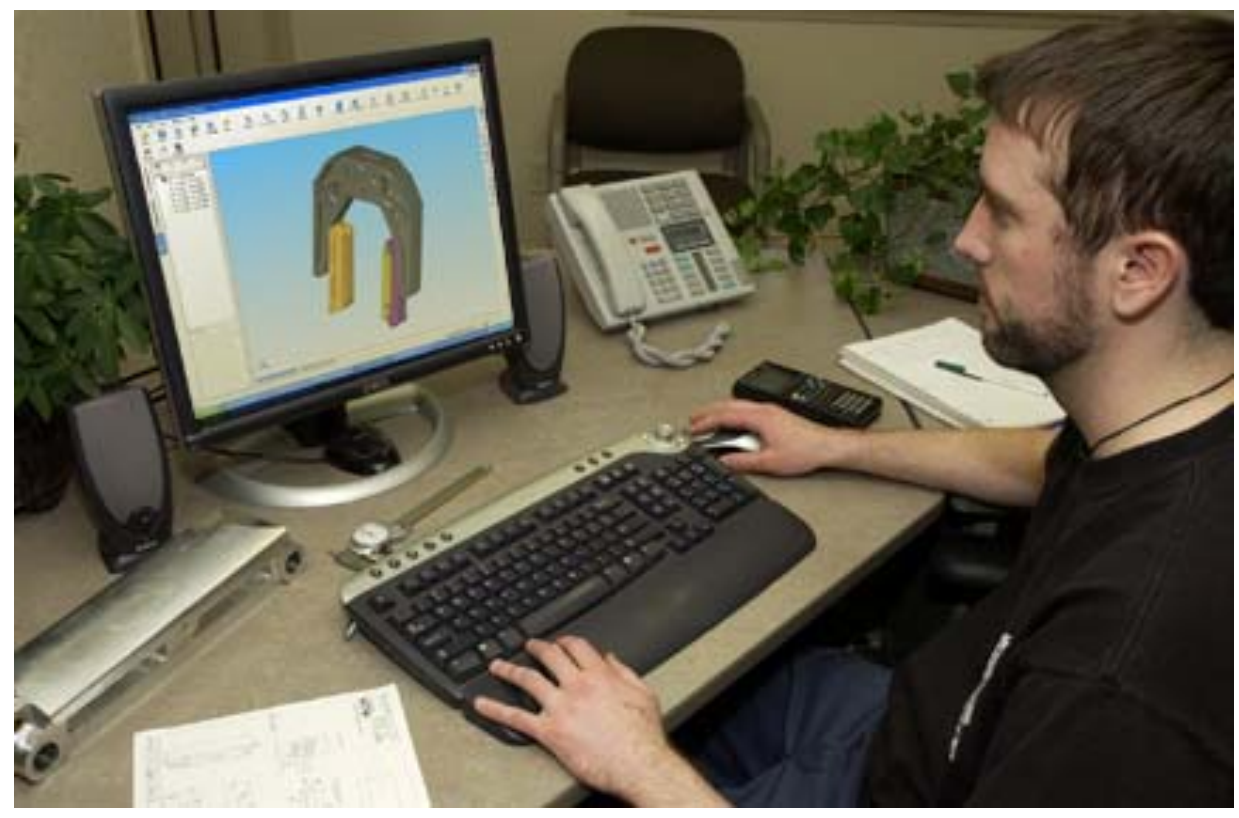

Figure 2: SolidWorks ${ }^{\circledR} 3 D$ modeling of the mechanical tool design 
Specific design goals included:

- Lightweight construction

- Top-down application

- Operation from ground level

- Operation in confined space or keyhole opening

- Effective operation on 4-inch diameter PE pipe.

The optimum design concept (Figure 3) was chosen and a test tool was developed and tested in the laboratory to determine functionality, safety and reliability.

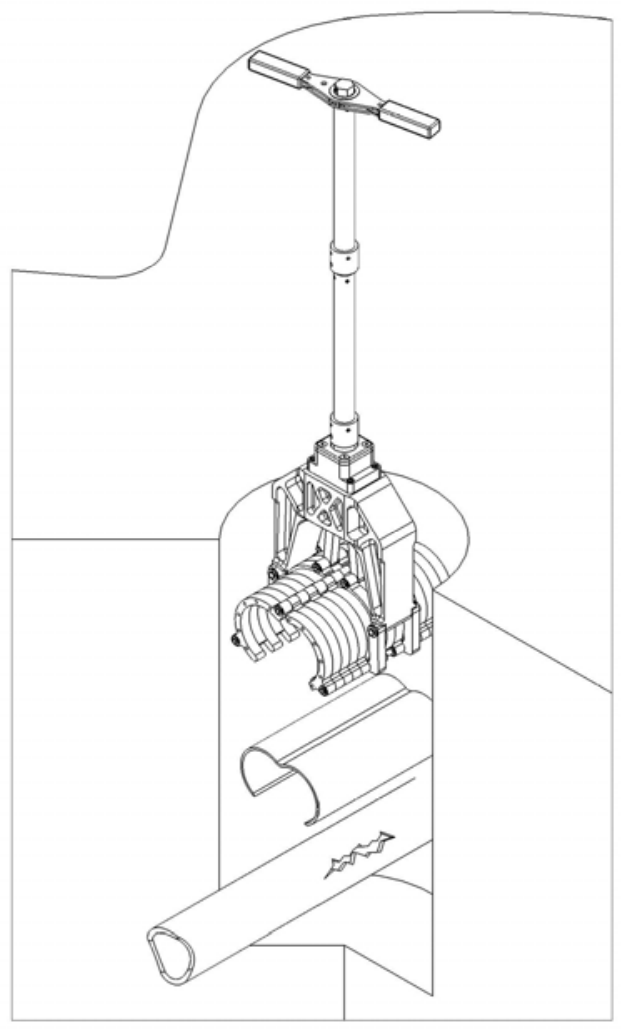

Figure 3: Final Test Tool Design

\section{Development of the Repair Patch}

Two unique repair approaches were investigated. Both methods incorporated the technique of polymer hot welding and used the same mechanical tool to apply the patch.

1. PE gel film bonding: A gel-like bonding agent was used to attach the PE patch and join the surfaces of the PE patch material and the damaged pipe. The research focused on defining a PE gel to bond PE to PE natural gas pipe 
and testing the bond to withstand at least 500 psi internal pipe pressure (the approximate quick burst pressure of undamaged 4-inch SDR 11.5 medium density polyethylene pipe (MDPE)). The investigation focused on using two solvents (xylene and decalin) to produce the gels. ${ }^{7}$

2. PE adhesives: This method utilized structural plastic glues to join the surfaces of the PE patch and the damaged PE pipe. This phase of the research focused on finding an adhesive to bond PE to PE natural gas pipe, which would withstand at least 500 psi (as with the gel concept above). Although many different adhesives were considered, the investigation focused on three structural plastic glues (3M DP8005, 3M DP8010 and Loctite 3030). Glue strength was tested on all three glues with an overlap shear test using an Instron machine (Figure 4).
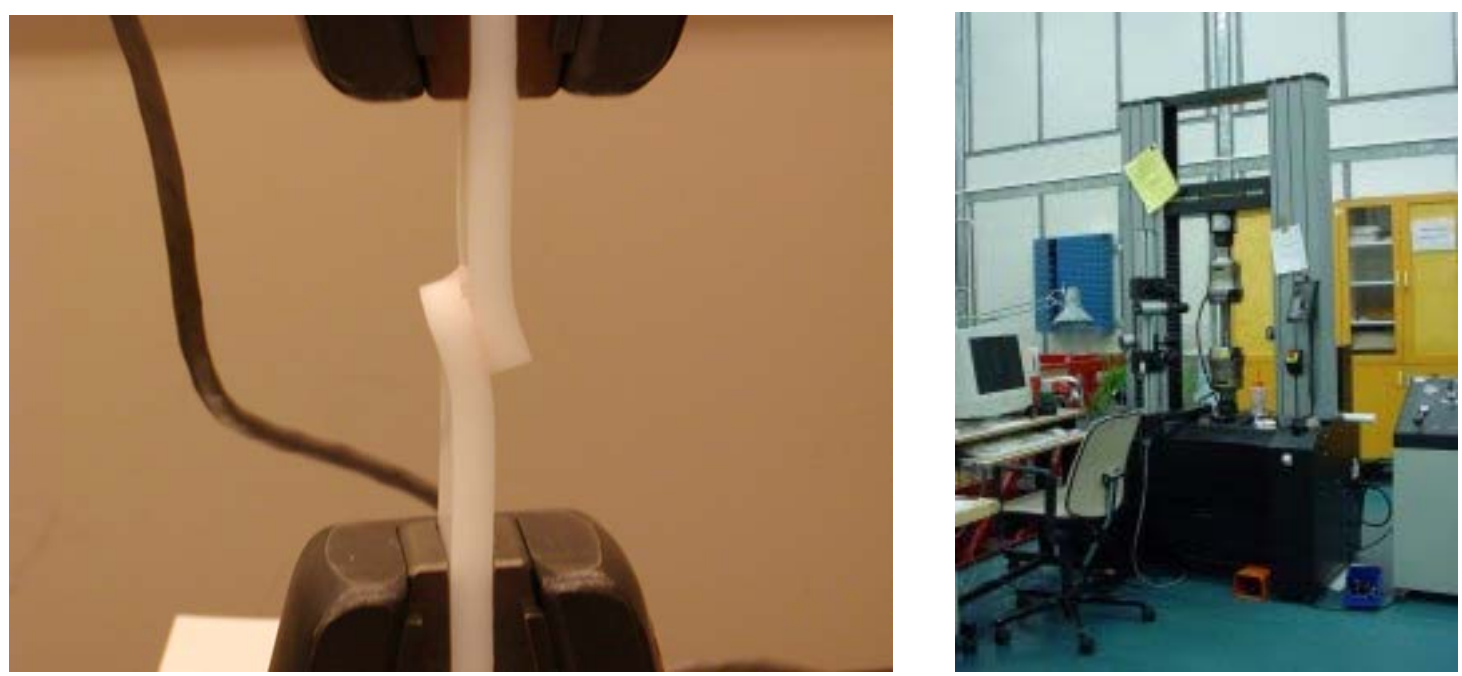

Figure 4: Overlap Shear Test using an Instron Machine

Phase 1 work also included investigation to determine if a dissimilar polymer existed that could be utilized to polymer hot weld the PE patch to the PE pipe. The optimal configuration for the repair patch with respect to size, thickness, and material (low density polyethylene (LDPE), MDPE, HDPE, ultra-high molecular weight polyethylene (UHMWPE) or PE composite pipe) was investigated during this phase.

\section{Laboratory Testing on Repaired Pipe Sections}

Laboratory tests (quick-burst tests and sustained pressure tests) were performed on PE pipe sections repaired by the test tool to determine the overall performance and the quality of the repair. These tests were completed in accordance with ASTM D1598 (sustained pressure) and ASTM D1599 (quick-burst) at $73^{\circ} \mathrm{F} / 23^{\circ} \mathrm{C}$ and $176^{\circ} \mathrm{F} / 80^{\circ} \mathrm{C}$. 


\section{PHASE 2}

Information from Phase 1 was used to guide the final design of the engineered prototype and the repair patch (Figure 5).

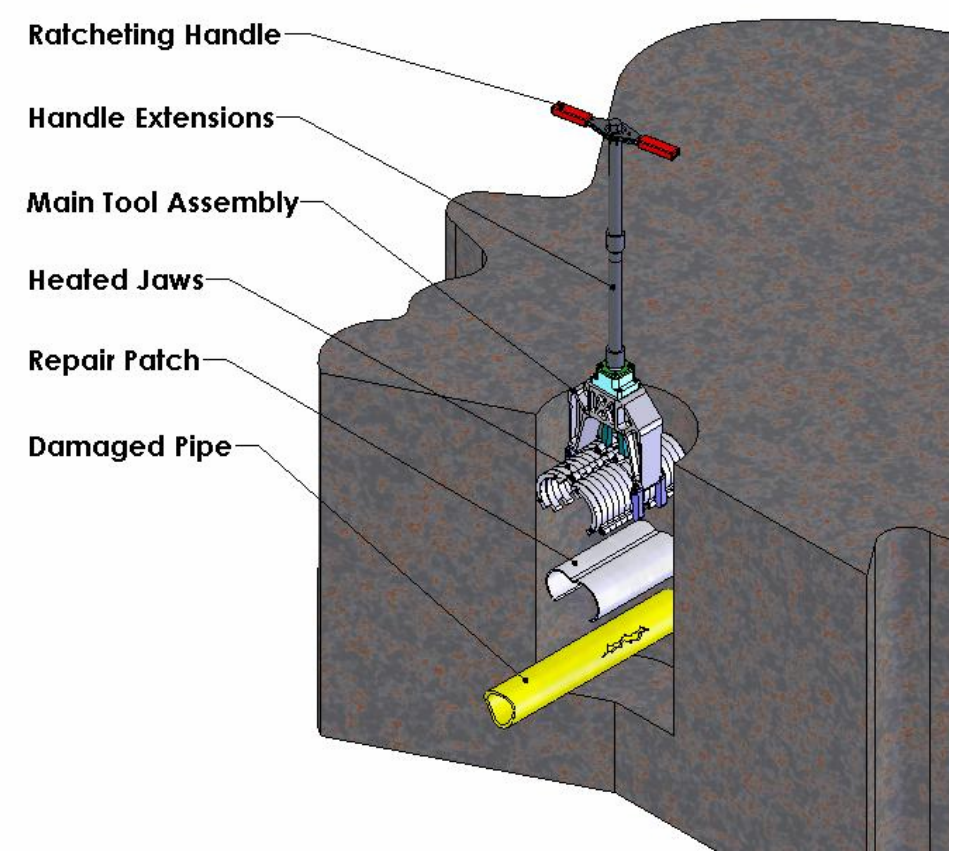

Figure 5: Final design of the engineered prototype for PE pipe repair

\section{Mechanical Design and Construction of Engineered Prototype}

Based on initial test results, several improvements to the test tool were incorporated in the design of the engineered prototype. The preferred design was 3-D modeled and a prototype was constructed of 6061-T6 aluminum. A series of functionality tests, per ASTM F1563 were performed to validate the design changes.

\section{Chemical Bonding Process for Repair Patch}

Based on Phase 1 results, two patch configurations emerged as the most promising:

1. PE gel film patch utilizing an UHMWPE gel-like material and a HDPE patch material.

2. $P E$ thermal adhesive patch consisting of commercially available PE adhesives on a HDPE patch material.

Research was completed to determine the temperature, pressure, set-time, and cure-time necessary for optimum bonding of each configuration and to compare the two. Laboratory tests were performed on pipe samples repaired with the engineered prototype using both patch configurations. These tests included: lap shear, ASTM 1598 (accelerated age and sustained pressure tests) and ASTM D1599 (quick-burst tests at $73^{\circ} \mathrm{F} / 23^{\circ} \mathrm{C}$ and $176^{\circ} \mathrm{F} / 80^{\circ} \mathrm{C}$ ). 


\section{Results and Discussion}

This project was performed in two Phases. During Phase 1, various conceptual designs were developed for the mechanical tool to apply the thermo-chemical patch to the compromised area on the PE pipe (Figures $8,9 \& 10)$. A preferred mechanical tool and repair patch design were selected and laboratory tests (quickburst tests and sustained pressure tests) were performed on repaired PE pipe sections to determine the overall performance of the test tool, and the quality and adequacy of the repair procedure. In Phase 2, information gained in Phase 1 was used to continue the research on the thermo-chemical repair patch and construct two engineered prototypes. Laboratory tests were performed on repaired PE pipe sections using the same testing protocol and procedures as Phase 1. Specific results and progress are discussed under each task listed below.

\section{PHASE 1}

\section{Task 1.0 - Research Management Plan}

A Research Management Plan was developed and submitted to DOE/NETL in December 2003 for their review and approval. The plan included a work breakdown structure addressing the overall project, a summary of the technical objectives and technical approach for each task and subtask, a detailed schedule (Figures 6 and 7), planned expenditures for each task and all major milestones and decision points.

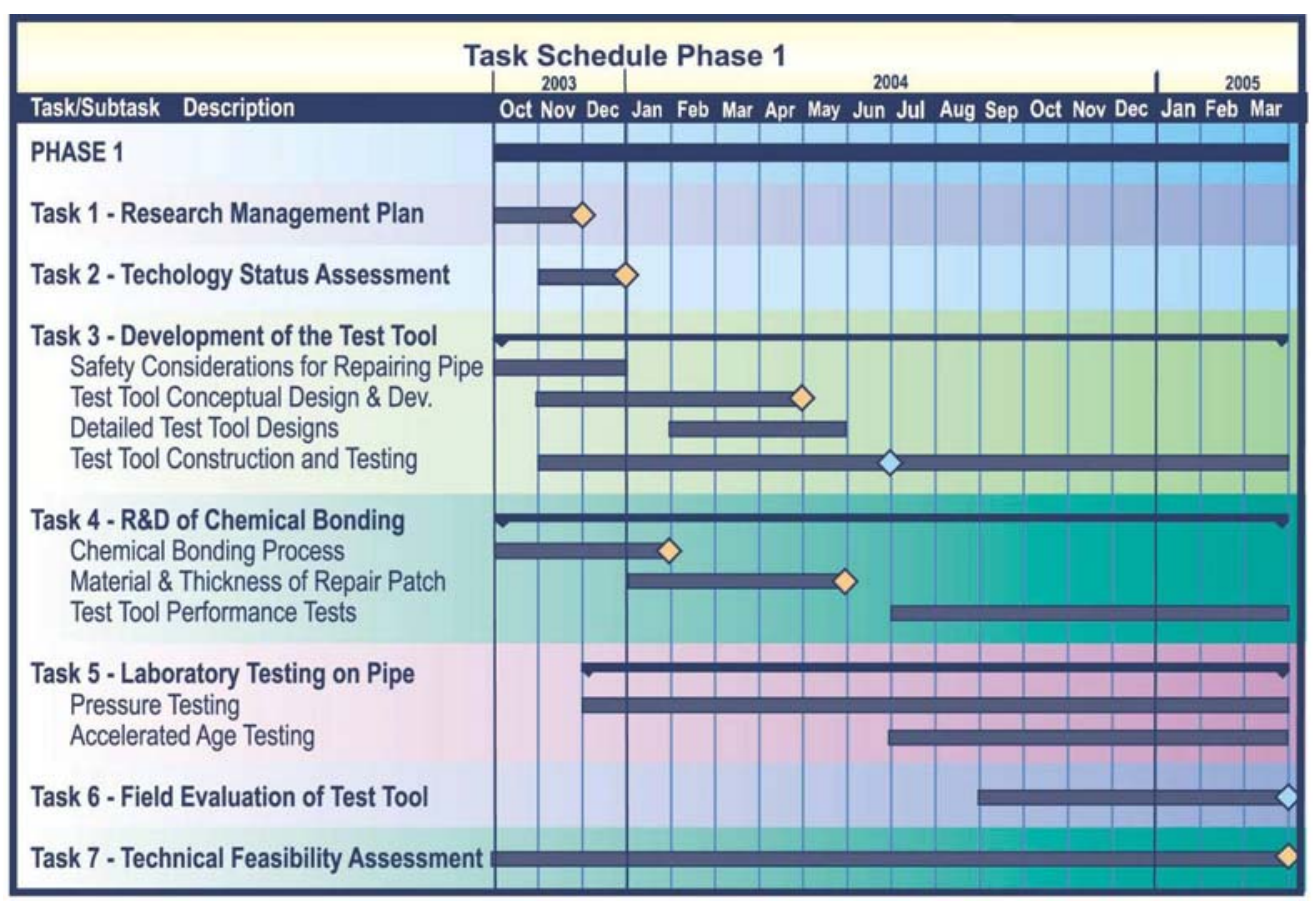

Figure 6: Phase 1 Timeline 


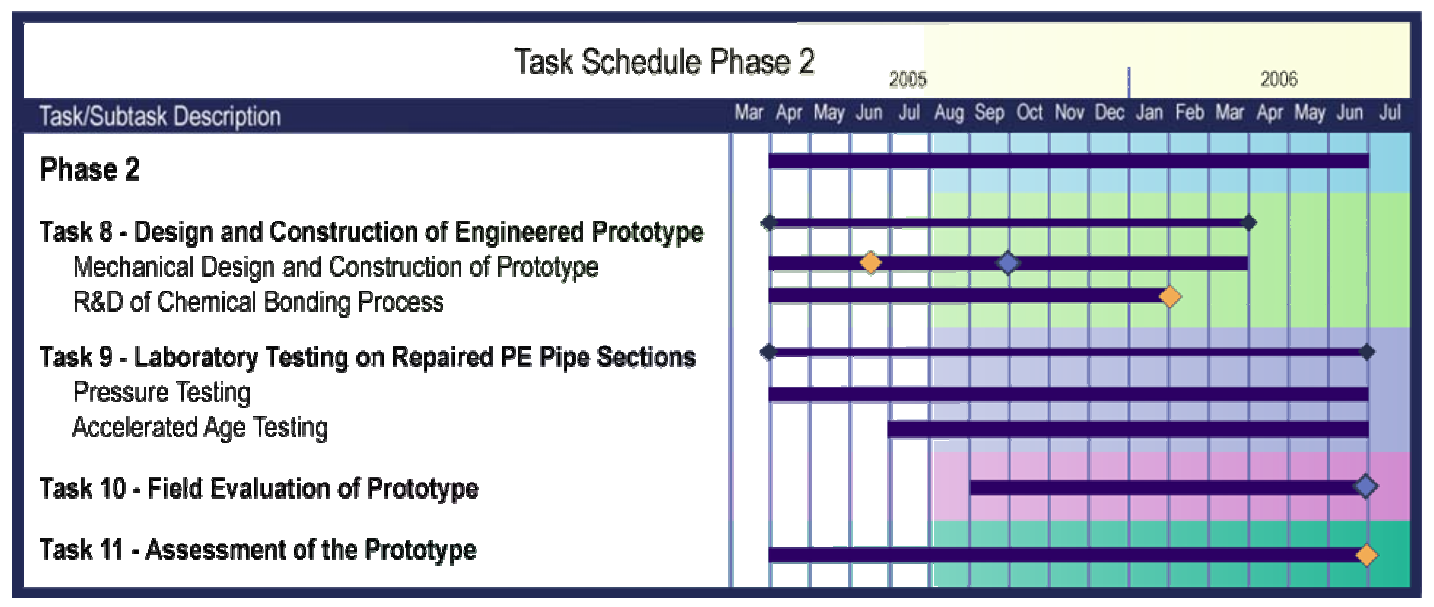

Figure 7: Phase 2 Timeline

\section{Task 2.0 - Technology Status Assessment}

A Technology Status Assessment was submitted to DOE/NETL describing the current state-of-the-art of PE pipe repair technology. The report described the technology being developed by this project and the positive and negative aspects compared to competing technologies. There is currently no method available for external permanent repair of PE pipe. Current repair methods interrupt service to the customer and require costly excavation, isolation and removal of the damaged section of pipe followed by fusing a new section in place. ${ }^{8}$ The report showed that the proposed technology would provide significant advantages for repairing PE pipe under live conditions and would provide a permanent, cost-effective, safe solution to repair PE pipe.

\section{Task 3.0 - Development of the Test Tool}

The objective of this task was to develop a mechanical tool that could apply and cure the repair patch being developed concurrently at OSU. During this task, research was performed to determine constraints and guidelines the tool had to meet in order to be successful in both laboratory and field evaluations. The entire process from conceptual design to producing a working test tool is discussed in detail in the following subtasks.

The following subtasks were undertaken to develop several test tool mechanical design concepts in Phase 1. Each of the design concepts were suitable for accepting and applying the patch being developed in Task 4. 


\section{Subtask 3.1 - Safety Considerations for Repairing Pressurized Pipe}

An optimal test tool configuration and process to safely repair a fully pressurized PE pipe was established by:

- Researching the safety requirements for workers when performing repairs on pressurized PE gas pipe.

- Researching current methods used to repair PE pipe and the type of damage typically encountered.

- Researching pipeline safety requirements to ensure that the PE pipe repair tool and process conforms to federal and state regulations.

- Performing laboratory shear tests on samples of bonded PE to determine the type of patch configuration the tool would be able to accommodate.

The following natural gas companies participated in field evaluations.

- Northwest Natural Gas - Portland, OR

- Southern California Gas - Los Angeles, CA

- San Diego Gas \& Electric - San Diego, CA

- Southwest Gas Corporation - Tempe, AZ

- Questar - Salt Lake City, UT

- Nicor - Naperville, IL

- Michcon - Detroit, MI

- KeySpan Energy - Long Island, NY

Emphasis on safety issues when repairing PE gas pipe under live conditions were addressed. The operating procedures varied by company and region. A major concern for all companies was the possibility of trench collapse and ignition of blowing gas. The information provided by the gas companies stressed the importance of safety. They made it clear that the repair tool needed to greatly reduce the risk, and the number of people at risk, in repairing a compromised section of gas pipe. All the companies were very interested in repair tool technology to keep their operators out of the trench and away from blowing gas.

When contacted regarding current operating procedures and safety concerns, the gas companies were also queried on the types of damage typically encountered. They reported damage to gas pipelines might occur as a result of:

- Third party damage

- Failure of butt fusion joints

- Rock impingement

- Slow crack growth (SCG) which often results from scrapes, nicks or gouges during installation, maintenance or repair operations.

All respondents replied that third party damage was the most frequently encountered. The size of the damage ranged from small, pinhole leaks to large 
ruptures. Based on the information regarding the size of the damage typically encountered, the repair tool was designed to deliver a repair patch to fully encapsulate a 4-inch diameter pipe and cover a 12-inch long section of pipe.

Research was conducted at OSU on potential patch configurations (detailed in Task 4) and requirements for bonding polyethylene to PE pipe. Results revealed that heat and a small amount of pressure would be required for both adhesive and thermochemical bonding methods to produce a desirable bond. Therefore, the tool was designed to provide heat to the patch, and apply a sufficient amount of pressure to the bond area.

\section{Subtask 3.2 - Test Tool Conceptual Design \& Development}

Using the information obtained from chemical testing conducted at OSU and input from participating gas companies, the project team developed a list of constraints and guidelines for the design and development of the repair tool.

Using the design constraints and criteria listed below, several conceptual mechanical designs were evaluated to meet the PE pipe repair objectives. The candidate mechanical designs were 3-D modeled and Finite Element Analysis (FEA) was performed by Timberline engineers to determine a suitable design.

Design Constraints:

- Does not provide a source of ignition: To meet this requirement, low or non-sparking material, such as aluminum, was used. In addition, the electrical components providing the current for the heat were well insulated to protect from any arcing.

- Does not require a person to enter the ditch: Since trench wall collapse is a major safety concern in the natural gas industry, the tool was designed to be fully operable from ground level.

- Functions in an 18-inch diameter keyhole: Since the natural gas industry is moving towards keyhole excavations, the tool was designed to be fully operable within an 18-inch diameter keyhole.

- Requires less than four inches of excavation under the pipe: The tool was designed to apply a patch underneath the pipe within a keyhole excavation.

- Weighs less than 60 lbs: The tool was designed to be easily transported by a single individual.

- Requires only one person for operation: In an effort to minimize work force needed to repair a pipe, the tool was designed for one person to transport the tool and complete the repair process.

- Meets physical requirement of ASTM F 1563-01: Although there are no ASTM standards for such a repair tool, the ASTM standards for PE pipe squeeze tools were used to ensure mechanical reliability. 
- Applies a chemical and/or thermo-chemical patch that retains or improves the integrity of the pipe: Once OSU determined the ideal chemical patch system and process, the mechanical tool was designed to apply the patch to completely encapsulate the pipe.

- Applies a chemical and/or thermo-chemical patch that stops the flow of gas from the leak: To eliminate the risk of igniting the issuing gas, the repair tool was designed to stop the flow of gas immediately upon application, and apply sufficient pressure to the patch and pipe to maintain the seal.

- Constructed from chemical and/or thermo-chemical resistant materials: Since the established chemical patching process uses both heat and chemicals, the tool was designed to withstand any adverse affects from these processes.

Design Guidelines:

- Simple design: The tool was designed to be easy to maintain and simple to manufacture.

- Ability to repair the majority of ruptures: The tool was designed to repair small nicks as well as large gouges.

- Cost effective: The tool was manufactured to be affordable and offer substantial cost savings to the industry.

- Capable of operating in environmental extremes: The tool was designed for use in very cold as well as very hot climates.

- Requires minimal to no pipe preparation: To keep operating costs at a minimum, the thermo-chemical patch and tool were designed to require little or no pipe preparation.

Eight initial design concepts were investigated ranging from simple and straightforward to very complicated. Three were researched further based on computer aided design (CAD) validity with one design concept chosen for development. 
CAD Concept 1 (Figure 8): Solid jaws were incorporated and manipulated by three linkage points. Solid jaws were beneficial in applying constant controlled pressure, but were not favorable for work on more than one pipe size. In order for the tool to apply pressure to the repair patch, a constant downward force and/or the use of loaded springs or cylinders was required. This concept had an asymmetrical closure on the pipe, which could present problems when used in keyhole excavations.

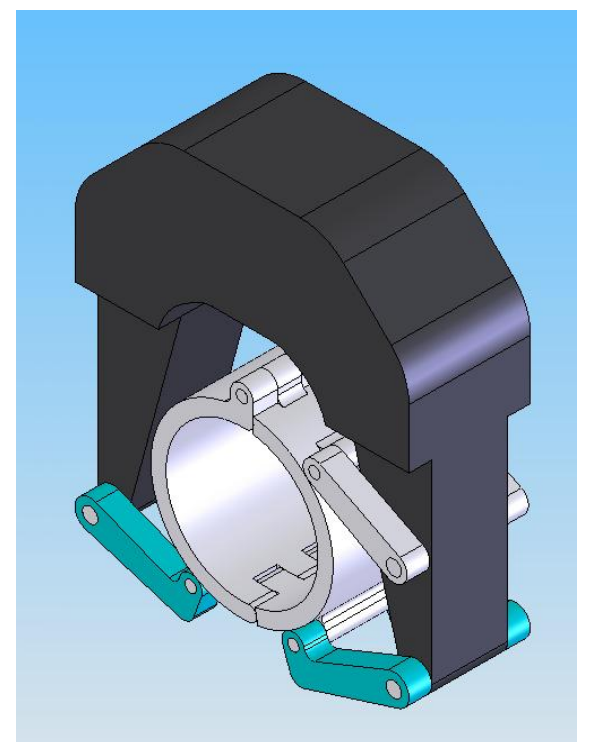

Figure 8: Repair Tool Design Concept 1

CAD Concept 2 (Figure 9): Solid jaws were incorporated with four linkage points to open and close the jaws. Closure was controlled mechanically by turning a drive thread. This concept provided symmetrical closure on the pipe making it more advantageous than Concept 1 , especially for use in keyhole excavations.

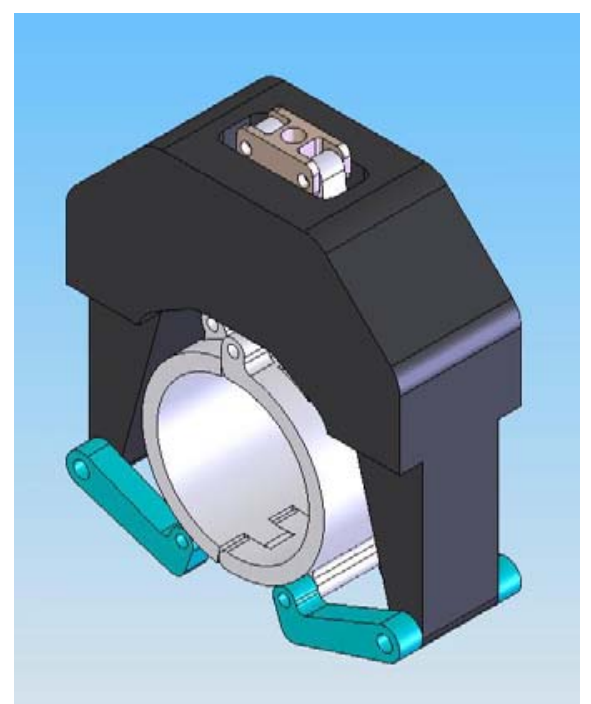

Figure 9: Repair Tool Design Concept 2 
CAD Concept 3 (Figure 10): This concept differed from the other two CAD concepts by utilizing a flexible jaw made from either spring steel or a band heater. Three linkage points wrapped the jaw around the pipe, and with downward force and/or loaded springs applied pressure to the patch. However, the jaw closure did not exhibit as much control as CAD Concept 1 or 2.

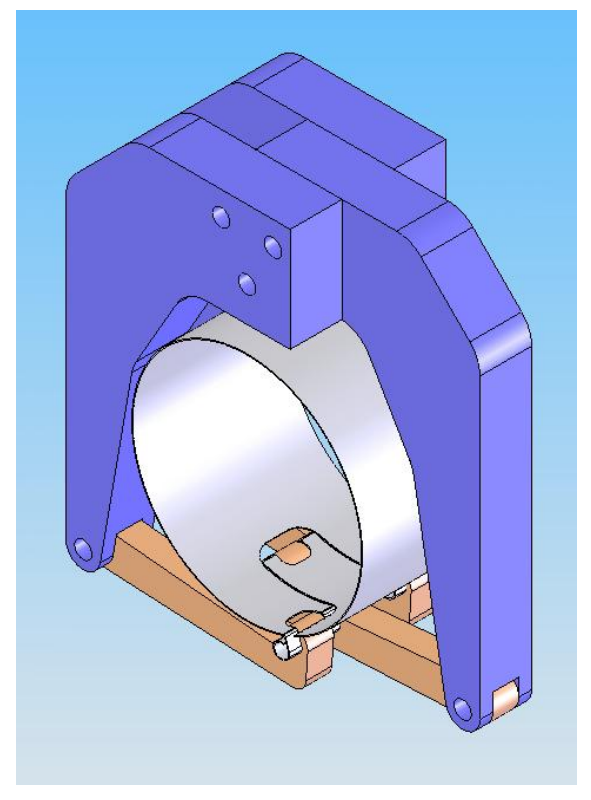

Figure 10: Repair Tool Design Concept 3

Concept 2 was chosen for further investigation because it provided several advantages over the other concepts:

- Relatively easy to manufacture due to few moving parts

- Solid jaws with four linkage points on each jaw

- Applied uniform pressure to the patch

- Easily controlled mechanical closure 


\section{Subtask 3.3 - Detailed Test Tool Design}

The technical objective of this subtask was to refine the design selected for implementation in Subtask 3.2, and create mechanical drawings needed to manufacture the test tool. The design of the tool (Figure 11) was refined utilizing FEA and CAD, with the following enhancements made to the final tool:

- The dynamics of the tool were reviewed and verified.

- Mechanical stops were added to insure the reliability of the tool.

- The weight of the tool was minimized while ensuring structural integrity.

- The design was reviewed to ensure suitability for manufacturing.

- The jaws were redesigned as layered components and cut using the water jet method to simplify the production process.

- The jaw design was improved to accommodate cartridge heaters and a thermocouple.

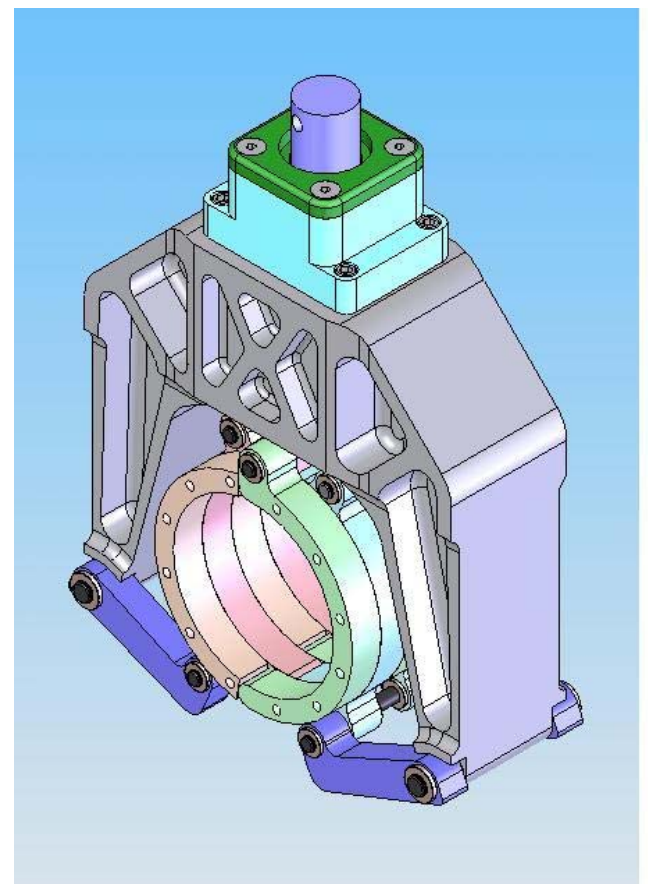

Figure 11: Final Test Tool Design 


\section{Subtask 3.4 - Test Tool Construction and In-house Testing}

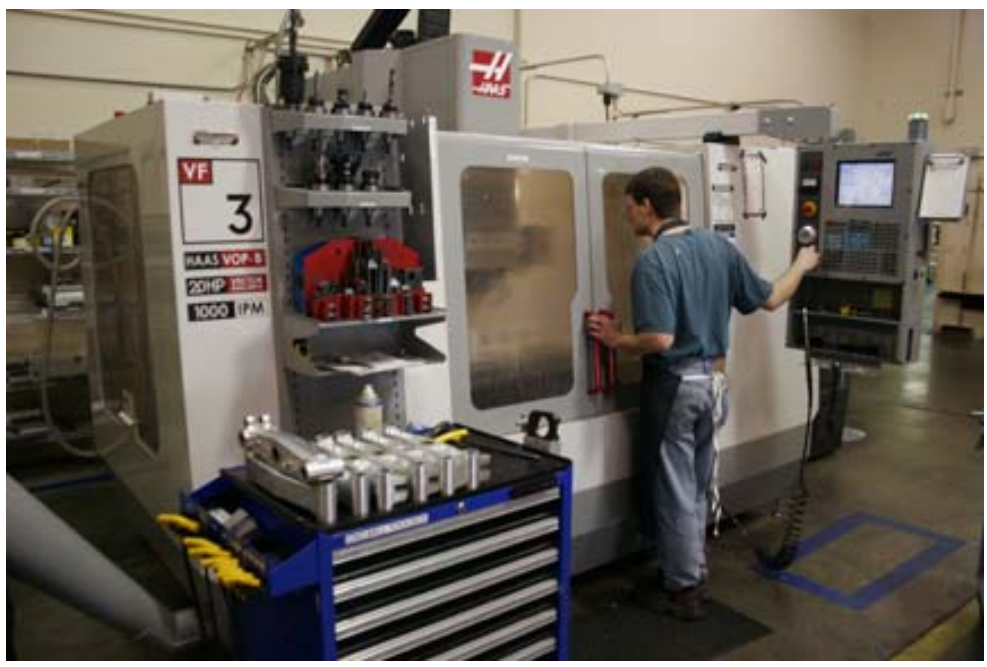

Figure 12: Computer Numerically Controlled (CNC) Machining Center

The preferred design was transferred from SolidWorks ${ }^{\circledR}$ to Computer Aided Machining (CAM) software for virtual machining of each part. The CAM software output a program to manufacture each tool component using Computer Numerically Controlled (CNC) machining centers (Figure 12). The test tool was assembled (Figure 13) based on the mechanical drawings presented in Subtask 3.3. A majority of the mechanical components were fabricated from 6061-T6 aluminum. In-house testing was performed to determine safe and effective operation of the test tool.

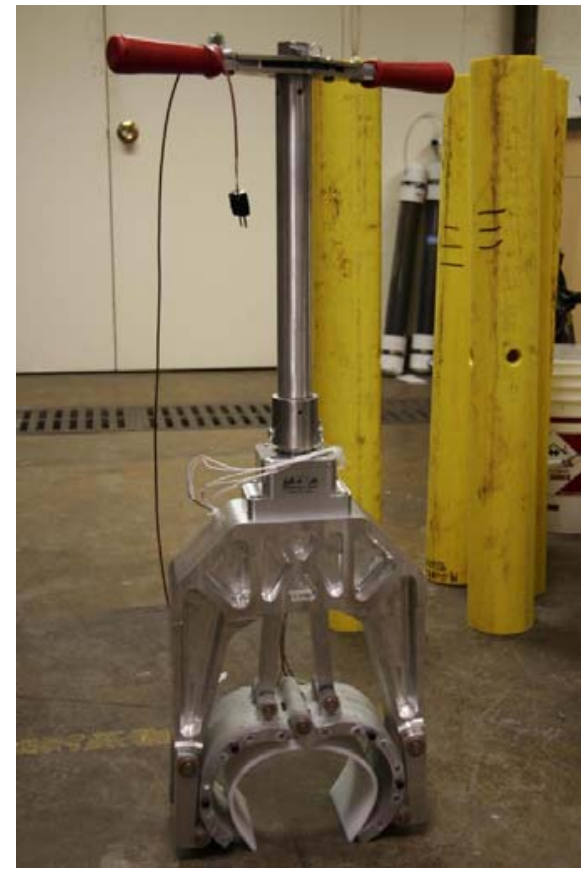

Figure 13: Final Test Tool with Repair Patch 
The mechanical design proved successful (Figure 14) during initial functionality testing. A 1-inch hole was drilled into the pipe wall of a $3 \mathrm{ft}$ section of 4-inch IPS SDR 11.5 MDPE pipe to simulate damage produced by a large gouge. This pipe section was used to test the ability of the test tool to successfully apply a thermochemical patch over the simulated damage. Little effort was required to fully wrap the PE gel film patch around the damaged area of the pipe. The tool applied adequate constant pressure to the patch. The internally heated (cartridge heaters) jaws heated rapidly and held the temperature at $\sim 257^{\circ} \mathrm{F} / 125^{\circ} \mathrm{C}$. The repair process was completed in 90 minutes. The initial repaired pipe sample was able to withstand $>450$ psig of hydraulic pressure during a quick burst test.

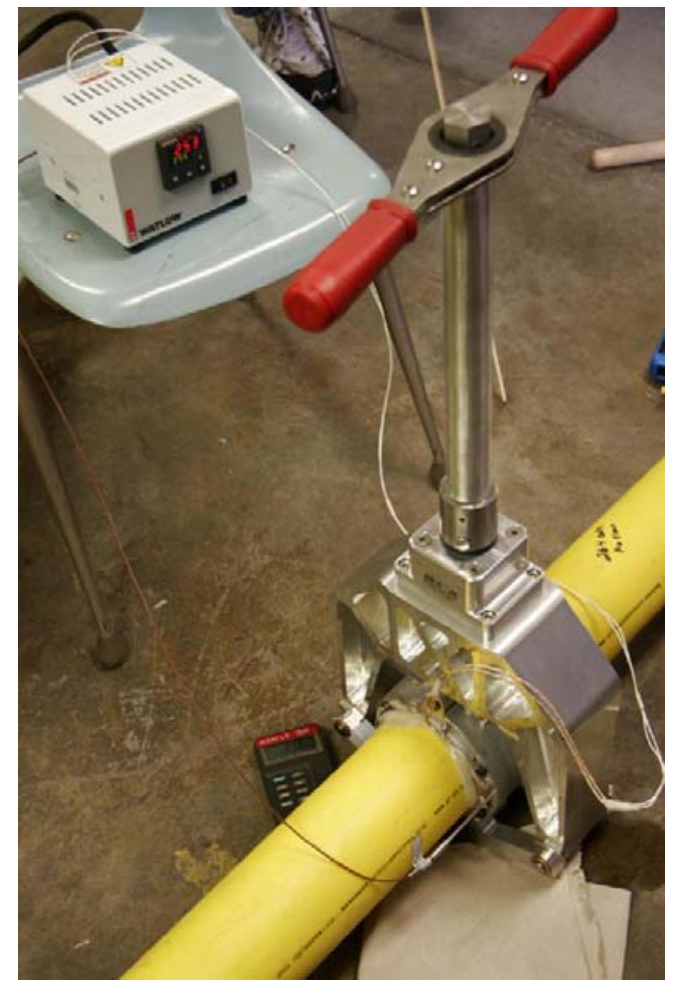

Figure 14: Test tool successful in bonding the repair patch to 4-inch PE pipe

\section{Task 4 - Research \& Development of Chemical Bonding Process for PE Repair Patch}

The technical objective of this task was to develop a patch repair process using either a PE gel-like adhesive or a polymer composite patch process. This task was performed concurrently with Task 3 . At the conclusion of this task, the decision was made to proceed with a gel-like adhesive patch for implementation with the test tool design chosen in Task 3. Detailed descriptions of each Subtask follow. 


\section{Subtask 4.1 - Chemical Bonding Process}

The technical objective of this subtask was to research and develop a chemical bonding process to repair damaged or defective PE pipe. Research focused on:

- Chemical bonding agent to be used (either a solvent or a two-part bonding system).

- Thermal gel-like adhesive (polymer/solvent matrix that liquefies on heating to release the bonding agent).

- Time and pressure required for the PE gel-like adhesive patch to bond satisfactorily to the PE pipe as a function of the bonding environment.

- Effect that the temperature of the PE pipe has on the bond.

- Requirement for a release mechanism to release the patch from the jaws of the tool.

The chemical bonding processes that were investigated are discussed below:

\section{Commercial Adhesives}

Research of commercially available adhesives for suitable bonding of PE to PE or PE composites revealed that $3 \mathrm{M}$, Loctite, and Phillystran currently manufacture these products. Four adhesives were selected for further study: 3M DP8005, 3M DP8010, Loctite 3030, and Phillystran Socketfast Blue A-20

Lap shear samples were prepared for each of the adhesives and shear tests were conducted using an Instron machine. The lap shear configuration used is described later in Subtask 8.2.

With the exception of 3M DP8010, all the adhesives demonstrated one or more of the following characteristics: poor strength, difficulty in application, or lengthy cure times. Therefore, extensive testing with the DP8010 was conducted to determine the optimum cure temperature and time. By varying the amount of heat applied to the sample, it was determined that DP8010 performed best at a cure temperature of $176^{\circ} \mathrm{F} / 80^{\circ} \mathrm{C}$, which resulted in a cure time of 90 minutes. While preparing and testing lap shear test specimens, it was also found that the adhesive performed better on an unprepared clean surface, as opposed to a roughened (sanded or scraped) clean surface. Tensile tests for various conditions showed that the maximum consistent shear strength of this adhesive was approximately 850 psi and all failures were adhesive (the adhesive pulled away from the surface of the PE substrate).

\section{PE Gels}

PE gels were researched as a method for adhering PE to PE once the peak strength of the DP8010 was determined. The PE gel produced in this project consisted of an UHMWPE powder dissolved into a solvent (Figure15). Then the resulting mixture 
was pressed into a sheet (Figure 16) that consisted of approximately 3-8\% of PE (93-98\% solvent). This pressed sheet was then dried (Figure 17) to an approximate solvent concentration of $10-20 \%$.

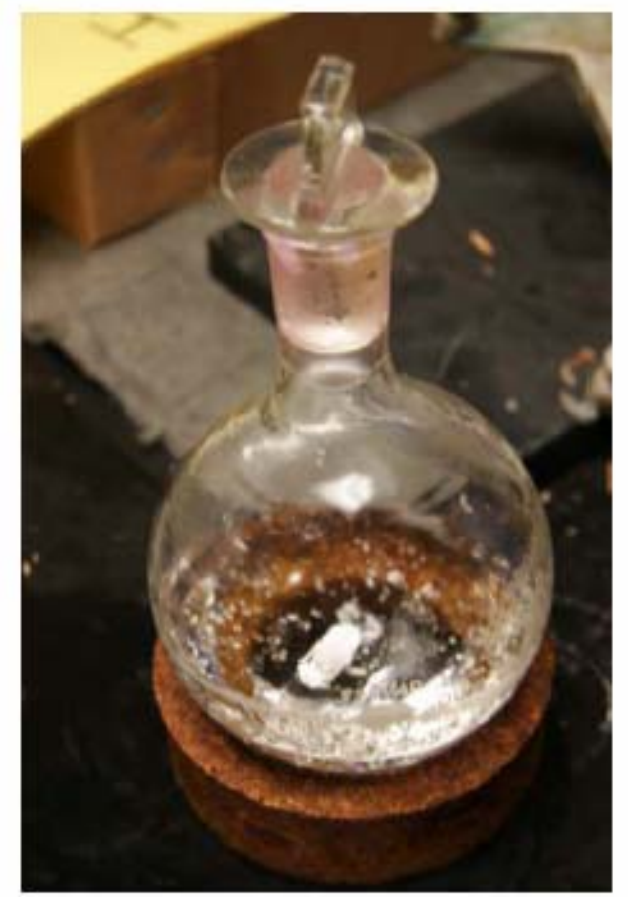

Figure 15: UHMWPE powder dissolved in heated solvent

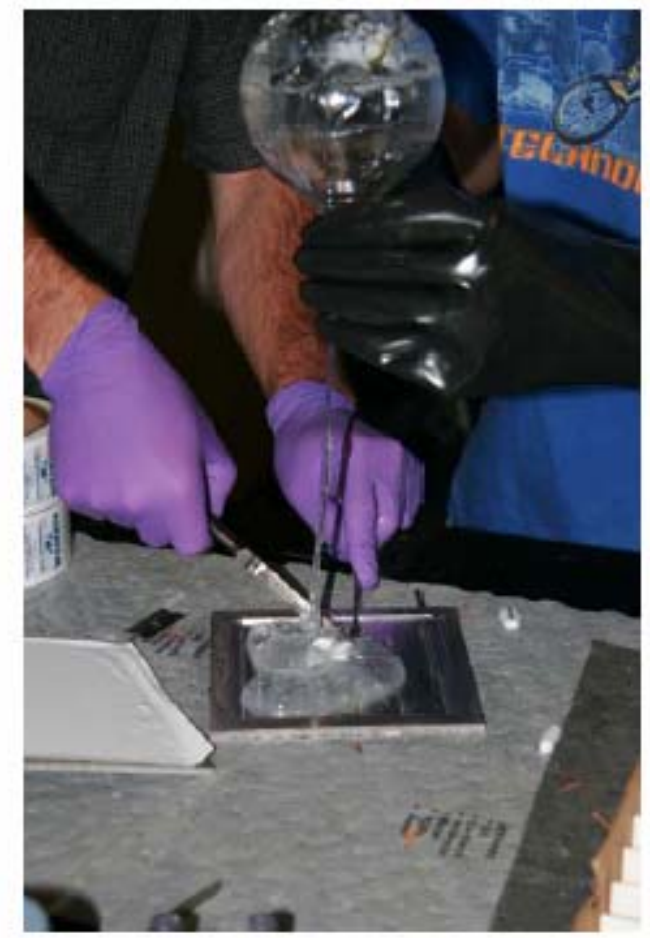

Figure 16: Dissolved UHMWPE pressed into a sheet 


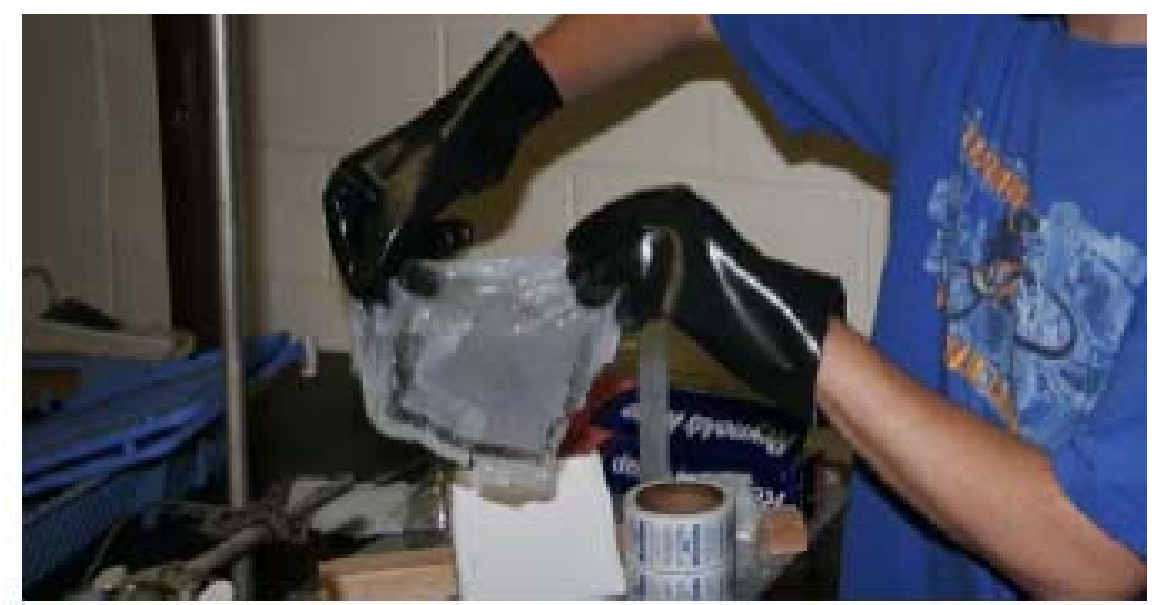

Figure 17: Pressed Gel Sheet

Subsequently, the UHMWPE gel sheet was cut into strips and sandwiched between two pieces of HDPE substrate (Figure 18). The HDPE substrates were bonded using the PE gel in a Carver press (Figure 19) equipped with heated platens. Various scenarios of the lap shear tests were performed varying the test sample thicknesses, pressure of application, and temperature of the platens. All the samples were prepared using a modified version of the ASTM standards D3163, D3165, and D5868.

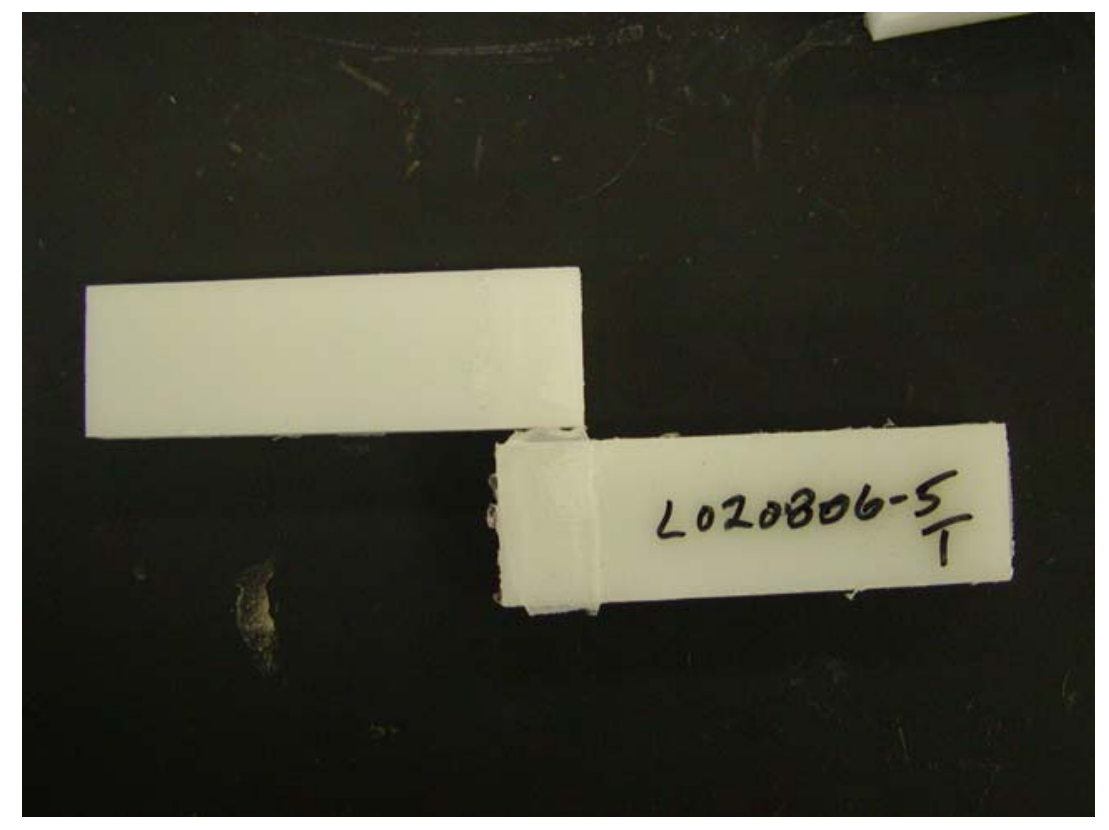

Figure 18: UHMWPE gel sheet prior to being sandwiched between HDPE substrates 


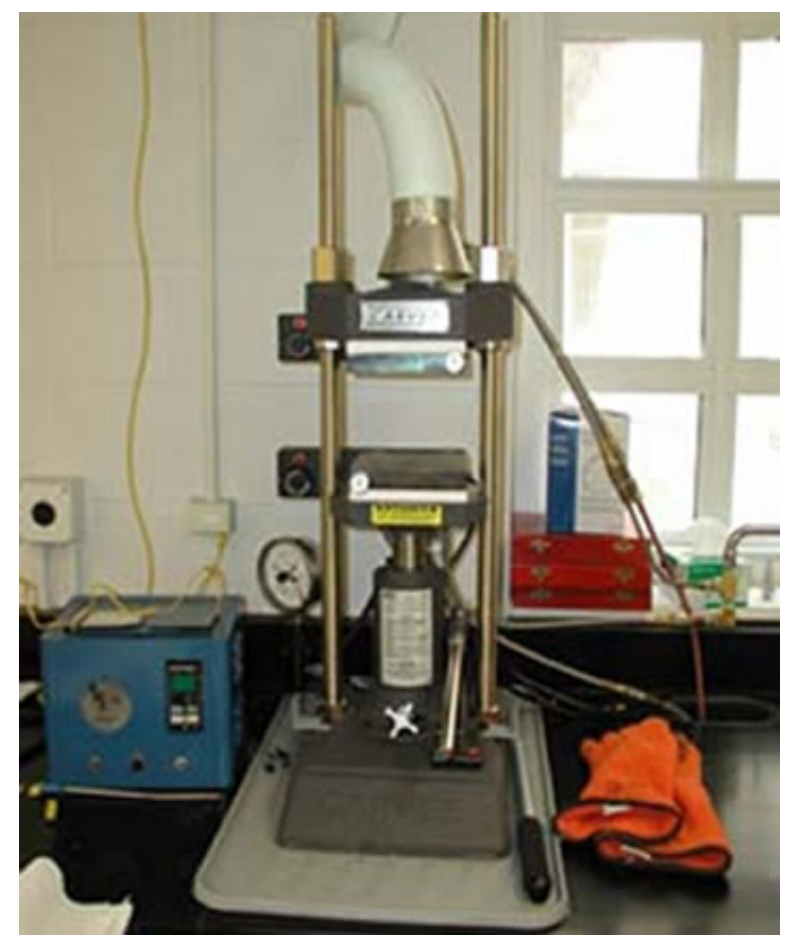

Figure 19: Carver press equipped with heated platens

For the early test results shown in Table 1 (Appendix A), the modified parameters were:

- Overlap = 0.5 square inches (1" wide X 0.5"long)

- Pull rate $=0.5 \mathrm{inch} / \mathrm{min}$

- Substrate thickness $=0.1875 "$ \& $0.375 "$

- Backers were glued to the back of the substrates to keep samples in shear (by minimizing the twisting of the lap joint during testing).

- Spacers were glued on the inside of the lap shear sample to allow the samples to be vertically aligned in the Instron testing machine jaws.

- Substrate sheets were cut into pieces for overlap shear tests according to ASTM standards.

- Substrate pieces for the lap shear tests were $4.5 " \times 1 " \times 0.1875 "$

- Spacers were 4" X 1" X $0.1875 "$

- Backers were 3.5" X 1" X 0.1875"

When these PE gel lap shears were tested in an Instron, they exhibited cohesive failures (i.e., the substrate (PE) failed) as opposed to the adhesive failures seen with the DP8010 bonds. A graph showing adhesive vs. cohesive failures during a lap shear test is shown in Figure 20. 


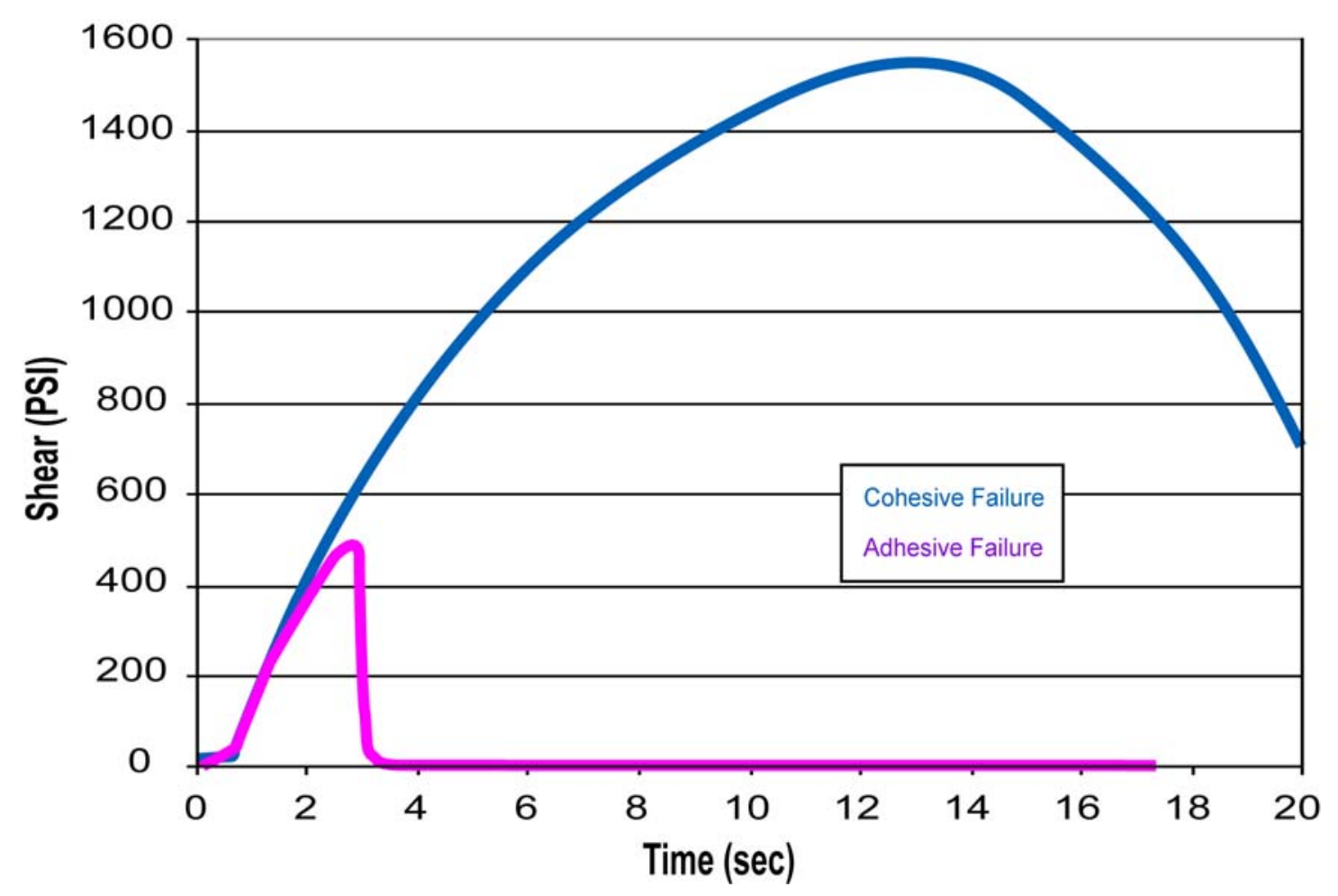

Figure 20: Graph of cohesive vs. adhesive failures during lap shear tests

\section{PE Gel Films}

PE gel films were tested at the same time that PE gels were being developed. PE gel films consist of a commercially available UHMWPE film that is infused (swollen) in a heated solvent bath until the specified solvent content of the film is reached. The PE gel film used in this research was made from a sheet of 10 mil (0.010") UHMWPE infused with the desired solvent (Decalin) until the specified solvent concentration of $20 \% \mathrm{wt}$. was reached. The advantage of using PE gel films, over PE gels, is that the PE gel films can be infused with the desired amount of solvent, thus removing the drying step required with the PE gels. Furthermore, PE gel film maintained the majority of its strength during storage and application while PE gels had a tendency to delaminate. The behavior of the PE gel film in a bond was almost identical to the PE gel as long as the solvent content of the PE gel film was maintained.

The PE gel film was then cut into strips and sandwiched between two HDPE substrates for lap shear testing. The HDPE substrates were bonded using the PE film in a Carver press equipped with heated platens. The lap shear tests were conducted with varied HDPE substrate sample thicknesses, application pressures, and platen temperatures. The samples were prepared using a modified version of the ASTM standards D3163, D3165, and D5868. 
For the results shown in Table 2, the modified parameters were:

- Overlap $=0.5$ square inches (1" W X 0.5" L)

- Pull rate $=1 " / \mathrm{min}$, substrate thickness $=0.375^{\prime \prime}$

- Substrate sheets were cut into pieces for overlap shear tests according to ASTM standards.

- Substrate pieces used for the lap shear tests were 4" L X 1"W X 0.375" Th

- Offset set jaws were used on the Instron testing machine for these later studies so spacers were not required to properly align the samples.

\section{Subtask 4.2 - Polymer Hot Weld}

The technical objective of this subtask was to complete polymer composite patch research to:

- Determine the optimum "dissimilar polymer" known to be compatible with PE with a melting point below that of PE

- Determine the time and pressure required for a satisfactory bond

- Determine the effect of temperature on the bonding process.

Many dissimilar polymers were studied but none produced strength results equal to the chemical bonding processes of PE gels and PE gel films. Therefore, further efforts were focused on the PE gels and PE gel films.

\section{Subtask 4.3 - Material and Thickness of the Repair Patch}

The technical objective of this subtask was to determine the optimal configuration for the repair patch with respect to design concept, size, thickness, and material. Consideration was given to the field environmental conditions (e.g., temperature, moisture), as well as the size and type of pipe damage (e.g., gouged or punctured pipe), when determining the patch configuration and application process.

1. The following repair patch concepts were studied:

a. Pressed MDPE Pipe Patch - the simplest patch concept. The patch consisted of a molded piece of MDPE substrate adhered over the damaged area of the pipe. The patch was adhered with either DP8010 adhesive glue or PE gel; but neither attained a sufficient level of bonding. The patched section of pipe exhibited about one-half the tensile strength of an un-patched section of pipe.

b. Banded Pressed MDPE Pipe Patch - a simple variation of the pressed MDPE pipe patch. The patch consisted of bands wrapped around the pipe and over 
the patch to support the hoop stress. Quick burst tests showed that the pipe failed before the patch/straps.

c. Fiber Reinforced Wrap - a patch made with a rectangular "loose mesh" of Spectra ${ }^{\circledR}$ cloth, long enough to wrap around the pipe about five times with a total width of four inches. This patch was applied in much the same manner as fiberglass matting is applied when making fiberglass-resin objects. Early testing indicated that this was a very strong patch but would be difficult to apply under field conditions. The patch held in quick burst tests. The pipe failed before the patch.

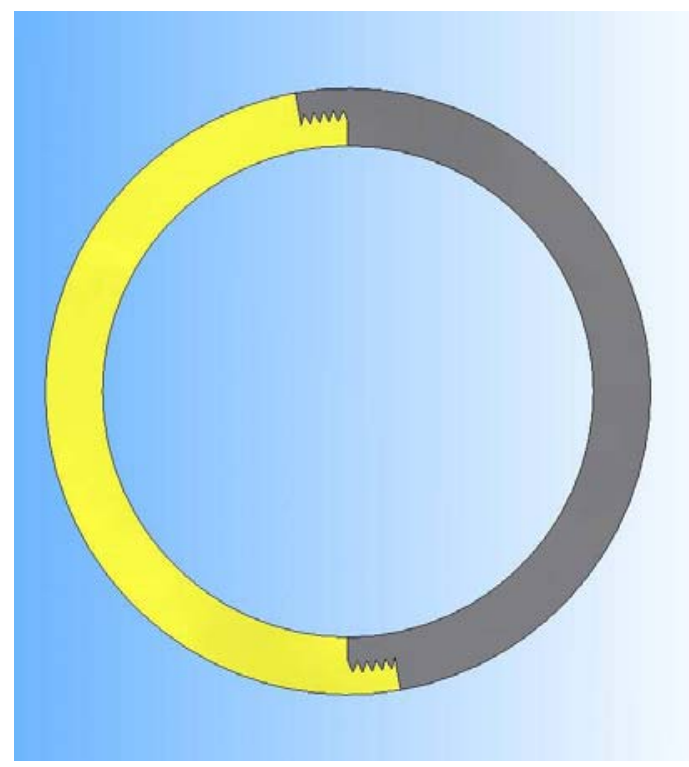

Figure 21: Overlapping half-wrap patch design concept

d. Overlapping Half-Wrap Patch - a broad category of patches in which two half section patches were placed on opposite sides of the pipe and overlapped on both ends to provide support for the hoop stress (Figure 21). Several potential configurations were investigated:

1) A patch with ridges in the overlapping areas of the patch that interlock mechanically, providing some support for hoop stress and total pipe coverage.

2) A patch with the overlapping ends of the patch tapered to bond to each other rather than mechanically interlocking..

3) A patch similar to the overlapping patch with the tapered ends, but fibers were used to reinforce the half patches in the direction of the hoop stress. This patch was able to reproduce the performance of the fiber-reinforced patch without the need for wrapping.

e. Overlapping Full-Wrap Patch - a hybrid of the above concepts in which a single full-wrap patch was placed around the pipe and overlapped on the 
ends (Figure 22). A full-wrap patch substrate was pre-formed to fit inside the open jaws of the repair tool (see Figure 23). Once the tool was placed over the pipe, the patch assembly was molded to tightly wrap around the pipe and overlap at the tapered joint.

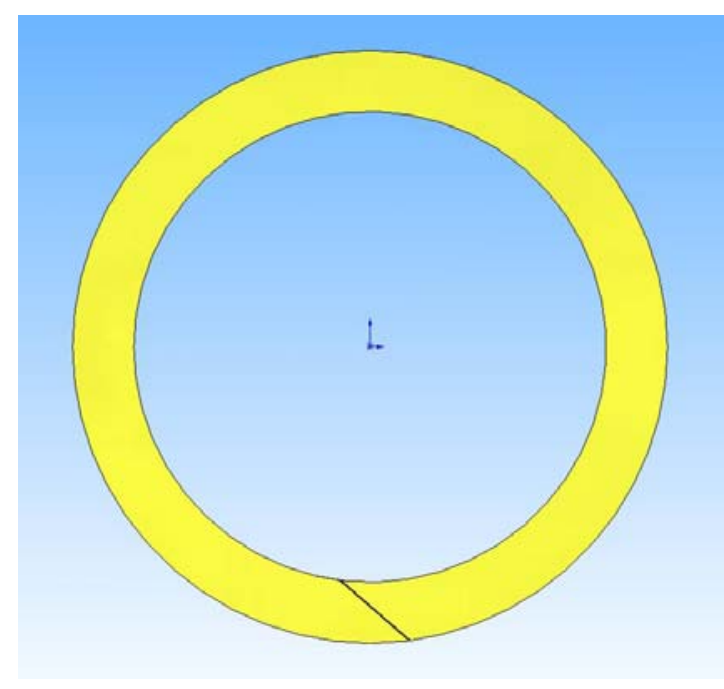

Figure 22: Overlapping full-wrap patch design concept

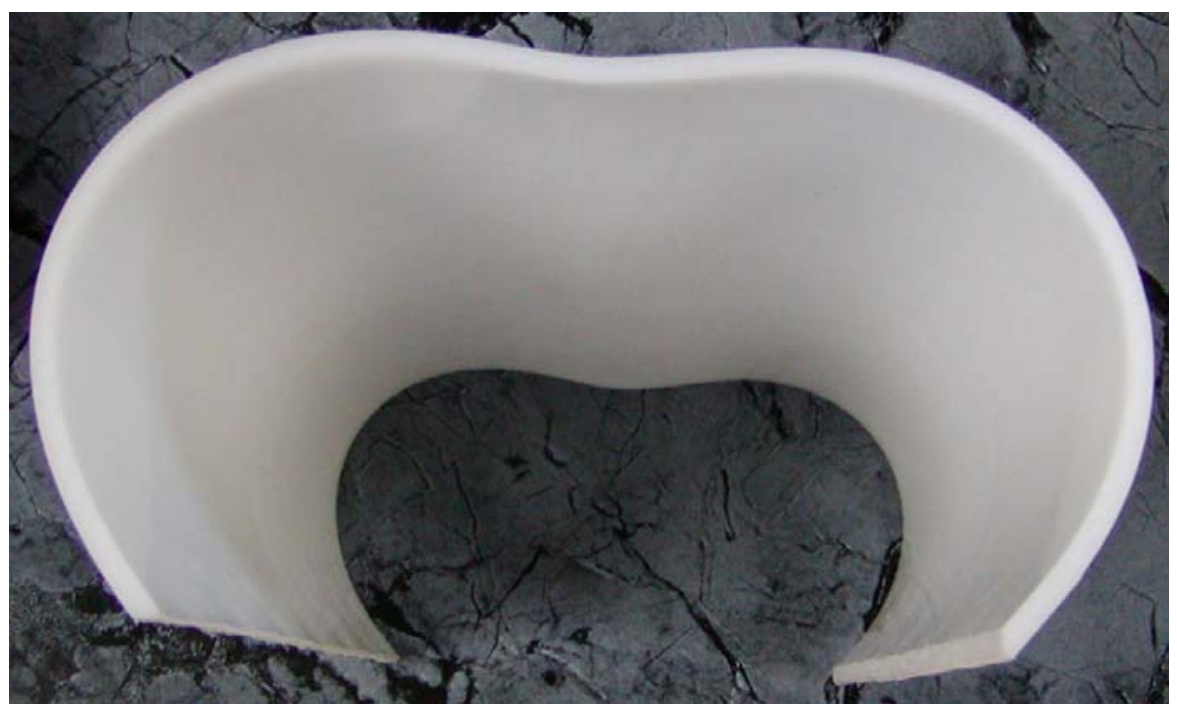

Figure 23: Preformed overlapping full-wrap patch

All of the wrapping patch concepts were compatible with the PE gel film and PE adhesive processes where a layer of gel, swollen film or adhesive was placed on the underside of the patch substrate. The entire patch assembly was then wrapped in a 1 mil HDPE film, and then applied to the pipe. The overlapping half-wrap patch design was selected for further investigation 
because it met the requirement for top-down placement of the tool on the pipe.

2. The size, thickness and material of the repair patch for the test tool was determined in this task. For initial research applications, the patch configuration was designed to be four inches wide with its thickness dependent on the PE material to be used for the patch. Tensile strengths of LDPE, MDPE, HDPE and UHMWPE were studied to determine the strongest and most flexible PE material to be used for the patch substrate. Based on the research a 3/16 inch thick HDPE substrate was chosen for the patch.

\section{Subtask 4.4 - Test Tool Performance Tests}

The technical objective of this subtask was to perform preliminary tests on the test repair tool. The chemical engineering team at OSU performed these tests. This task evaluated the functionality of the test tool to stop pressurized flow (air) through a ruptured 4-inch MDPE pipe by encapsulating the damaged area of the pipe and applying the full wrap patch assembly. To repair the damaged section of pipe, the thermo-chemical repair patch assembly was placed in the open jaws of the tool. The tool was then lowered onto the pipe and placed so the jaws with the attached repair patch assembly covered the damaged area completely. The jaws were then closed around the pipe allowing the patch to totally encapsulate the area of damage and stop the gas leak. The cartridge heaters in the jaws were then activated to maintain a constant temperature of $257^{\circ} \mathrm{F} / 125^{\circ} \mathrm{C}$ for 90 minutes. This temperature and time combination ensured proper bonding of the patch assembly to the pipe. When the soak time of 90 minutes had elapsed, the control unit was turned off and the tool allowed to cool. Once the tool had cooled to $185^{\circ} \mathrm{F} / 85^{\circ} \mathrm{C}$, the jaws were opened and the tool removed from the patched pipe. Samples of twelve repaired PE pipe sections with varying types of damage (1-inch holes, gouges, and scrapes) were sent to the laboratory for quick burst and accelerated age testing.

\section{Task 5 - Laboratory Testing On Repaired PE Pipe Sections}

The technical objective of this task was to perform laboratory testing (pressure testing and accelerated age testing) on the samples of repaired 4-inch MDPE pipe sections obtained from tests performed at Timberline Tool and OSU during Tasks 3.2 and 4.4. These tests were performed at OSU.

\section{Subtask 5.1 - Pressure Testing}

The technical objective of this subtask was to determine the overall performance of the PE adhesive patch, the PE gel patch, and the PE gel film patch with ASTM D1599 quick-burst tests at $73^{\circ} \mathrm{F} / 23^{\circ} \mathrm{C}$ and $176^{\circ} \mathrm{F} / 80^{\circ} \mathrm{C}$. 
Pressure tests were performed on repaired 4-inch MDPE pipe samples obtained during the test tool performance tests in Task 4.4 to determine how well the PE adhesive, PE gel and PE gel film patches adhered to the pipe surface. The initial pressure tests conducted were quick burst tests performed by raising the hydrostatic pressure in the patched pipe to 600 psi over a short time period (1-5 min) and held until the repaired pipe failed (Figure 24).

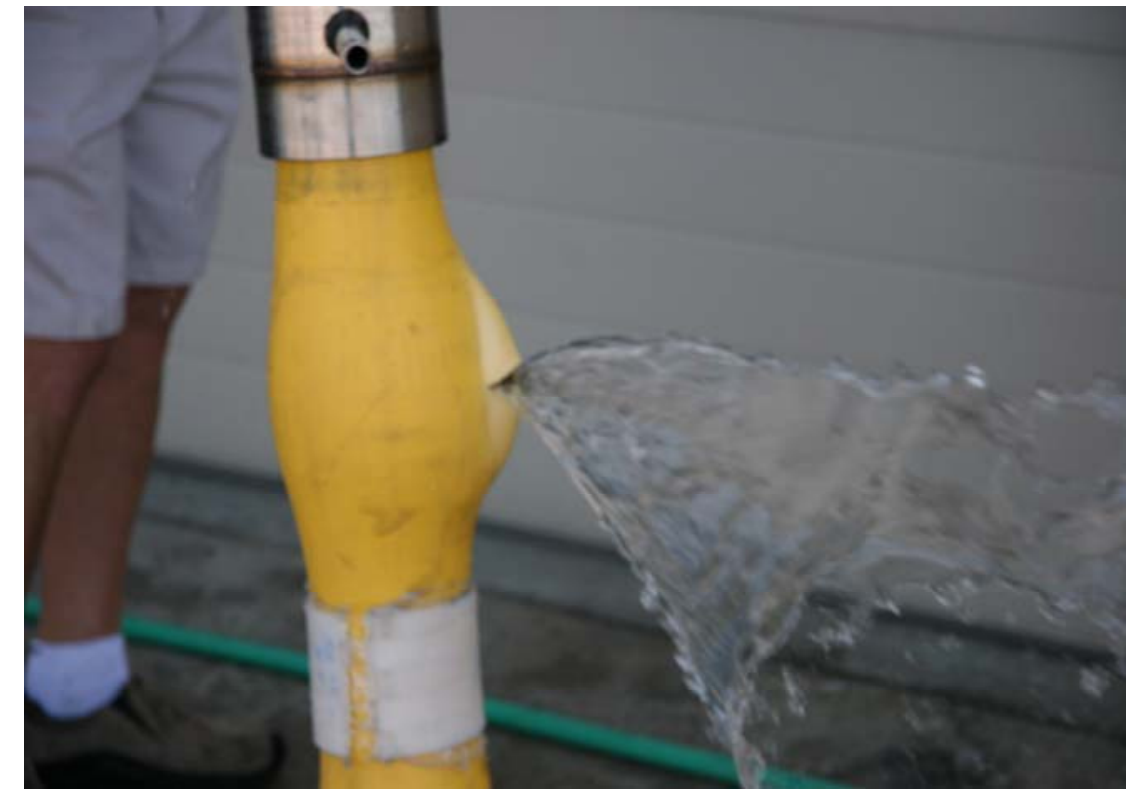

Figure 24: Successful bond of PE gel patch to 4" MDPE pipe at 600 psi during quick burst testing

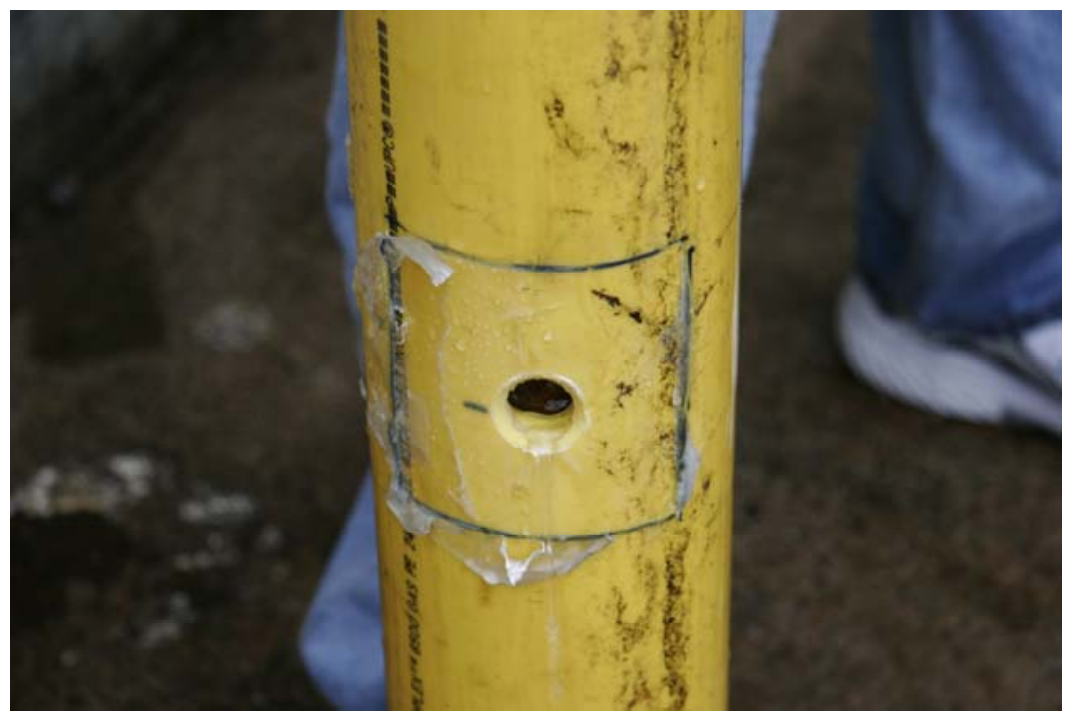

Figure 25: Failure of adhesive patch during quick burst testing at 450 psi 
All the quick burst tests performed on the repaired PE pipe samples using DP8010 commercial adhesive patches resulted in patch bond failures between $250 \mathrm{psi}$ and 450 psi (Figure 25). The PE gel and PE gel film patches, however, resulted in many successful quick burst tests where the pipe failed at locations away from the patch (Figure 26).

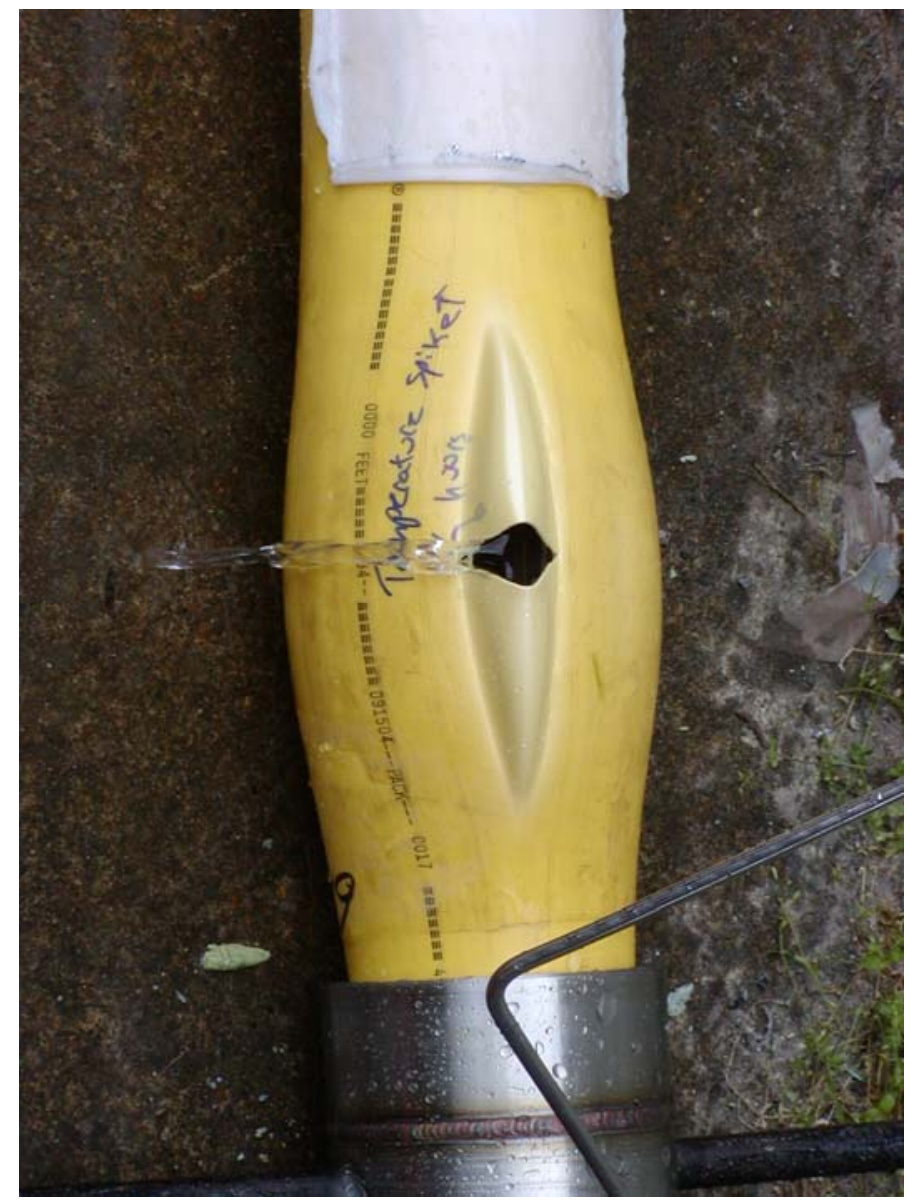

Figure 26: Quick burst test shows pipe failure below PE gel film patch Indicative of successful bonding 
During initial quick burst tests, it was observed that the pipe seemed to be reinforced for hoop stress in the vicinity of the patch, even if only a half patch was applied (Figure 27).

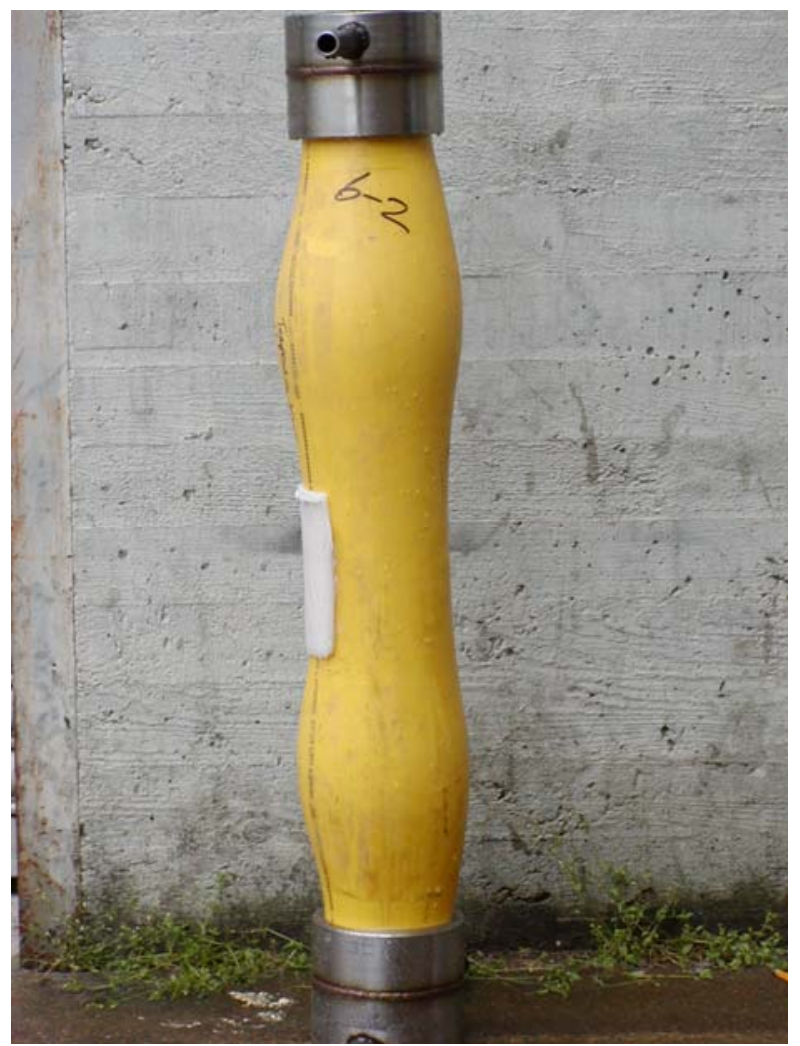

Figure 27: Pipe sample repaired with half patch showing hoop stress reinforcement

\section{Subtask 5.2 - Accelerated Age Testing}

The technical objective of this subtask was to determine the long-term safety and structural integrity of the repaired MDPE pipe samples. ASTM D1598 sustained pressure tests at $73^{\circ} \mathrm{F} / 23^{\circ} \mathrm{C}$ and $176^{\circ} \mathrm{F} / 80^{\circ} \mathrm{C}$ were conducted using long-term hydrostatic test tanks and equivalent "aging" on lap shear samples. These tests simulated a 50-year lifespan of the pipe-patch assembly in as little as 3-5 days.

Per ASTM D2837, ,73 $7{ }^{\circ} \mathrm{F} / 23^{\circ} \mathrm{C}$ stress-rupture regression longer runs were also conducted to allow for multiple data points along the Comparative Stress vs. Time to Failure temperature lines. This data was used to simulate actual expected lifetimes of equivalent pipe samples buried in the field. The results of these tests were used to continue the research during Phase 2 of this project. 


\section{Task 6.0 - Field Evaluation of Test Tool}

The technical objective of this task was to determine the functionality and reliability of the test tool.

At demonstrations performed for Northwest Natural Gas field crews in Portland, Oregon on February 25, 2005 (Figures 28 \& 29), a thermo-chemical PE gel film repair patch (developed in Task 4.1) was applied over a 1-inch diameter hole drilled into the wall of one $4 \mathrm{ft} \mathrm{section} \mathrm{of} 4$-inch IPS (SDR 11.5) MDPE pipe pressurized to 45 psig. The repair patch was applied using the test tool developed during Phase 1. The repair patch successfully bonded to the pipe under pressure. Subsequently, the repaired pipe sample was sent to OSU for quick burst testing as reported in Subtask 5.1. The test tool was also successfully demonstrated to DOE/NETL project managers at Timberline Tool facilities in Kalispell, Montana on July 13-14, 2005 (Figures 30 \& 31).

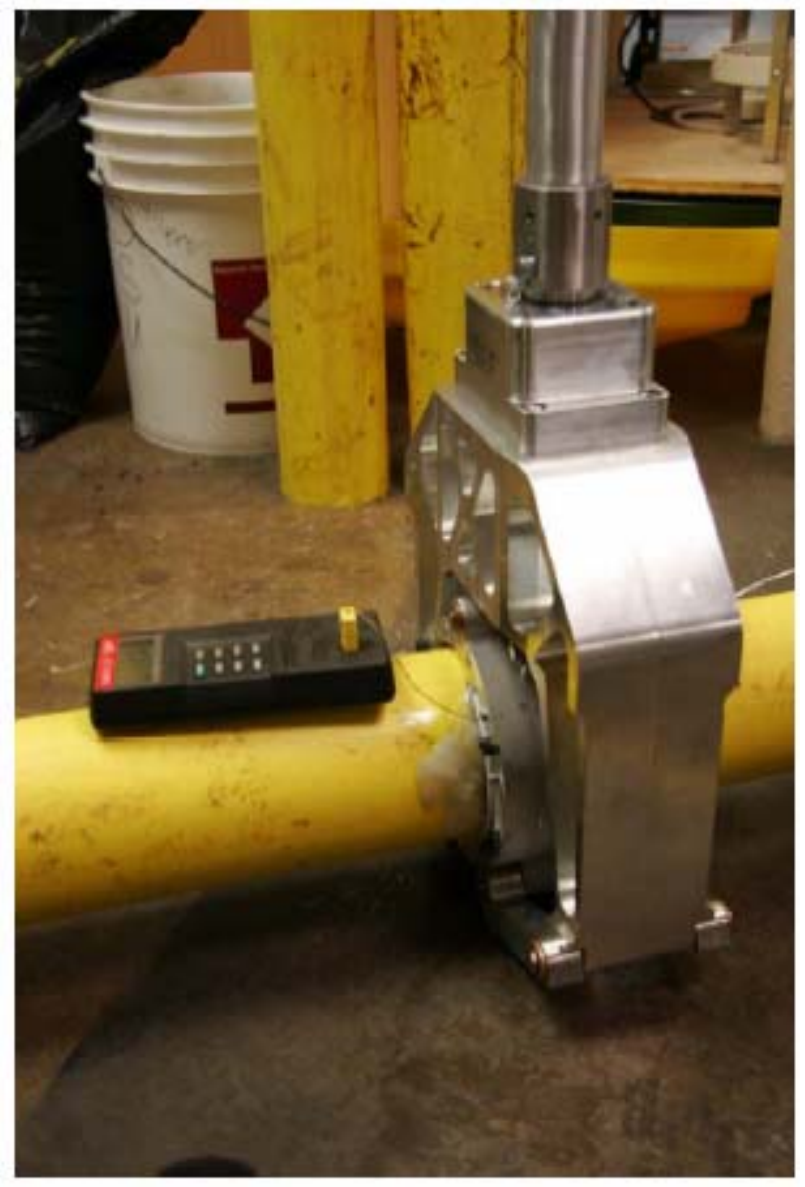

Figure 28: Overlapping full-wrap patch applied to 4-inch MDPE pipe during demonstration for Northwest Natural 


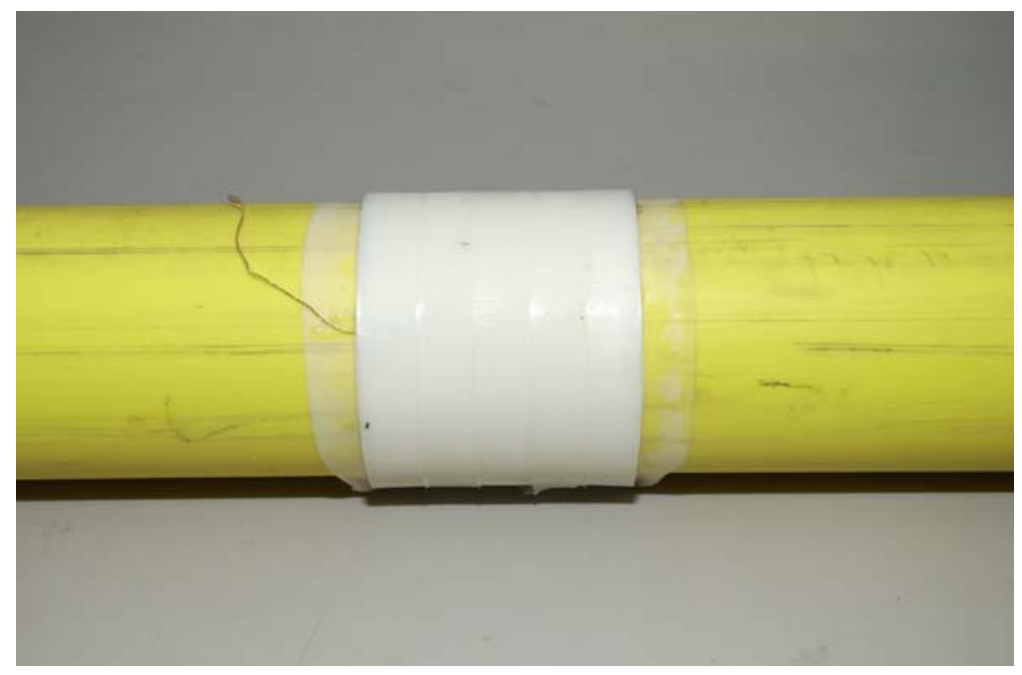

Figure 29: Completed bonding of overlapping full-wrap patch on 4- inch MDPE pipe

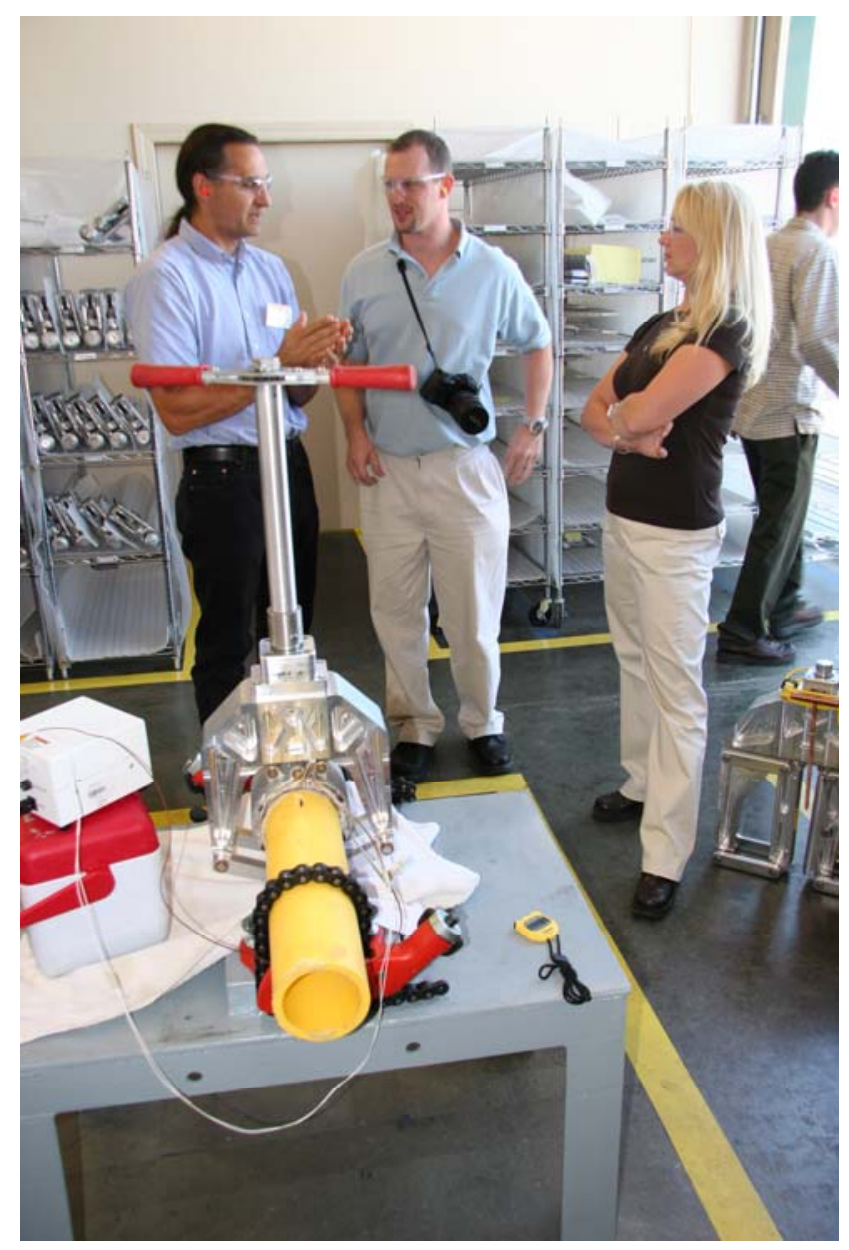

Figure 30: Test tool and PE gel film patch repair process successfully demonstrated to DOE/NETL project managers at Timberline Tool facilities 


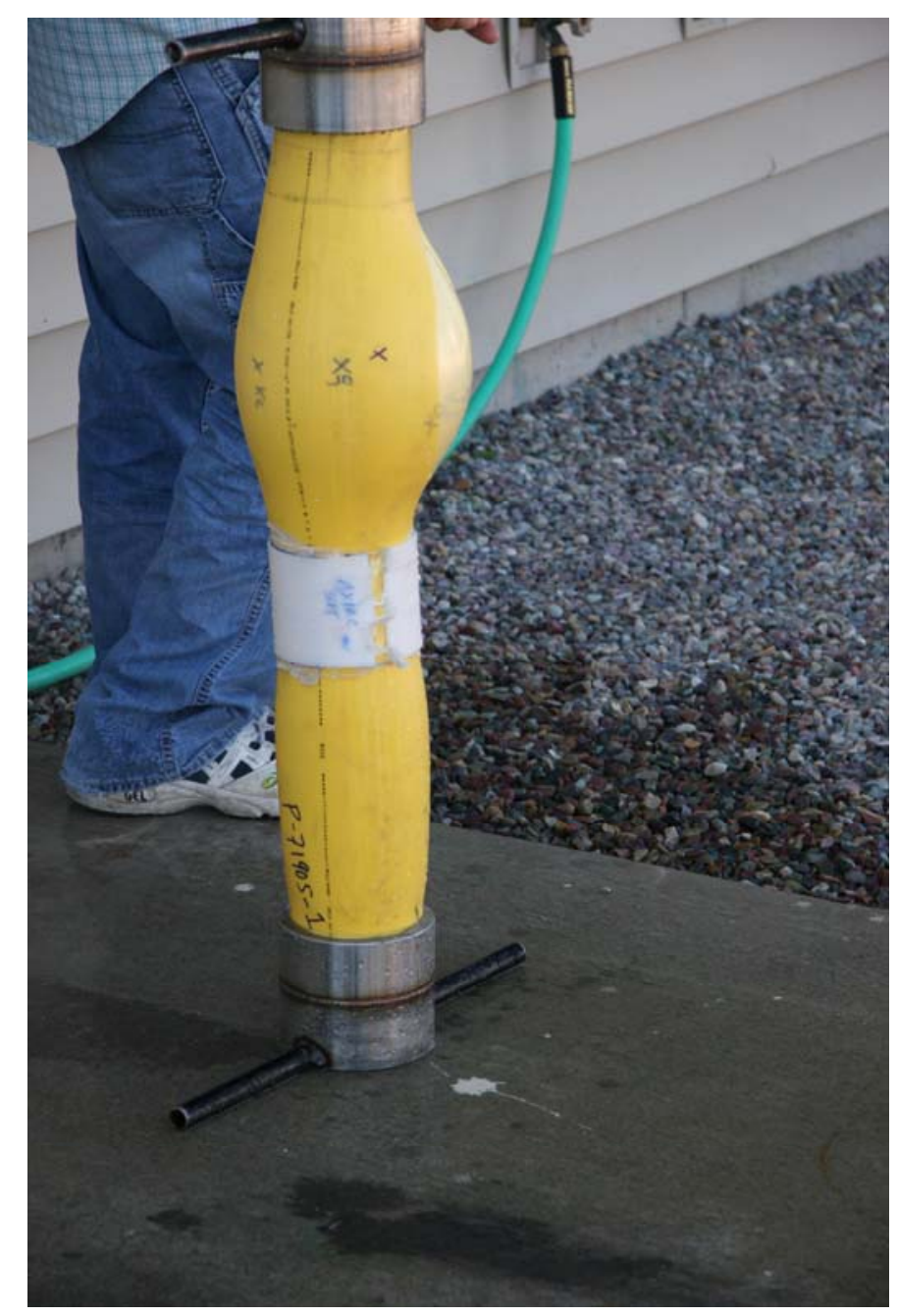

Figure 31: Quick burst test for DOE/NETL demonstrates successful bonding of PE gel film patch on 4-inch MDPE pipe

\section{Task 7.0 - Technical Feasibility Assessment Of The Test Tool}

This task determined the technical feasibility of the test tool in preparation for the design and construction of the engineered prototype. The mechanical tool and the thermo-chemical process were evaluated separately as detailed below:

Assessment of the mechanical tool:

- Curved jaw encapsulated the pipe,

- Symmetrical jaws applied uniform pressure to the pipe

- Cartridge heaters in the jaws heated the patch/pipe interface to $243^{\circ} \mathrm{F} / 117^{\circ} \mathrm{C}$

- Tool was compact and operated satisfactorily in keyhole and open trench excavations 
Assessment of the thermo-chemical process:

- Suitable bond strength was achieved using adhesives, PE gels and PE gel films

- Process to attain a consistent \%wt of solvent with the PE gel was complicated

- Decision was made to continue R\&D of adhesives and PE gel films

- Successful bonding to PE pipe was achieved with both MDPE and HDPE patch material

At the conclusion of the technical feasibility assessment, the project team agreed to proceed to Phase 2 with the test tool design and to focus on HDPE for the patch material because of its strength properties.

\section{PHASE 2}

At the conclusion of Phase 1, the project team agreed that the test tool design would be suitable for applying the repair patch and suggested some design modifications for the engineered prototype repair tool. Likewise, the team agreed that the preferred repair patch system would be the PE gel film. With these recommendations, the project team agreed the project should proceed to Phase 2. The research conducted in Phase 2 focused on these recommendations.

\section{Task 8.0 - Design \& Construction Of Engineered Prototype}

The technical objective of this task was to review the mechanical design of the test tool and the chemical design of the repair patch in preparation for the design and construction of an engineered prototype or prototypes.

A detailed description of each subtask follows:

\section{Subtask 8.1 - Mechanical Design \& Construction of Engineered Prototype}

The technical objective of this subtask was to design, fabricate and modify as necessary one, or possibly more, engineered prototypes. One engineered prototype was developed.

Based on initial test results, several improvements to the test tool were incorporated into the design of the engineered prototype.

- The bearing and lead screw were redesigned to reduce the amount of stress exerted on the other components of the tool.

- The curved jaws were redesigned to eliminate flex in the jaw components. 
- The jaw components were redesigned to cover a section of pipe 12 inches long in order to repair the majority of damaged pipe (small nicks as well as large gouges), (Figure 32).

- The internal cartridge heaters were redesigned to accommodate the extension of the jaws.

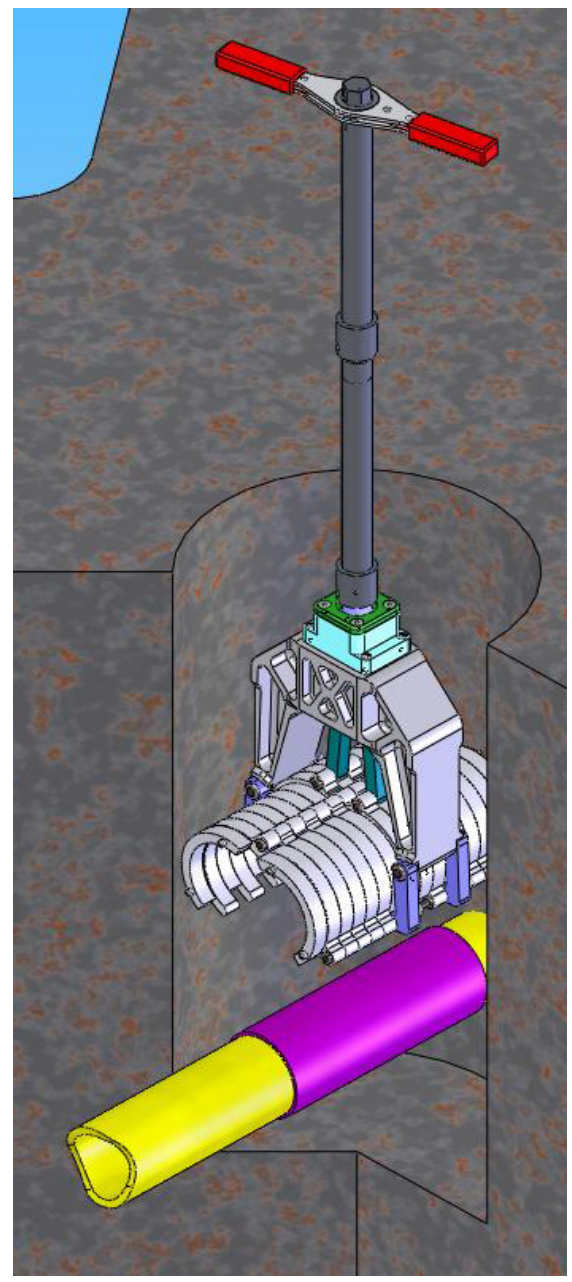

Figure 32: Engineered prototype design shown with 12-inch jaws

The preferred design concept of the engineered prototype was 3-D modeled and a prototype was constructed of $6061 \mathrm{~T} 6$ aluminum. A series of functionality tests were performed to validate the design changes detailed above. The engineered prototype applied a full wrap PE gel film patch to 4 damaged sections of 4-inch MDPE pipe samples. The pipe samples had simulated damage as follows: (1) Three 1" holes drilled into the pipe; (2) $1 / 2$ " $\times 6$ " cut in the pipe; (3) $1 / 16$ " $\times 6$ " slit to simulate SCG; and (4) 3" $\times 6$ " rupture. Results of these functionality tests validated the design changes that were incorporated in the engineered prototype. The engineered prototype utilizing heated jaws was successful in applying a full wrap PE gel film patch to all pipe samples tested. 


\section{Subtask 8.2 - R\&D of Chemical Bonding Process for Repair Patch}

The technical objective of this subtask was to further develop the chemical bonding process of the patch and design the repair patch and application process for the engineered prototype. The repair patch research focused on the half patch overlapping design selected in Task 4.3. Initially, it was assumed that the overlapping half patch design would be required to achieve the desired strength. However, further research focused on a full wrap patch design and subsequent quick burst tests validated this design.

In order to minimize solvent losses during the patching process, further research was done using PE gel films to replace the PE gel between the patch and the pipe. With PE gels, the solvent squeezed out while the patch was being applied. In comparison, the PE gel films were very resistant to solvent loss. This made the PE gel films a good candidate for patching the pipe under line pressure. In addition, the patches made of the PE gel film were very durable, portable, and had an extended shelf life. Swelling procedures (infusing the solvent into the PE) were researched and modified to eliminate inconsistencies of the wt\% of polymer in the PE gel and ensure consistency during production. Accelerated age tests were performed on pipe samples repaired with PE gel film patches. Tests were also conducted to determine the required range of solvent percent in a film in order to achieve acceptable bonding strengths. This was accomplished for both HDPE and UHMWPE films. A swell curve for wt\% vs. time was created for the two types of film. Simple drying experiments were performed in order to determine the amount of polymer lost during swelling.

\section{Bonding Mechanism (PE Gels and PE Gel Films)}

Differential Scanning Calorimetry (DSC) of PE, in the presence of the solvent, showed an effective lowering of the melting point of both MDPE and HDPE (Figure 33). Lowering the melting point allowed for fusion welding to take place at the substrate-film-substrate interface without significantly diminishing the overall strength of the bulk of the substrate polymers during the bonding process. PE gel films reached their peak strength with a cure temperature of $230^{\circ}-248^{\circ} \mathrm{F} / 110^{\circ}-120^{\circ} \mathrm{C}$. It was vital, however, to have enough solvent in the PE gel film (or PE gel) to allow the solvent to affect both substrate surfaces during the cure process. 


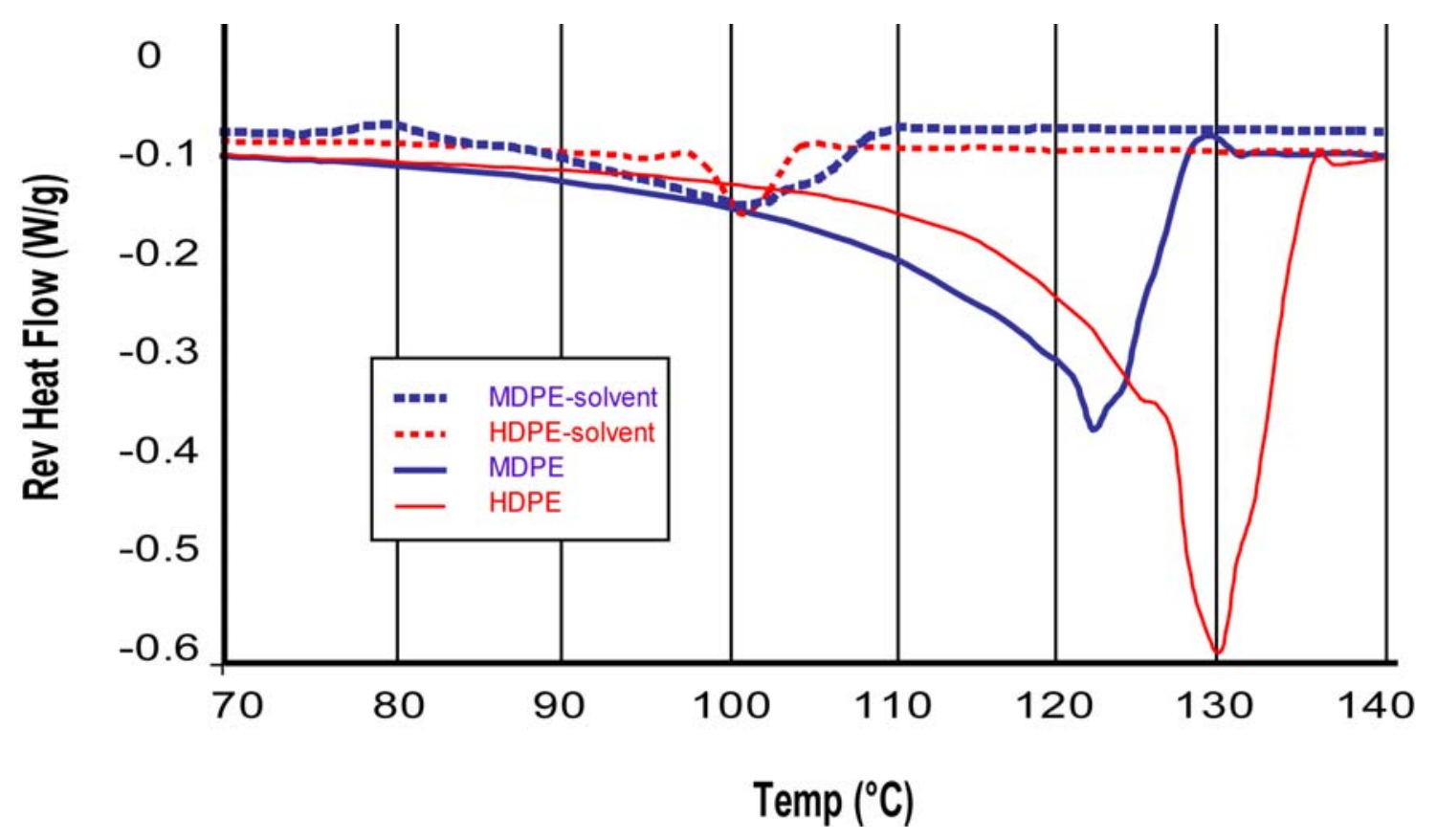

Figure 33: Differential scanning calorimetry curves of virgin PE vs. PE with solvent shows the effect of solvent on lowering the melting point of $P E$

Another indication that the bonding mechanism was successful is shown by a scanning electron microscopy (SEM) micrograph of the bonded area (Figure 34). From this SEM micrograph, a uniform area was seen with no defined layers. This uniform bond area indicated a seamless fusion of the two substrates.

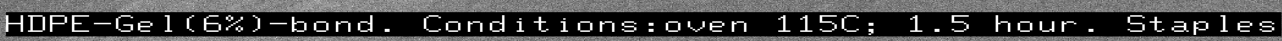

between $Z$ sheets of HDPE. Siample $Z$

$\square=\Xi$, B日Ex

$16 \overline{1 \mathrm{r} \mu \mathrm{m}}$

$P$ : 1 , 마마

1E. $\mathrm{EK}$

Amarar

\#GEG 1

Figure 34: SEM micrograph showing uniform PE bond interface 


\section{Bond Strength Testing}

Lap shear samples were designed to test the bond strength of the PE gel or PE gel film bonds (Figure 35). The lap shear samples were then pulled at a rate of 1 -inch per minute to test the strength of the bonds (early work samples were pulled at 1/2inch per minute). The major variables affecting bond strength were time, temperature, and pressure. For these tests, the platen pressure was maintained at $20 \mathrm{psi}$. The polymer fusion process required just enough pressure to keep the substrate-film-substrate in firm contact since lower pressures resulted in air gaps, and higher pressures squeezed out the gel layer, both of which resulted in inferior bonds.

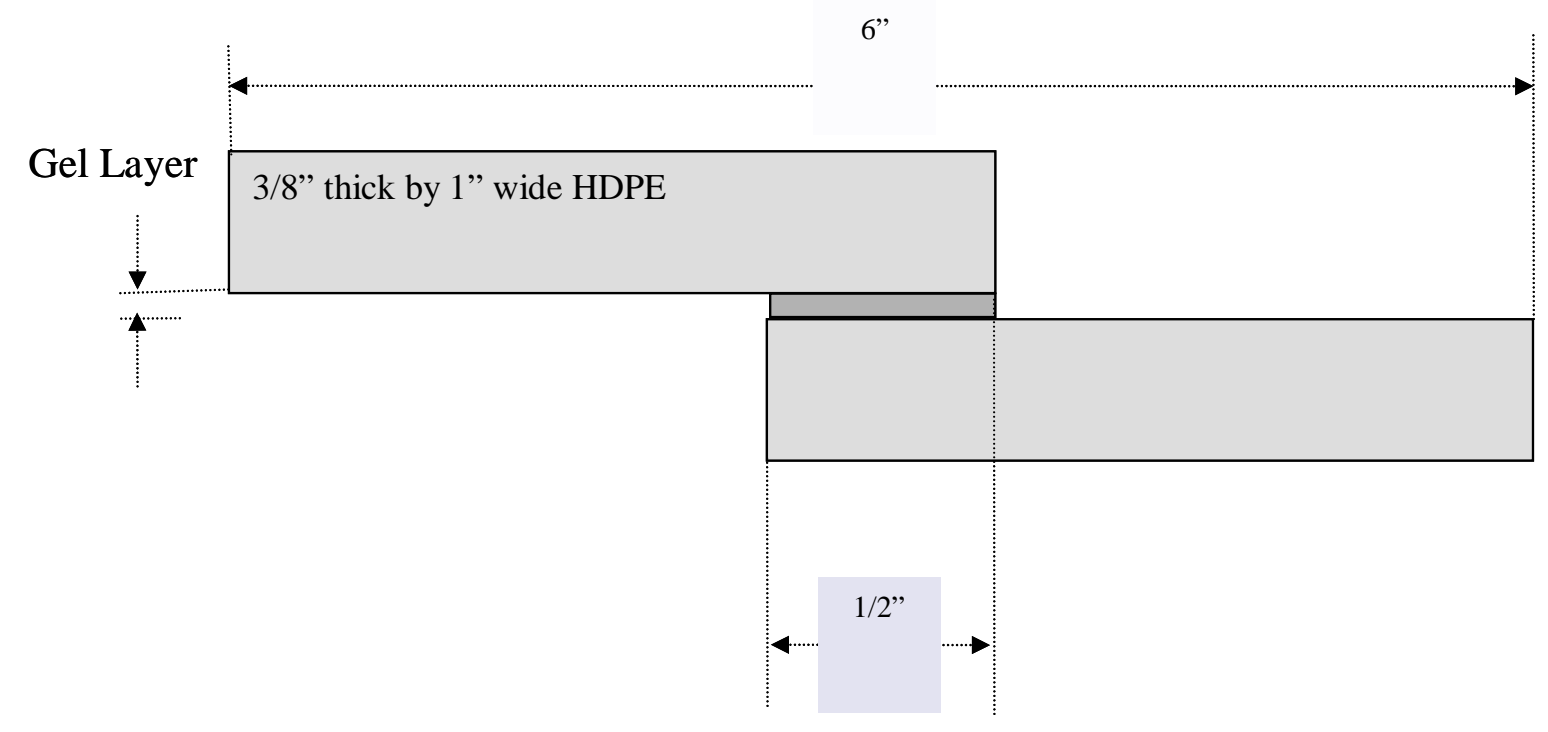

Figure 35: Diagram of lap shear sample design

The key factor in bond strength was the amount of time required for the interface temperature to reach the desired melt range and then to allow the polymers adequate time to fuse. For the timed experiments, an interface temperature of $239^{\circ} \mathrm{F} / 115^{\circ} \mathrm{C}$ was used. This temperature was chosen because, in the presence of the solvent, the surfaces of both PE substrates were in their melt region. However, the temperature was still below the melting point of the unaffected bulk of the substrates. The lap shear data revealed that 30-60 minutes, at the desired $239^{\circ} \mathrm{F} / 115^{\circ} \mathrm{C}$ interface temperature, provided bond strengths that resulted in consistent cohesive failures of lap shear test samples (the HDPE substrate failed).

Temperature experiments were performed with a total cure time of 90 min. For these tests, the lap shear samples were produced at a temperature range of $223^{\circ}$ $248^{\circ} \mathrm{F} / 106^{\circ}-120^{\circ} \mathrm{C}$. The curve of these points is shown in Figure 36 . As expected, in this temperature range, the strength of the bond increased almost linearly as the temperature increased. 


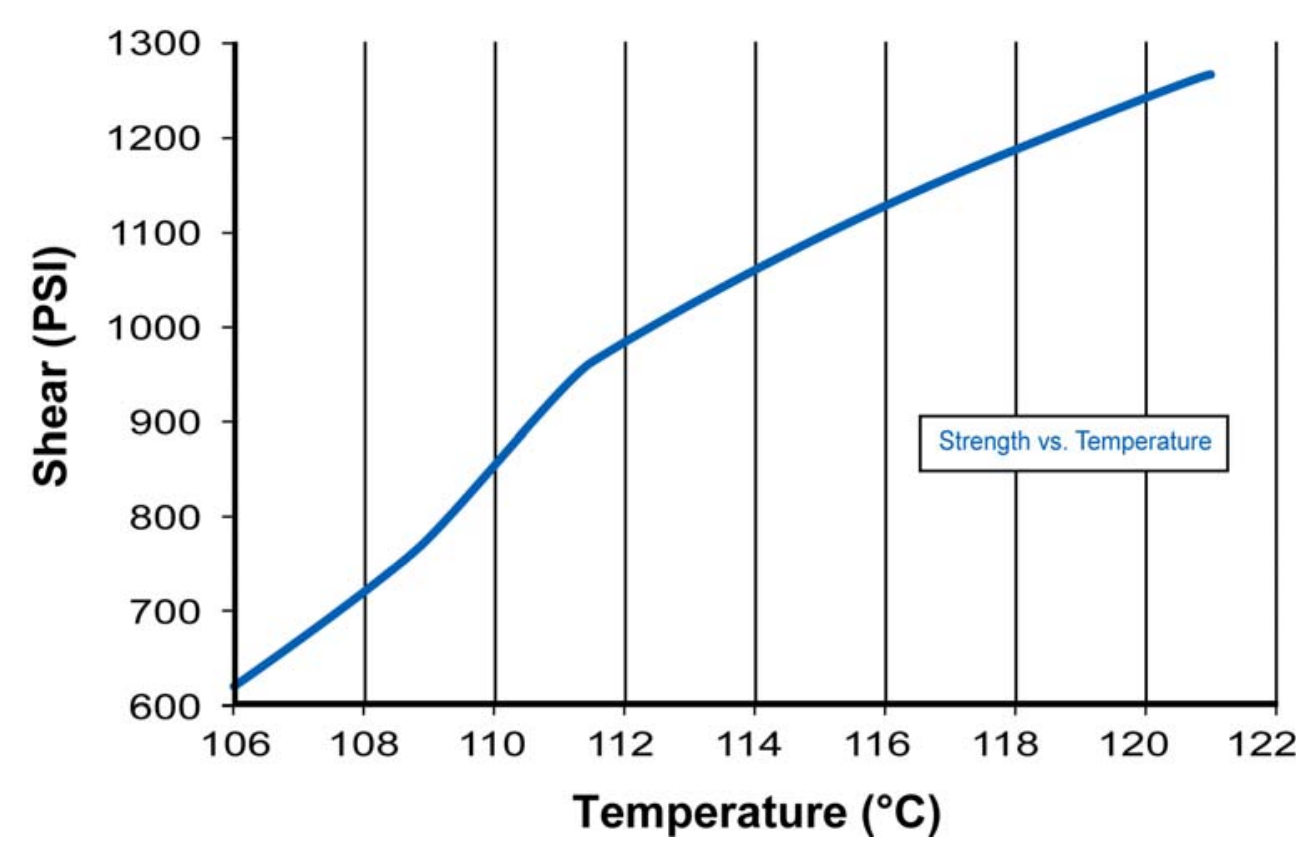

Figure 36: Graph of bond strength as a function of bonding temperature

\section{Pipe Patch Assembly}

The large PE gel film patches were made by swelling (Figure 37) 8" X 8" UHMWPE films in solvent until they were larger (Figure 38) than a 14" X 14" swollen film. This PE gel film was then placed between a pre-formed sheet of HDPE substrate (the patch) and a very thin sheet of HDPE (0.001"-0.003") (the packaging material) in a sandwich-like configuration (Figure 39).

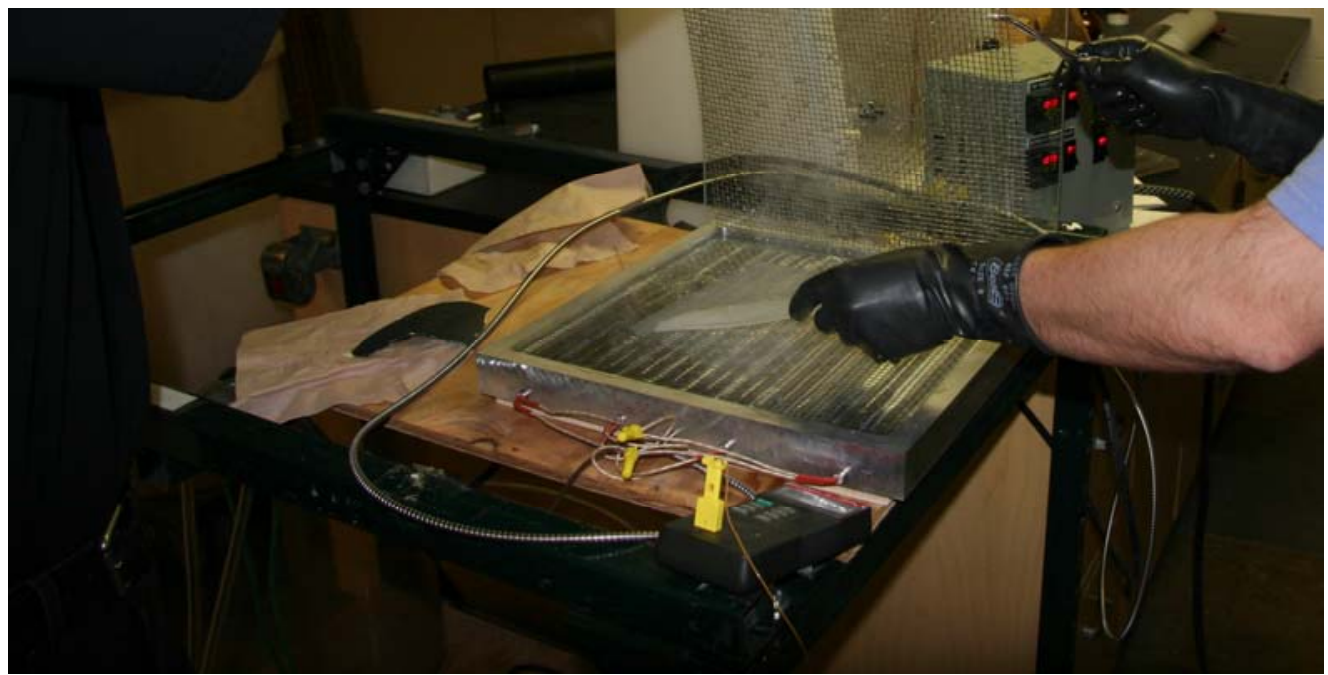

Figure 37: Swelling process used to fabricate a large PE gel film patch 


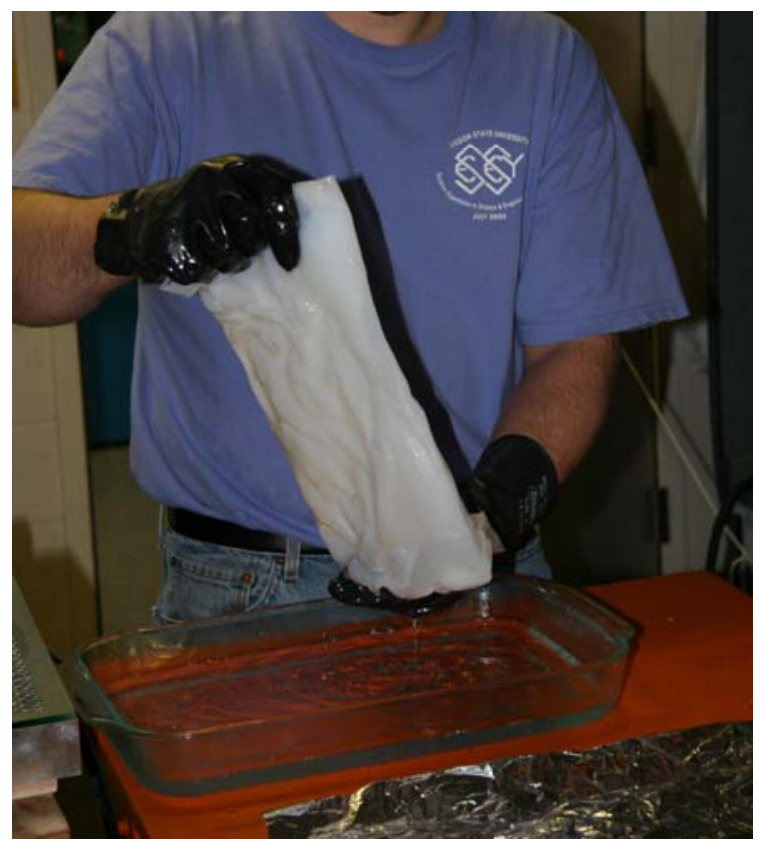

Figure 38: Photo of the final large PE gel film patch after the swelling process

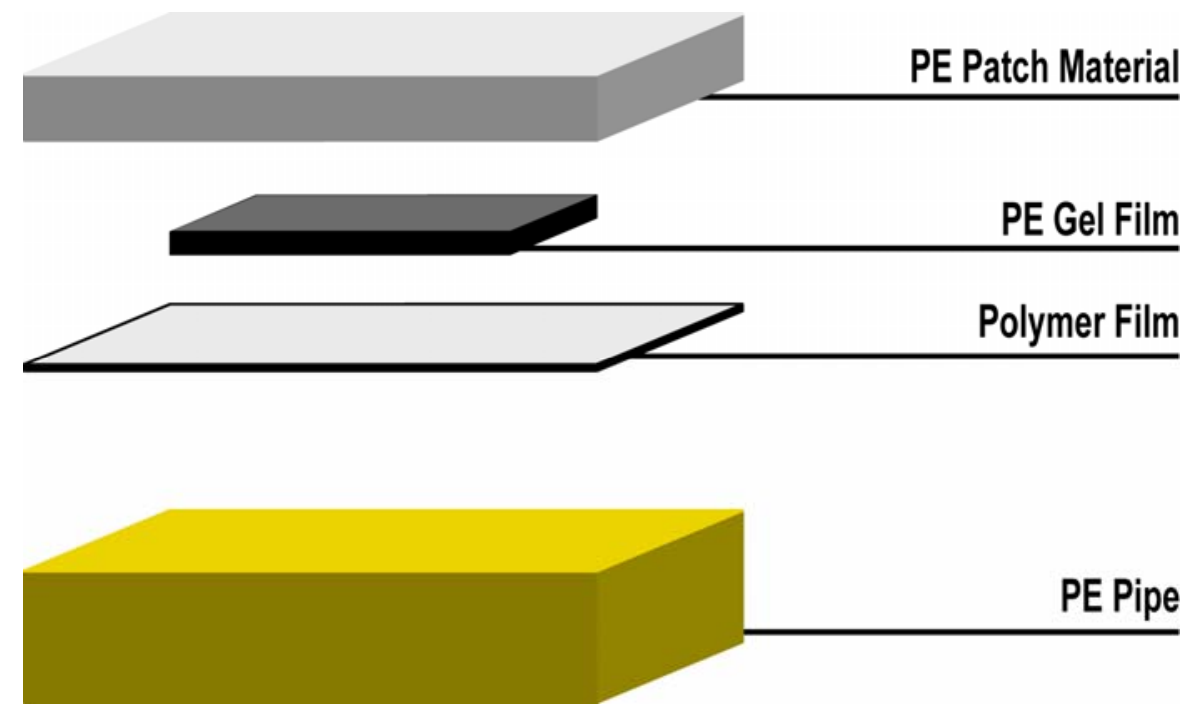

Figure 39: Diagram of PE gel film patch design

One of the big hurdles to move from the platen based small lap shear samples to the large pipe patch application was the time required to reach temperature at the interface. The small lap shear samples used the double-heated method whereby both platens of the press were heated to $243^{\circ} \mathrm{F} / 117^{\circ} \mathrm{C}$ and resulted in a satisfactory bond in approximately 10-15 minutes. However, heating and maintaining 
temperature on an actual pipe sample was significantly different due to the onesided heating and the additional heat losses. For this reason, heating profiles were developed for the engineered prototype tool (Figure 40). These profiles showed that, starting at a temperature of $86^{\circ} \mathrm{F} / 30^{\circ} \mathrm{C}$, approximately 20 minutes was required for the interface temperature to reach the desired temperature. It also illustrated that the pipe being patched remained well below its natural melting point. As with the lap shears, the pipe patch interface required a minimum of 30-60 minutes at the desired temperature to achieve good bond strength. Therefore, a total cure time of 90 minutes was used when patching pipes with the engineered prototype repair tool. This allowed the bond interface polymers enough time to fuse.

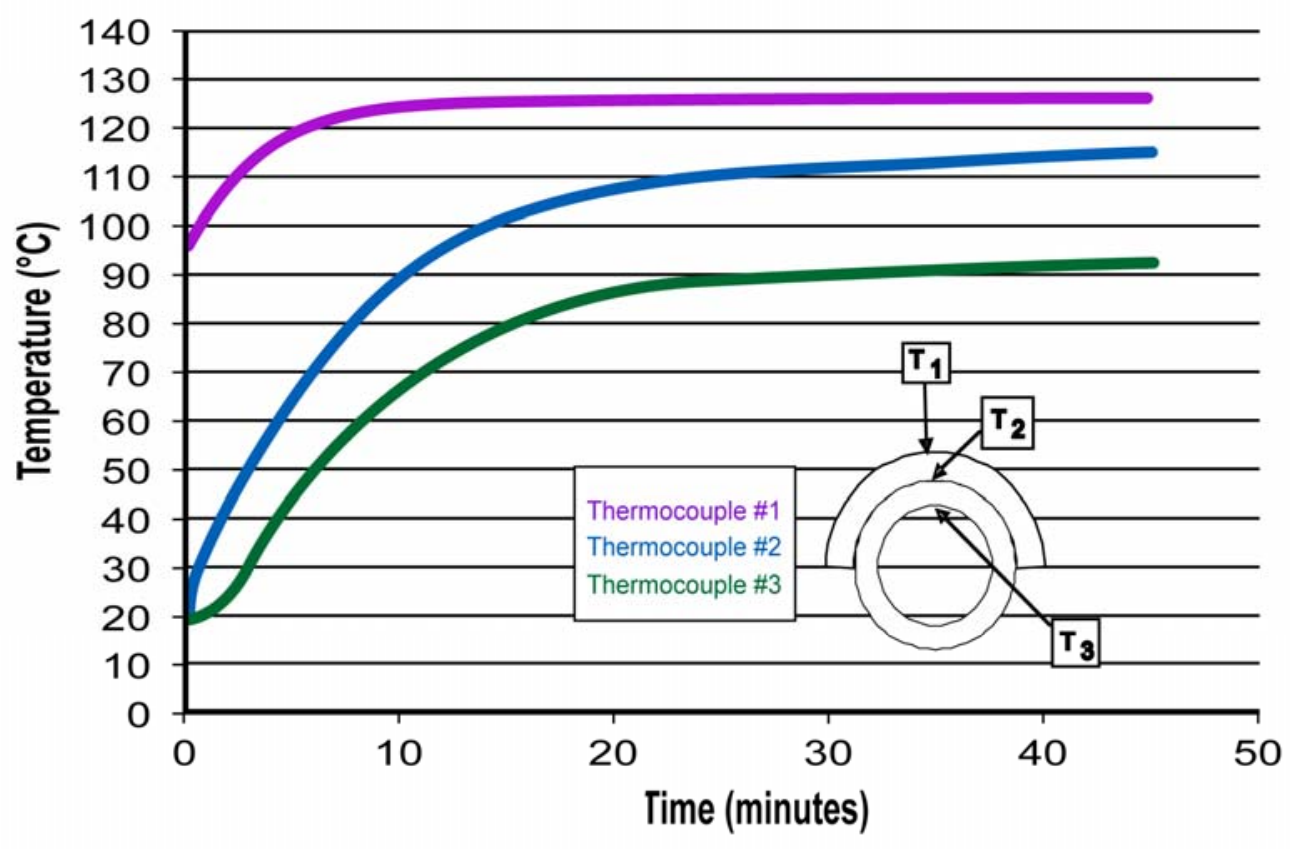

Figure 40: Temperature vs. heating time for $257^{\circ} \mathrm{F} / 125^{\circ} \mathrm{C}$ platen temperature 


\section{Task 9.0 - Laboratory Testing On Repaired PE Pipe Samples}

The technical objective of this task was to perform laboratory tests on sections of pipe repaired using the engineered prototype from the in-house and field tests in Tasks 8.1 and 10.

\section{Subtask 9.1 - Pressure Testing}

The technical objective of this subtask was to determine the overall performance of the HDPE repair patch (full wrap-overlapping PE gel film) using quick-burst testing to $600 \mathrm{psi}$, sustained pressure testing to $200 \mathrm{psi}$ and stress-rupture regression on PE pipe samples repaired by the engineered prototype in Phase 2 . Tests were conducted to determine the overall performance of the repair patch (including bonding) with ASTM D1599 quick-burst tests (Figures 41 \& 42) at $73^{\circ} \mathrm{F} / 23^{\circ} \mathrm{C}$ and $176^{\circ} \mathrm{F} / 80^{\circ} \mathrm{C}$; ASTM D1598 sustained pressure tests at $73^{\circ} \mathrm{F} / 23^{\circ} \mathrm{C}$ and $176^{\circ} \mathrm{F} / 80^{\circ} \mathrm{C}$; and $73^{\circ} \mathrm{F} / 23^{\circ} \mathrm{C}$ stress-rupture regression per ASTM D2837. Results of these tests showed successful bonding of a full wrap patch. Furthermore, a closed system full wrap-overlapping PE gel film patched pipe was held at room temperature and 200 psi for greater than 5 months without any loss in pressure (Figure 43).

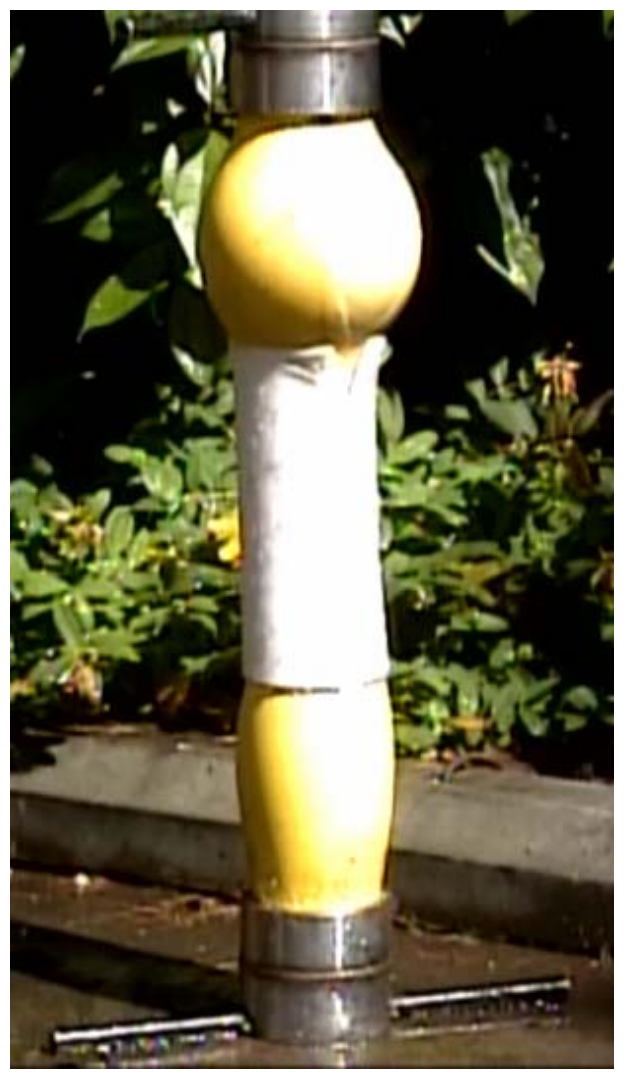

Figure 41: Quick burst test with overlapping full-wrap gel film patch shows successful bond at $\mathbf{5 0 0}$ psi 


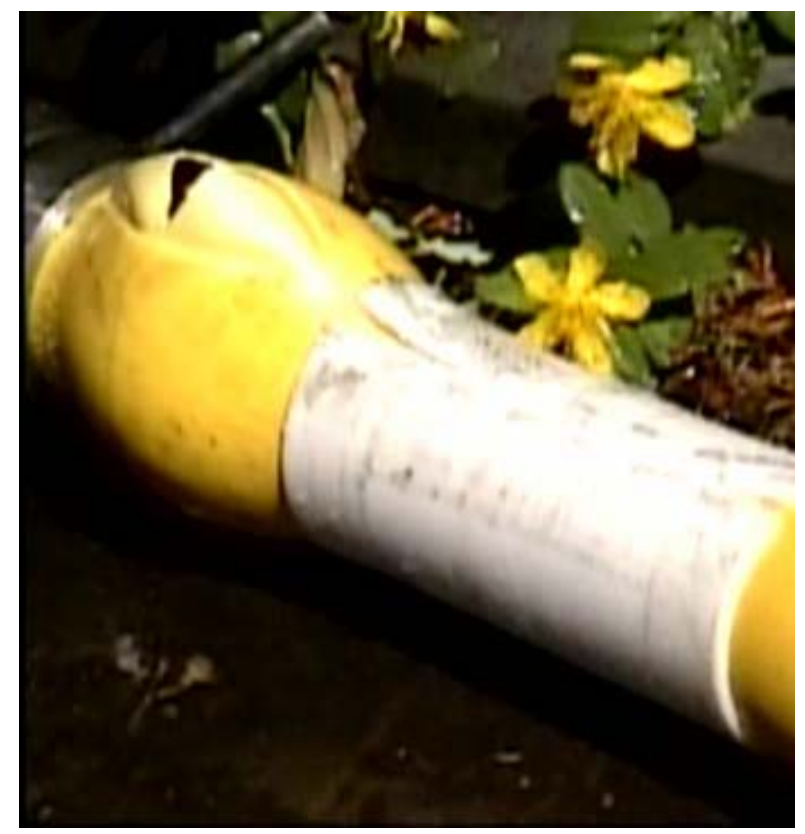

Figure 42: Quick burst test with overlapping full-wrap gel film patch shows successful bond \& pipe failure below the patch at 600 psi

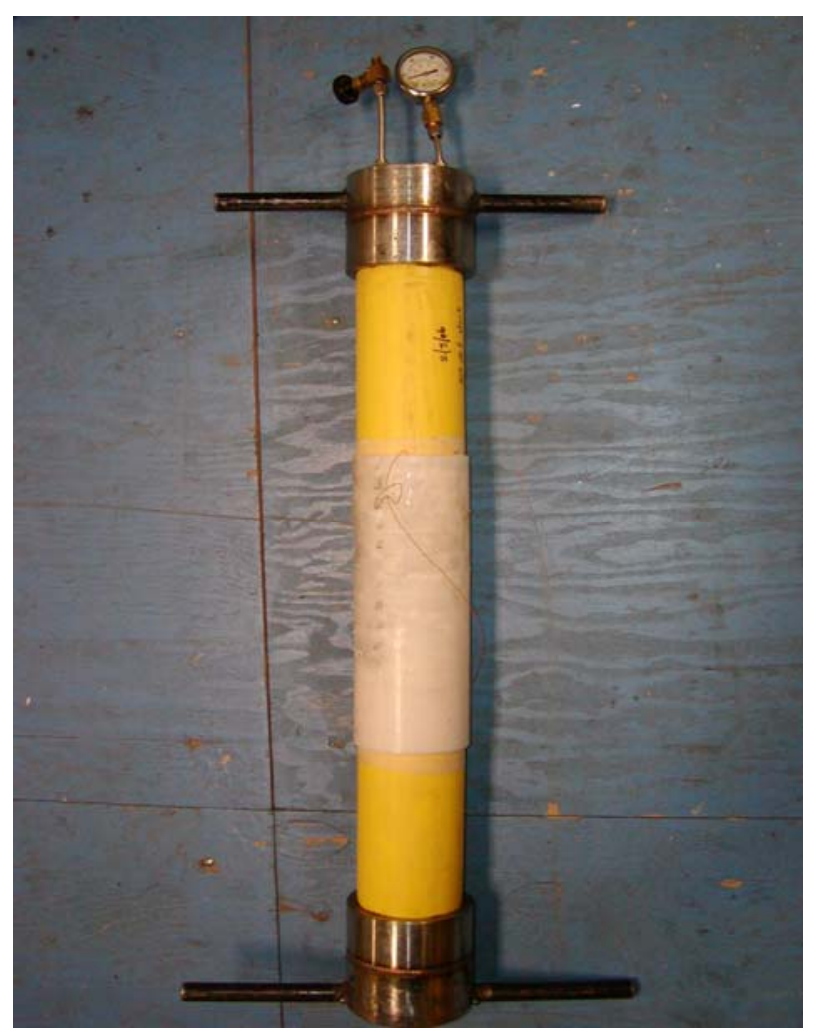

Figure 43: Closed system overlapping full-wrap gel film patch held at room temperature \& 200 psi for $>5$ months without any loss in pressure 


\section{Subtask 9.2 - Accelerated Age Testing}

The technical objective of this subtask was to determine the long-term safety and structural integrity of the PE pipe samples repaired by the engineered prototype utilizing thermal cycling of pressurized pipe sections between $-13^{\circ} \mathrm{F} /-25^{\circ} \mathrm{C}$ and $+176^{\circ} \mathrm{F} /+80^{\circ} \mathrm{C}$, and pressure cycling of pipe at constant temperatures of $73^{\circ} \mathrm{F} / 23^{\circ} \mathrm{C}$. The testing was accomplished as per ASTM D1598 and ASTM D1599.

Initial accelerated age testing of repaired pipe sections showed that the applied 3/16" thick HDPE patches developed a small crack in the high-stress areas surrounding the patched hole within the first 48 hours of hot water testing (Figure 44), which indicates the patch material has an approximate 25-year lifespan. Based on these results, the repair patch material will need to be stronger to achieve a satisfactory 50 year patch system. The use of very high molecular weight PE (VHMWPE) or UHMWPE for the patch material is being investigated.

Additional tests were also conducted to evaluate whether any of the critical performance properties of the PE pipe were reduced or compromised by the repair technique and product. This testing verified a satisfactory 50-year patch system. Ongoing testing includes external pressure tests to determine if the repaired pipe section is vulnerable to compressive failure at the site of the repair, and comparative impact testing per ASTM D2444.

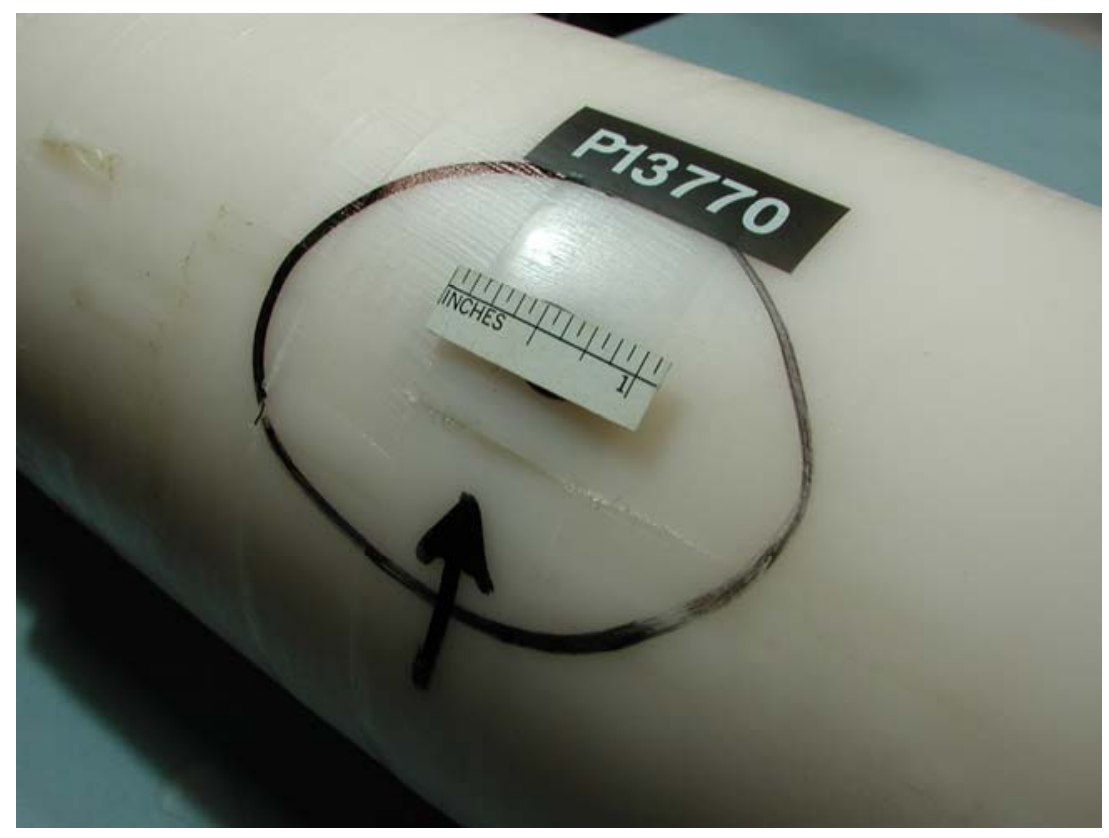

Figure 44: Photo of HDPE patch material failure at the 25-year mark during accelerated age testing 
This HDPE repair patch substrate failure was of a brittle nature that was not seen in the room temperature lap shear tests in Task 8.2. In order to find the mechanism associated with these failures, lap shear samples were thermally "aged" in days and then pulled to find what effect thermal aging had on the bonds and substrates.

These tests showed that the adhesive bond interfaces retained the majority of their strength, while the HDPE substrates themselves became embrittled and weakened. Figure 45 shows this weakening trend for HDPE as a function of time in $176^{\circ} \mathrm{F} / 80^{\circ} \mathrm{C}$ water. The HDPE lost more than half of its strength within 5-6 days at these conditions.

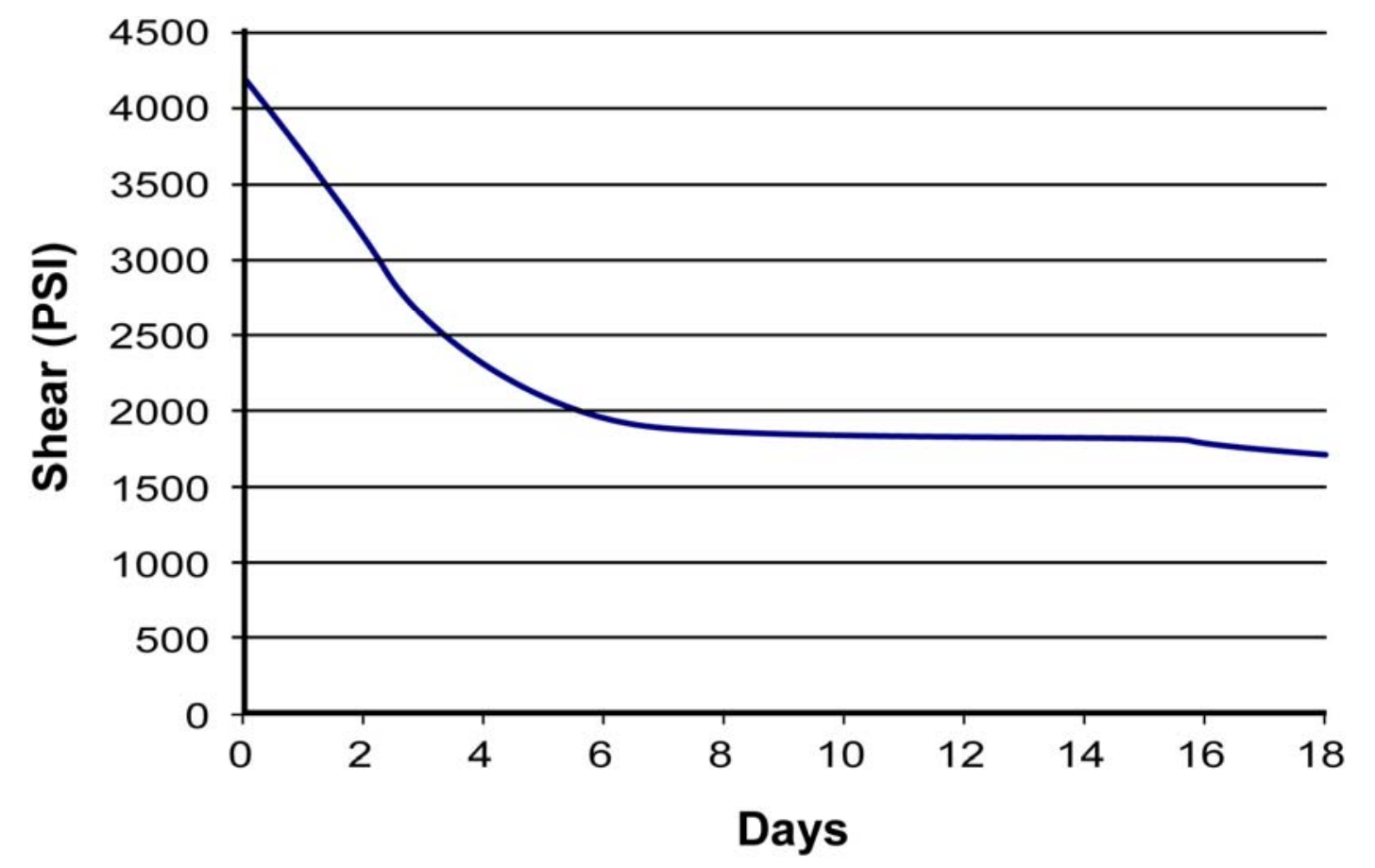

Figure 45: Graph of HDPE patch material strength loss vs. time (days) 
The same information is presented in Figure 46, where the average pull data (shear) was graphed for 5, 15, and 18 days, compared to non-aged samples (baseline).

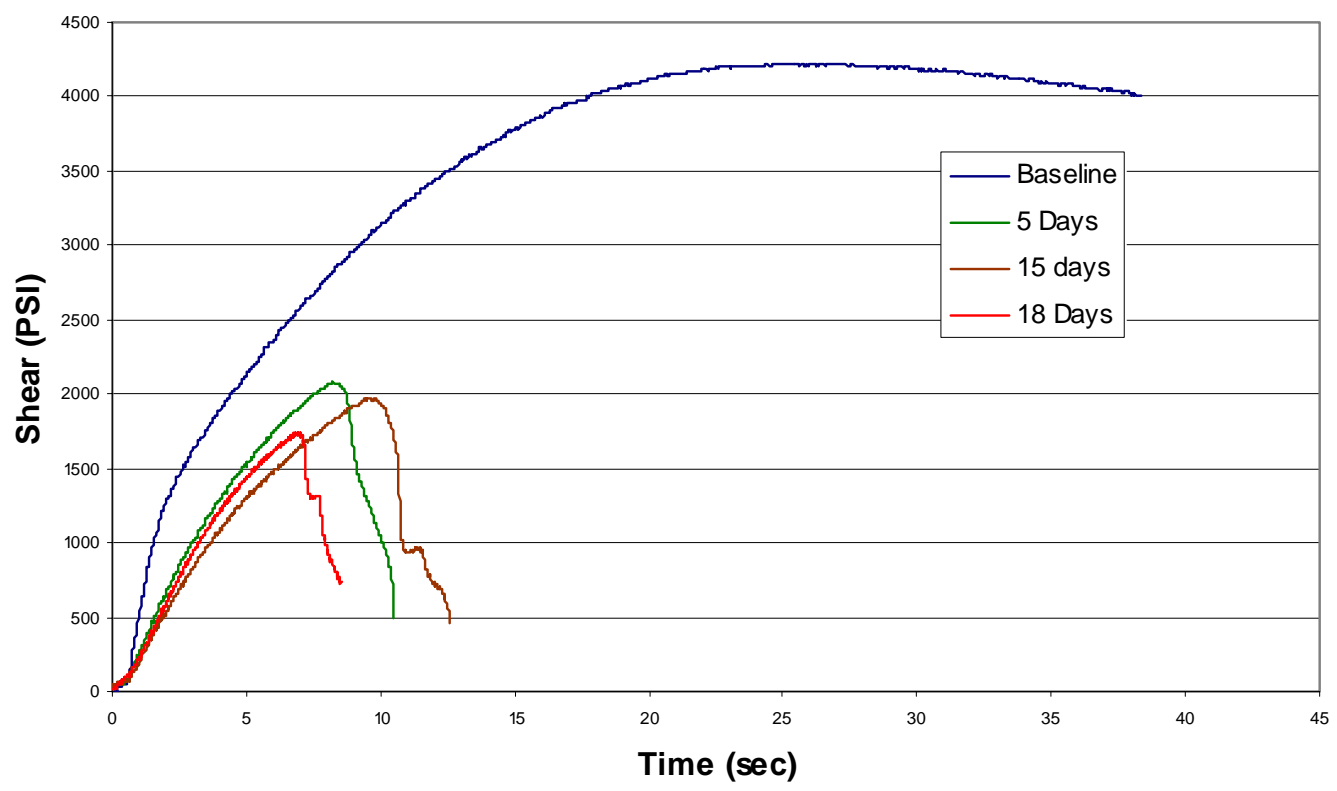

Figure 46: Graph of HDPE patch material strength loss at 5, 15, and 18 days

Figure 47 compares samples of broken embrittled HDPE lapshear samples that were subjected to solvent and the typical necking seen in the control HDPE sample of the same material.

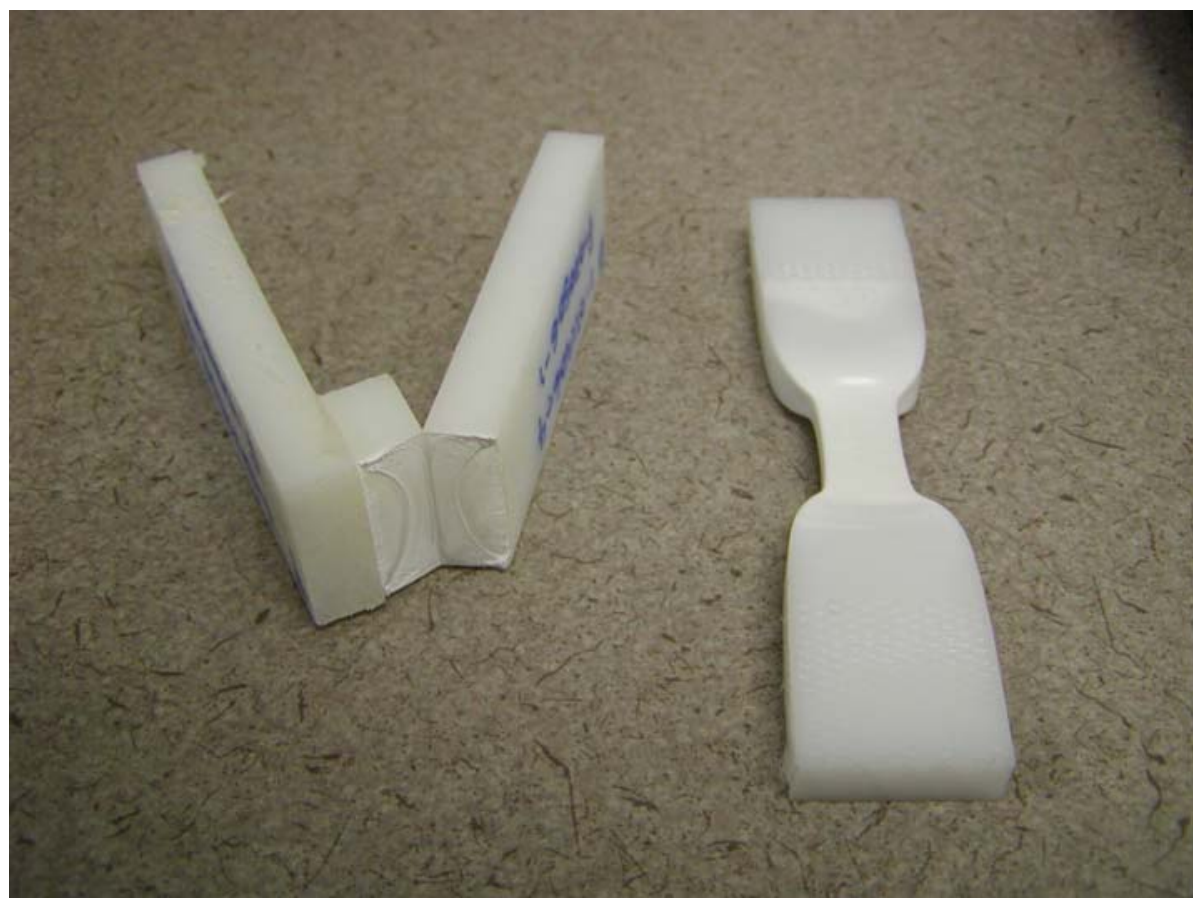

Figure 47: Broken embrittled HDPE material (left) compared to typical necking in HDPE control sample (right) 
As a result of these tests, further research was initiated to identify the optimum patch material. Preliminary tests with VHMWPE and UHMWPE as a patch material provided very positive results with respect to bonding and lack of embrittlement. It is anticipated that use of VHMWPE and UHMWPE for the patch material will alleviate the embrittlement issues that were seen with the HDPE.

\section{$\underline{\text { Task } 10 \text { - Field Evaluation Of Engineered prototype }}$}

The technical objective of this task was to perform field evaluations of the engineered prototype. The engineered prototype used in these demonstrations was developed as reported in Task 8.1 during Phase 2 of this project. The repair patches were prepared at OSU according to procedures developed in Task 8.2. For safety reasons, natural gas company operating procedures require extensive laboratory testing of new products and technologies prior to field testing under live conditions. Therefore, this task was performed on pressurized pipe in a laboratory setting instead of actual field conditions. The results of these simulated field conditions are listed below:

At demonstrations performed for Southwest Gas Company in Tempe, Arizona on September 10, 2005, a repair patch was applied over a 1-inch diameter hole drilled into the wall of two $4 \mathrm{ft}$. sections of 4-inch IPS SDR 11.5 HDPE pipe pressurized to 65 psi. The HDPE substrate/UHMWPE swollen film repair patch was applied using the engineered prototype repair tool developed during Phase 2. Both repair patches successfully bonded to the pipe, completely sealing off the leak under pressure. Quick burst tests were performed on the repaired pipe sections at Southwest Gas facilities. The results of these tests confirmed the PE pipe material failed while the repair patches held at 600 psi.

At demonstrations performed for Nicor Gas in Naperville, Illinois on April 19,2006, a HDPE PE gel film repair patch was applied over a 1-inch hole drilled into the wall of one $4 \mathrm{ft}$ section of 4 -inch IPS SDR 11.5 MDPE pipe. A similar repair patch was also applied over a second $4 \mathrm{ft}$ section of pipe with a series of holes drilled through the pipe wall in a pattern that approximated a 2"x 4" hole. Both sections of pipe were pressurized to 65 psi during application. Both repair patches successfully bonded the patch to the pipe. These sections were subsequently subjected to long term testing according to ASTM D1563 at Nicor's facilities. Within 48 hours, the patch material (HDPE) developed a small crack directly over the hole in both pipe samples. However, the bond between the patch and pipe was not affected. These findings were consistent with prior work at OSU (see Figures 48, 49, and 50). 


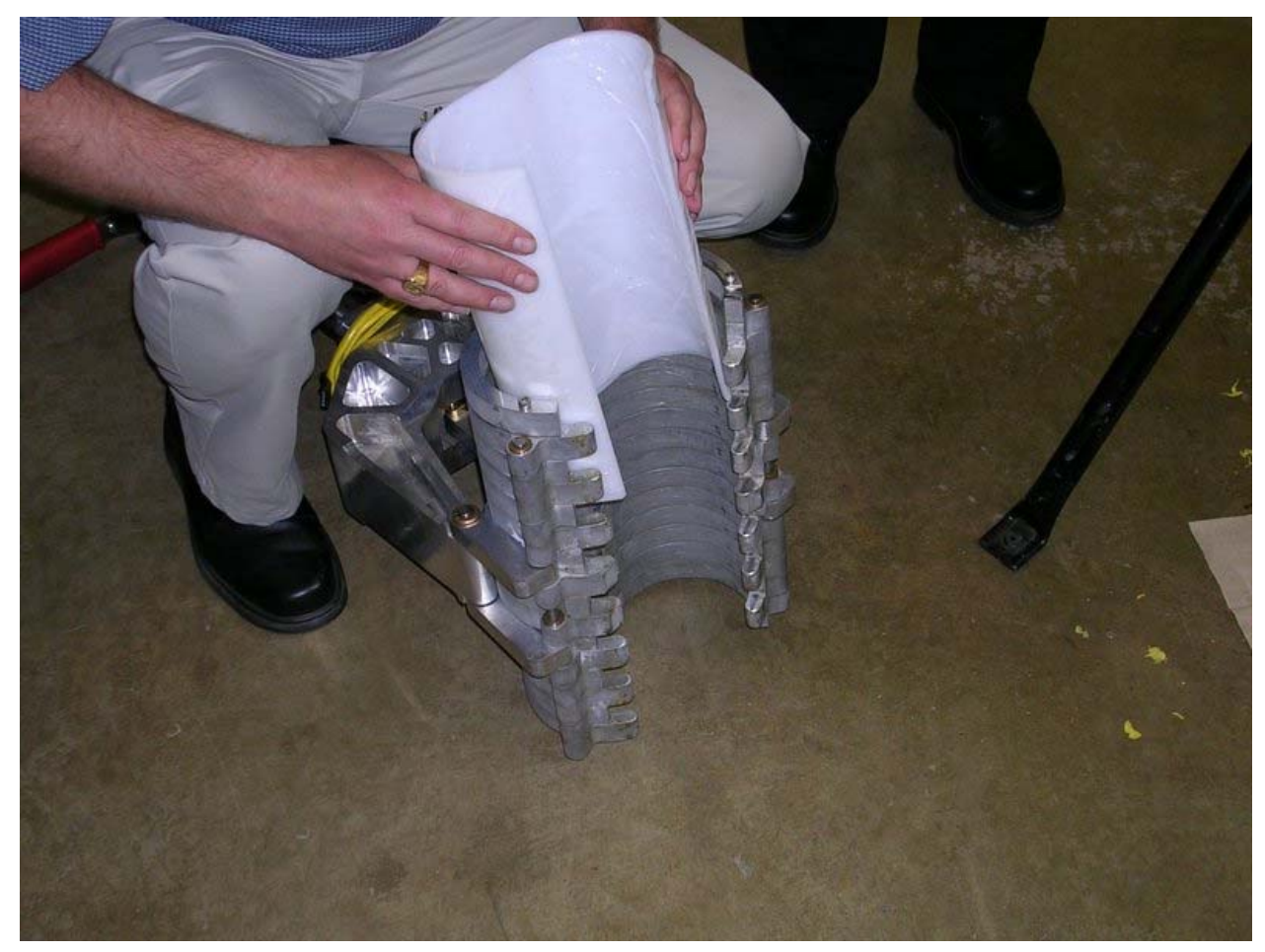

Figure 48: PE gel film repair patch being loaded into the engineered prototype for Nicor Gas demonstration in Naperville, IL

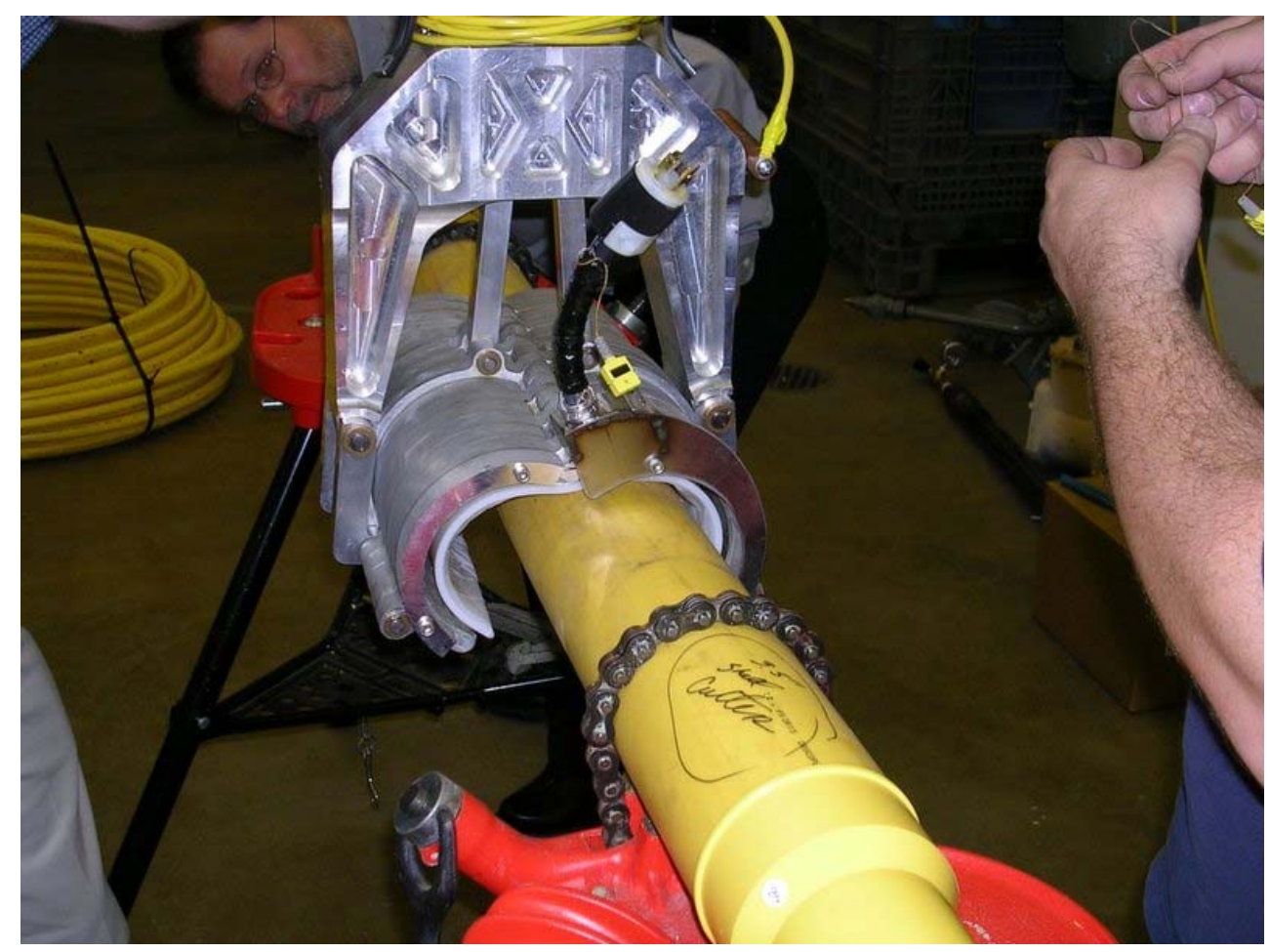

Figure 49: Engineered prototype with PE gel film repair patch being applied to damaged 4-inch MDPE pipe 


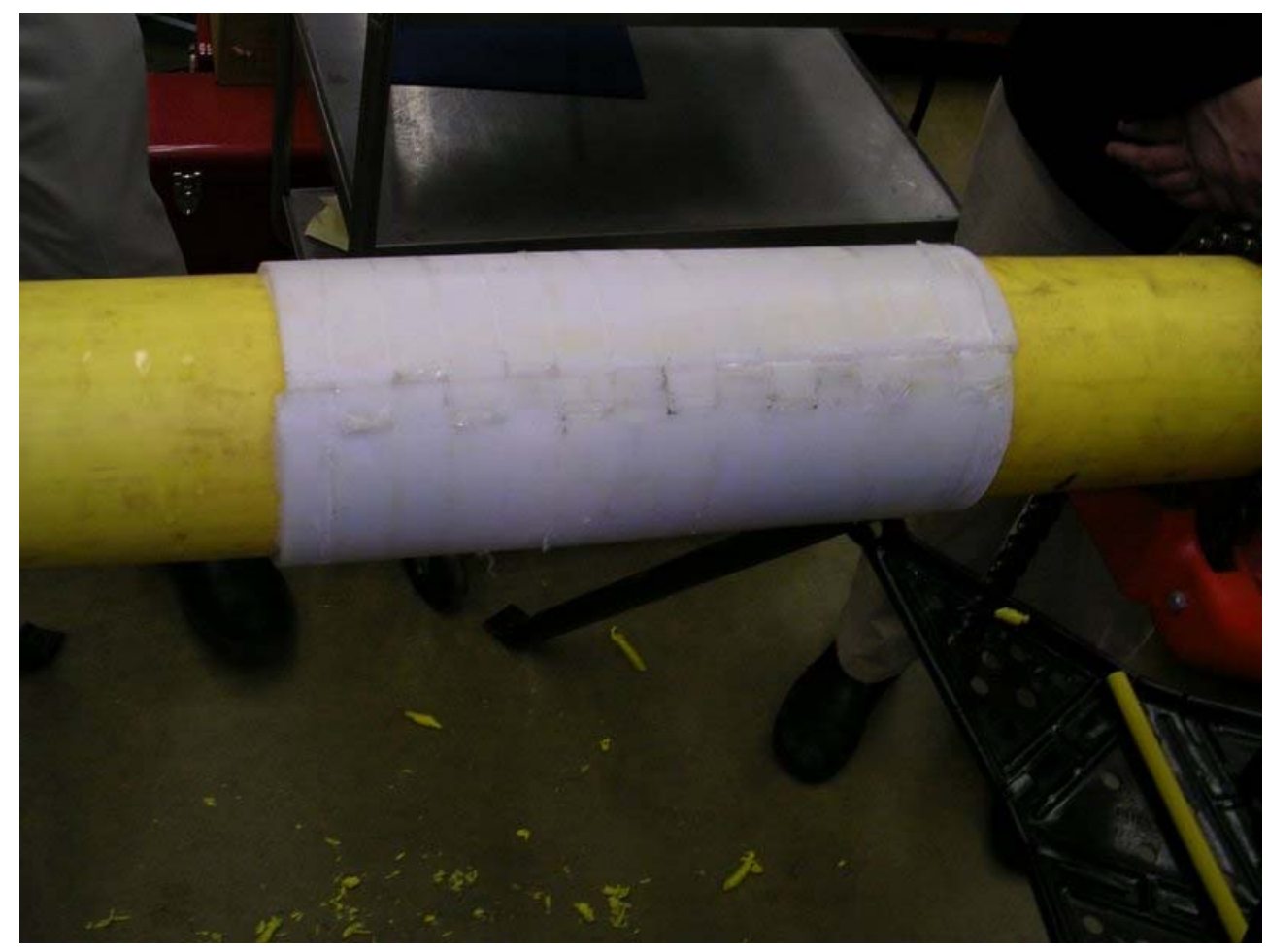

Figure 50: PE gel film patch successfully repaired a damaged 4-inch MDPE pipe

At demonstrations performed for Questar Gas in Salt Lake City, Utah on May 16, 2006, a HDPE substrate/UHMWPE gel film repair patch was applied over a 1-inch hole drilled into the wall of one $4 \mathrm{ft}$ section of 4-inch IPS SDR 11.5 MDPE pipe. A second identical patch was also applied to a damaged $4 \mathrm{ft}$ section of 4 " IPS SDR 11.5 MDPE that was covered with dirt. The simulated damage was a 1-inch hole with a gouge approximately 1 "x 2 " radiating out from it. Both pipe samples were pressurized to $95 \mathrm{psi}$. Both repair patches successfully bonded the patch to the pipe at 95 psi. However, upon accelerated age testing the patch material (HDPE) failed at the site of the damage. The bond strength between the patch and the pipe was not affected. These tests confirmed that the PE gel film patch successfully bonds to the damaged PE pipe. However, further research is necessary to find the optimum PE material for the patch. 
At demonstrations performed at Sempra Energy in Los Angeles, California on May 25, 2006, a HDPE substrate/ UHMWPE swollen PE gel film repair patch was applied over a 1-inch hole drilled into the wall of one $4 \mathrm{ft}$ section of 4-inch IPS SDR 11.5 HDPE pipe. A second identical patch assembly was applied to an oxidized $4 \mathrm{ft}$ section of 4-inch Aldyl-A pipe (Figure 51). This section of pipe had been buried in the ground for 25 years. The HDPE pipe was pressurized to 65 psig. The Aldyl-A pipe was not pressurized. Both repair patches successfully bonded to the pipe. The HDPE pipe section was subjected to 670 psi hoop stress ( $107 \mathrm{psig})$ in $176^{\circ} \mathrm{F} / 80^{\circ} \mathrm{C}$ water for 48 hours. As seen in prior tests at other gas companies, a small crack developed at the area of damage. However, the bond between the pipe and the patch was not affected. The repaired pipe samples were sent to the laboratory at OSU for further SEM tests (as discussed in Task 9.2).

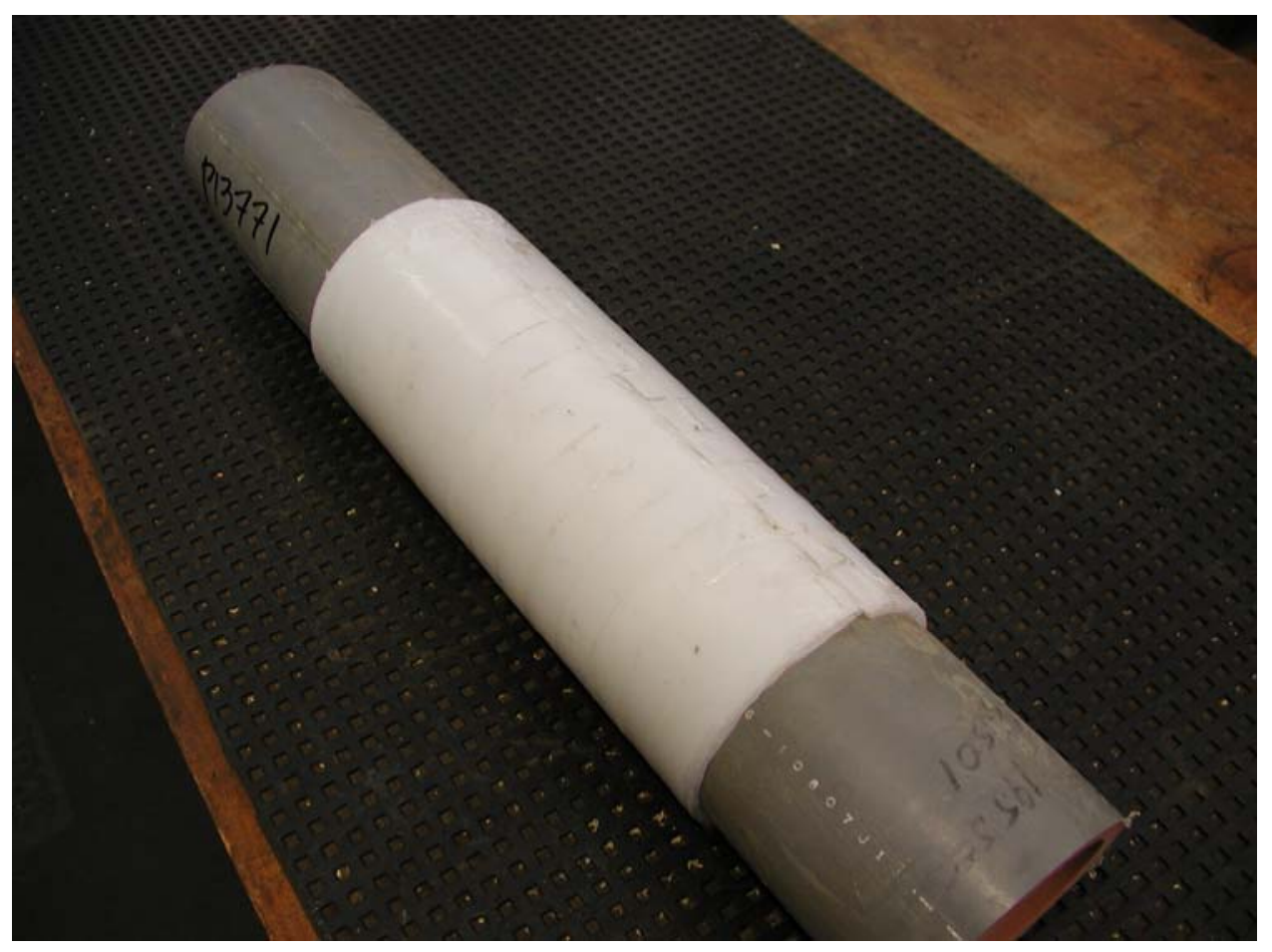

Figure 51: Overlapping full-wrap PE gel film patch successfully bonded to oxidized 4-inch IPS Aldyl-A pipe during demonstration for Sempra Energy 


\section{Task 11 - Performance \& Design Assessment of the Engineered prototype}

The design and performance of the engineered prototype (Figure 52) and the thermo-chemical patch process were successfully evaluated by the project team with critical input from the natural gas utility partners. The engineered prototype was evaluated against the design constraints as originally set forth in the proposal.

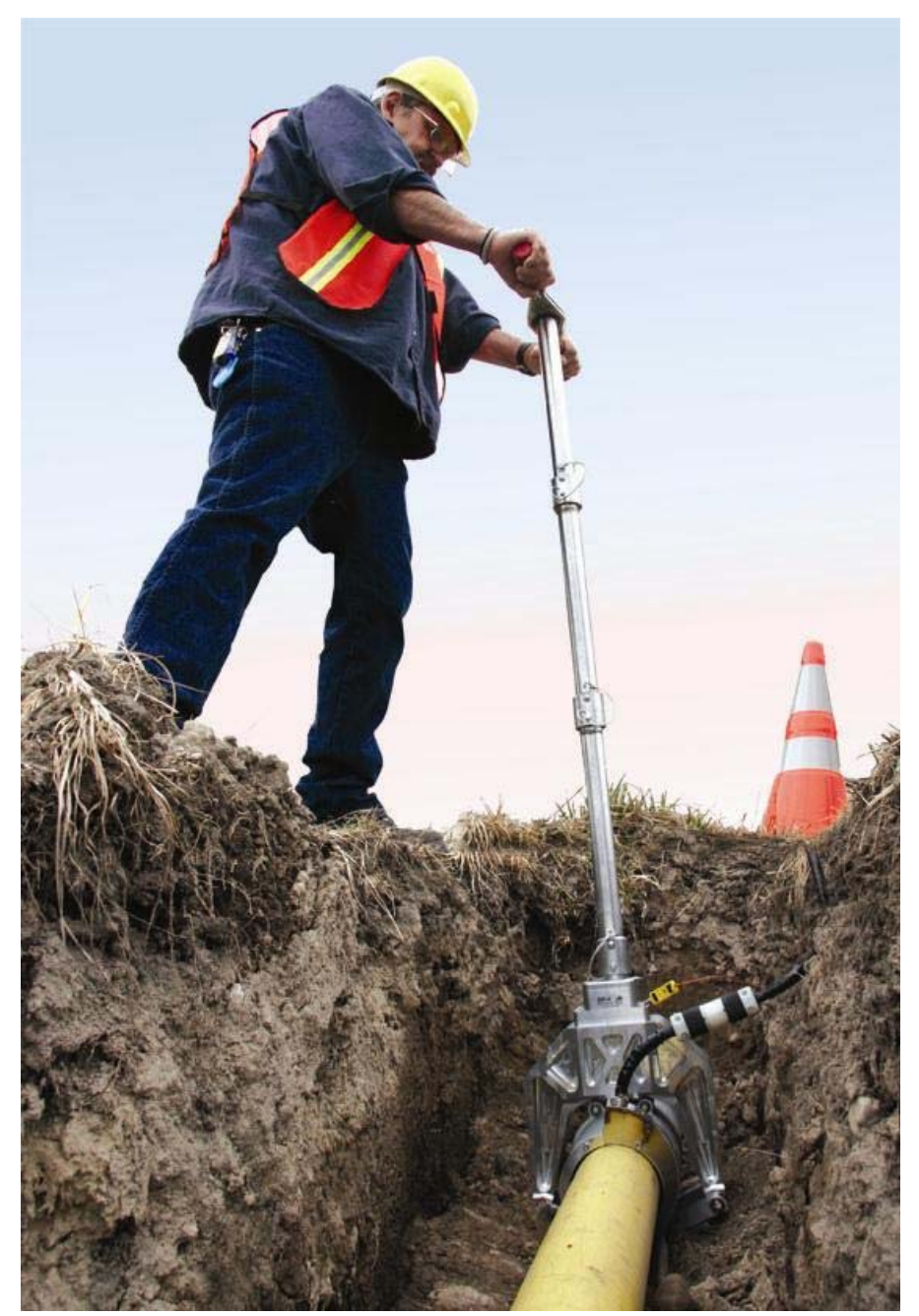

Figure 52: Final engineered prototype applying a $P E$ gel film patch on 4-inch MDPE pipe 
Summary of the evaluation:

- Does not provide a source of ignition: To meet this requirement low or non-sparking materials, such as aluminum, were used.

- Does not require a person to enter the ditch: The tool is fully operable from ground level.

- Tool functions in an 18-inch diameter keyhole: The tool is fully operable within an 18-inch diameter keyhole.

- Requires less than four inches of excavation under the pipe: The tool can apply a patch underneath the pipe within this minimum distance.

- Weigh less than 60 lbs.: The repair tool weighs less than 40 pounds.

- Requires only one person for operation: The repair tool is easily operable by one person.

- Meets physical requirement of ASTM F 1563-01: The repair tool meets the requirements of ASTM F1563-01. The tool applies the thermochemical patch that retains or improves pipe integrity and fully encompasses the circumference of the pipe.

- Applies a thermo-chemical patch that stops the flow of gas from the leak: The repair tool is able to stop the flow of gas immediately upon application, and applies sufficient pressure to the patch and pipe to maintain the seal.

- Constructed from chemical and/or thermo resistant materials: The tool is able to withstand any adverse affects from these processes.

In addition to the original design constraints, the engineered prototype was also evaluated for the following.

Assessment of the mechanical tool:

- The increased length and width of the jaws made it possible to repair most types of damage that might be encountered.

- The new (wider) jaws heated quickly and held temperature.

- The current design works only on 4-inch diameter pipe. Further research is necessary to determine if it is possible to modify the design for one tool to perform repairs on more than one pipe size.

Assessment of the thermo-chemical process:

- PE gel film patch was selected for the chemical repair process.

- HDPE patch material was reliable up to 25 year simulated lifespan.

- VHMWPE and UHMWPE will be investigated for patch material to withstand 50 year lifespan.

- Continue the research to imbed the heating element in the PE gel film to reduce application time. 


\section{Conclusion}

Current procedures for repairing PE pipe require excavation, isolation, and removal of the damaged section of pipe followed by fusing a new section of pipe into place. These techniques are time consuming, costly and very disruptive because the gas supply to homes and businesses is shut off while the repairs are made. An alternative repair method was developed at Timberline Tool with support from Oregon State University (OSU) and funding by the U.S. Department of Energy National Energy Technology Laboratory (DOE/NETL). By perfecting this repair process, thousands of pipe leaks (estimated at 150,000 per year) will be repaired at a fraction of the current remediation cost, saving on average, $\$ 2250$ per repair.

The DOE/NETL sponsored phase of development for a remote external repair tool that can be installed on damaged 4-inch PE pipe under system operating pressure is complete. This project successfully developed: (1) A thermo-chemical patch to bond PE to PE; (2) A mechanical tool to apply the thermo-chemical patch to a damaged or defective PE pipe under line pressure; (3) A remote, external repair tool for use in open trench or keyhole excavations; (4) A permanent repair method for PE pipe to provide substantial cost savings; and (5) A new method for quick, safe repair of PE pipe at the site of damage.

Since the design of the repair tool was intended to cope with a range of damage that can occur in service, the principal design challenge was to repair of a large opening (i.e. breach or gouge) in the pipe wall that allows pressurized gas to escape.

Therefore, the tool was designed to encapsulate the pipe at the sight of damage and apply the patch to immediately seal off the flow and stop the escape of gas. Various conceptual designs were developed for the mechanical tool to apply the thermochemical patch to repair the damaged areas of pipe. Work included 3D modeling the optimum design to ensure remote operation, keyhole application, and compliance with natural gas industry operating practices. Optimum design parameters included: a hinging, mechanical, aluminum jaw that opens to allow for top-down application, a curved jaw configuration for encapsulation of the pipe at the area of damage, jaws capable of heating the patch, and a closing mechanism on the tool for applying slight pressure (approximately $10 \mathrm{psi}$ ) to the pipe being repaired. Work also included the investigation of two unique repair approaches: (1) PE gel bonding for a repair patch and (2) an adhesive based patch approach. Both methods incorporated the use of the same mechanical tool to apply the patch and a method for heating the jaws to deliver the patch was developed. The preferred concept for the engineered prototype was designed and 3-D modeled. Functionality testing was performed on the engineered prototype and laboratory tests were performed on the repaired PE pipe sections.

Both the PE gel bonding and adhesive based patch demonstrated successful cohesion with the PE pipe; however the PE gel bonding approach emerged as the most promising and cost effective. A PE gel film patch utilizing an UHMWPE gel 
with a HDPE patch material was developed with this approach. The strength characteristics of the HDPE patch reduced the thickness requirement of the patch to less than 1/4" and increased its flexibility. This allowed for optimal placement over the damaged pipe.

The new repair tool technology was tested successfully in the laboratory. The mechanical tool to apply the thermo-chemical patch functioned as required when demonstrated at several natural gas companies. However, additional research is necessary to determine the optimum patch substrate to achieve a successful 50year life of the patch material. Further research will investigate moving the point of heat closer to the pipe, within the patch itself, to minimize the time required to repair the pipe. This research will continue over the next year followed by extensive laboratory and field tests at operating facilities of natural gas utility partners.

Overall the results of this project established a successful design and developed a permanent external repair method for use on damaged PE gas pipe in a safe and cost effective manner. 


\section{Acknowledgements}

The authors thank the Department of Energy and the National Energy Technology Laboratory for their financial, technical, and administrative assistance in funding and managing the project through which this technology was developed. The authors would also like to thank NW Natural, Sempra Energy Utility, Questar Gas Company, Southwest Gas Corporation and Nicor Gas for all their support and efforts during field evaluations for this project. 


\section{References}

1. Kyle Simpson, Proceedings of the Natural Gas Conference: Merging Technologies for the Natural Gas Industry, DOE's Perspective on Natural Gas, keynote address (Houston, Texas, March 24-27, 1997),p1.

2. Gene F. Palermo, Tech News: New Standard Fortifies Testing of Corrugated HDPE Pipe Materials, ASTM Standardization News, (October 2001)

3. Natural Gas Infrastructure Reliability-Pathways for Enhanced Integrity Reliability and Deliverability, September 2002, DOE/Office of Fossil Energy and NETL

4. Dennis Jarnecke, Steve Gauthier, Michael M. Mamoun, GTI Plastic Pipe Technologies Save Time and Improve Reliability, 2001 AGA Operations Conference, Dallas, TX, (April 2001)

5. As cited in Timberline Tool/Natural Gas Industry correspondence, KeySpan Energy, Northwest Natural Gas, Southwest Gas Corporation, (February 2003 - September 2005).

6. K. Takagi, H. Fujimatsu, H. Usami, and S. Ogasawara, Adhesion Between High Strength and High Modulus Polyethylene Fibers by Use of Polyethylene Gel as an Adhesive, J. Adhesion Sci. Technol., v.10 no.9 (1996) pp 869-882

7. As cited in KeySpan Energy protocol, Timberline External Exothermic PE Repair Process (February 18, 2003) Mario Carbone, Senior Project Engineer, and Tony Savino, Manager, Operations Research, KeySpan Energy Delivery, Brentwood, NY.

8. As cited in personal communication (October 10, 2003, John Hunt, Timberline Tool and Reid Hess, Construction Training, Questar Gas Company, Salt Lake City, UT) 


\section{List of Acronyms and Abbreviations}

$\begin{array}{ll}\text { ALDYL-A } & \text { ALDYL-A PE Pipe } \\ \text { ASTM } & \text { American Society for Testing Materials } \\ \text { A356-T6 } & \text { Aluminum Alloy } \\ \text { CAD } & \text { Computer Aided Design } \\ \text { CAM } & \text { Computer Aided Machining } \\ \text { CNC } & \text { Computer Numerically Controlled } \\ \text { DOE } & \text { Department of Energy } \\ \text { DSC } & \text { Differential Scanning Calorimetry } \\ \text { HDPE } & \text { High Density Polyethylene Pipe } \\ \text { IPS } & \text { Iron Pipe Size } \\ \text { LDPE } & \text { Low Density Polyethylene Pipe } \\ \text { MDPE } & \text { Medium Density Polyethylene Pipe } \\ \text { NETL } & \text { National Energy Technology Laboratory } \\ \text { NWNG } & \text { Northwest Natural Gas Company } \\ \text { OSU } & \text { Oregon State University } \\ \text { PE } & \text { Polyethylene } \\ \text { PSI } & \text { Pounds per Square Inch } \\ \text { PSIG } & \text { Pounds per Square Inch Gauge } \\ \text { SDR } & \text { Standard Dimension Ratio } \\ \text { SEM } & \text { Scanning Electron Microscopy } \\ \text { UHMWPE } & \text { Ultra High Molecular Weight Polyethylene } \\ \text { VHMWPE } & \text { Very High Molecular Weight Polyethylene }\end{array}$




\begin{tabular}{|c|c|c|c|c|c|c|c|c|c|c|c|}
\hline \multicolumn{12}{|c|}{ Appendix A: Table 1 - Polyethylene Gel Patch Failure Mode \& Shear Strength } \\
\hline Substrate & $\begin{array}{c}\text { Gel } \\
\text { Polymer }\end{array}$ & $\begin{array}{c}\text { Gel } \\
\text { Solvent }\end{array}$ & $\begin{array}{l}\text { Packaging } \\
\text { Film } \\
\text { Material }\end{array}$ & \begin{tabular}{|c|} 
Gel \\
Weight \\
Percent
\end{tabular} & $\begin{array}{c}\text { Gel } \\
\text { Thickness } \\
\text { (mm) }\end{array}$ & $\begin{array}{c}\text { Cure } \\
\text { Temperature } \\
\left({ }^{\circ} \mathrm{C}\right)\end{array}$ & $\begin{array}{c}\text { Cure } \\
\text { Time } \\
\text { (hours) }\end{array}$ & $\begin{array}{c}\text { Pressure } \\
\text { (gauge) } \\
\text { (PSIG) }\end{array}$ & Failure Mode & Comments & $\begin{array}{c}\text { Shear } \\
\text { Strength }\end{array}$ \\
\hline HDPE & HDPE & Decalin & LDPE & 6 & 0.81 & 110 & 1.5 & 40 & Cohesive & & 512 \\
\hline HDPE & HDPE & Decalin & LDPE & 6 & 0.81 & 110 & 1.5 & 40 & Cohesive & & 572 \\
\hline HDPE & HDPE & Decalin & LDPE & 8 & 1 & 115 & 1.5 & 30 & Cohesive & & 812 \\
\hline HDPE & HDPE & Decalin & LDPE & 8 & 1 & 115 & 1.5 & 30 & Cohesive & & 502 \\
\hline HDPE & HDPE & Decalin & LDPE & 8 & 1 & 115 & 1.5 & 30 & Cohesive & & 492 \\
\hline HDPE & HDPE & Decalin & LDPE & 6 & 1.19 & 120 & 1.5 & 20 & Cohesive & & 816 \\
\hline HDPE & HDPE & Decalin & LDPE & 6 & 1.19 & 120 & 1.5 & 20 & Cohesive & & 744 \\
\hline HDPE & HDPE & Decalin & LDPE & 6 & 1.19 & 120 & 1.5 & 20 & Cohesive & & 794 \\
\hline HDPE & HDPE & Decalin & LDPE & 10 & 0.81 & 120 & 1.5 & 40 & Cohesive & & 853 \\
\hline HDPE & HDPE & Decalin & LDPE & 10 & 0.81 & 120 & 1.5 & 40 & Cohesive & & 689 \\
\hline HDPE & HDPE & Decalin & LDPE & 8 & 0.81 & 120 & 1.5 & 40 & Cohesive & & 629 \\
\hline HDPE & HDPE & Decalin & LDPE & 8 & 0.81 & 110 & 1.5 & 40 & Cohesive & & 629 \\
\hline HDPE & HDPE & Decalin & LDPE & 8 & 0.81 & 110 & 1.5 & 40 & Cohesive & & 502 \\
\hline HDPE & HDPE & Decalin & LDPE & 8 & 0.66 & 115 & 1.5 & 30 & Cohesive & & 527 \\
\hline HDPE & HDPE & Decalin & LDPE & 8 & 0.66 & 115 & 1.5 & 30 & Cohesive & & 520 \\
\hline HDPE & HDPE & Decalin & LDPE & 10 & 1.19 & 110 & 1.5 & 20 & Cohesive & & 463 \\
\hline HDPE & HDPE & Decalin & LDPE & 10 & 1.19 & 110 & 1.5 & 20 & Cohesive & & 323 \\
\hline HDPE & HDPE & Decalin & LDPE & 10 & 0.81 & 120 & 1.5 & 20 & Cohesive & & 593 \\
\hline HDPE & HDPE & Decalin & LDPE & 10 & 0.81 & 120 & 1.5 & 20 & Cohesive & & 566 \\
\hline HDPE & HDPE & Decalin & LDPE & 10 & 1.19 & 110 & 1.5 & 40 & Cohesive & & 388 \\
\hline HDPE & HDPE & Decalin & LDPE & 10 & 1.19 & 110 & 1.5 & 40 & Cohesive & & 489 \\
\hline HDPE & HDPE & Decalin & LDPE & 8 & 1 & 115 & 1.5 & 30 & Cohesive & & 447 \\
\hline HDPE & HDPE & Decalin & LDPE & 8 & 1 & 115 & 1.5 & 30 & Cohesive & & 541 \\
\hline HDPE & HDPE & Decalin & LDPE & 8 & 1.34 & 115 & 1.5 & 30 & Cohesive & & 470 \\
\hline HDPE & HDPE & Decalin & LDPE & 8 & 1.34 & 115 & 1.5 & 30 & Cohesive & & 527 \\
\hline HDPE & HDPE & Decalin & LDPE & 8 & 1 & 115 & 1.5 & 46.8 & Cohesive & & 554 \\
\hline
\end{tabular}




\begin{tabular}{|c|c|c|c|c|c|c|c|c|c|c|c|}
\hline HDPE & HDPE & Decalin & LDPE & 8 & 1 & 115 & 1.5 & 46.8 & Cohesive & & 425 \\
\hline HDPE & HDPE & Decalin & LDPE & 6 & 0.81 & 110 & 1.5 & 20 & Cohesive & & 551 \\
\hline HDPE & HDPE & Decalin & LDPE & 6 & 0.81 & 110 & 1.5 & 20 & Cohesive & & 503 \\
\hline HDPE & HDPE & Decalin & LDPE & 6 & 1.19 & 120 & 1.5 & 40 & Cohesive & & 642 \\
\hline HDPE & HDPE & Decalin & LDPE & 6 & 1.19 & 120 & 1.5 & 40 & Cohesive & & 702 \\
\hline HDPE & HDPE & Decalin & LDPE & 8 & 1 & 123 & 1.5 & 30 & Cohesive & & 672 \\
\hline HDPE & HDPE & Decalin & LDPE & 8 & 1 & 123 & 1.5 & 30 & Cohesive & & 698 \\
\hline HDPE & HDPE & Decalin & LDPE & 8 & 1 & 106 & 1.5 & 30 & Cohesive & & 324 \\
\hline HDPE & HDPE & Decalin & LDPE & 8 & 1 & 106 & 1.5 & 30 & Cohesive & & 314 \\
\hline HDPE & HDPE & Decalin & LDPE & 11.4 & 1 & 115 & 1.5 & 30 & Cohesive & & 606 \\
\hline HDPE & HDPE & Decalin & LDPE & 11.4 & 1 & 115 & 1.5 & 30 & Cohesive & & 674 \\
\hline HDPE & HDPE & Decalin & LDPE & 4.6 & 1 & 115 & 1.5 & 30 & Cohesive & & 641 \\
\hline HDPE & HDPE & Decalin & LDPE & 6 & 0.81 & 115 & 1.5 & 20 & Adhesive/Cohesive & Not enough gel & 474 \\
\hline HDPE & HDPE & Decalin & LDPE & 8 & 0.81 & 115 & 1.5 & 20 & Cohesive & & 783 \\
\hline HDPE & HDPE & Decalin & LDPE & 10 & 0.81 & 115 & 1.5 & 40 & Cohesive & & 759 \\
\hline HDPE & HDPE & Decalin & LDPE & 6 & 0.81 & 115 & 1.5 & 40 & Cohesive & & 678 \\
\hline HDPE & HDPE & Decalin & LDPE & 8 & 0.81 & 115 & 1.5 & 40 & Cohesive & & 631 \\
\hline HDPE & HDPE & Decalin & LDPE & 8 & 1 & 120 & 1.5 & 30 & Cohesive & aged 1 week & 728 \\
\hline HDPE & HDPE & Decalin & LDPE & 8 & 1 & 120 & 1.5 & 30 & Cohesive & aged 1 week & 638 \\
\hline HDPE & HDPE & Decalin & LDPE & 8 & 1 & 120 & 1.5 & 30 & Cohesive & aged 2 weeks & 680 \\
\hline HDPE & HDPE & Decalin & LDPE & 8 & 1 & 120 & 1.5 & 30 & Cohesive & aged 2 weeks & 669 \\
\hline HDPE & HDPE & Decalin & LDPE & 8 & 1 & 120 & 1.5 & 30 & Cohesive & aged 4 weeks & 641 \\
\hline HDPE & HDPE & Decalin & LDPE & 8 & 1 & 120 & 1.5 & 30 & Cohesive & aged 4 weeks & 629 \\
\hline HDPE & HDPE & Decalin & $|\operatorname{LDPE}(0.04 ")|$ & 6 & 0.81 & 115 & 1.5 & 20 & Cohesive & & 725 \\
\hline
\end{tabular}




\begin{tabular}{|c|c|c|c|c|c|c|c|c|c|c|}
\hline \multicolumn{11}{|c|}{ Appendix B: Table 2 - Polyethylene Swollen Film Failure Mode and Shear Strength } \\
\hline Substrate & $\begin{array}{c}\text { Swollen } \\
\text { Film }\end{array}$ & $\begin{array}{c}\text { Film } \\
\text { Solvent }\end{array}$ & $\begin{array}{c}\text { Packaging } \\
\text { Film } \\
\text { Material }\end{array}$ & $\begin{array}{c}\text { Film } \\
\text { Weight } \\
\text { Percent }\end{array}$ & $\begin{array}{c}\text { Cure } \\
\text { Temperature } \\
\left({ }^{\circ} \mathrm{C}\right)\end{array}$ & $\begin{array}{c}\text { Cure Time } \\
\text { (hours) }\end{array}$ & $\begin{array}{l}\text { Pressure } \\
\text { (gauge) } \\
\text { (PSIG) }\end{array}$ & $\begin{array}{l}\text { Failure } \\
\text { Mode }\end{array}$ & Comments & $\begin{array}{l}\text { Shear } \\
\text { Strength }\end{array}$ \\
\hline HDPE & UHMWPE & Decalin & none & 60 & 121 & 90 & 20 & Adhesive & & 650 \\
\hline HDPE & UHMWPE & Decalin & none & 60 & 121 & 90 & 20 & Adhesive & & 675 \\
\hline HDPE & UHMWPE & Decalin & none & 60 & 121 & 90 & 20 & Adhesive & & 450 \\
\hline HDPE & UHMWPE & Decalin & none & 40 & 121 & 90 & 20 & $A-C$ & & 890 \\
\hline HDPE & UHMWPE & Decalin & none & 40 & 121 & 90 & 20 & $A-C$ & & 820 \\
\hline HDPE & UHMWPE & Decalin & none & 40 & 121 & 90 & 20 & $A-C$ & & 680 \\
\hline HDPE & UHMWPE & Decalin & none & 20 & 121 & 90 & 20 & Cohesive & & 1300 \\
\hline HDPE & UHMWPE & Decalin & none & 20 & 121 & 90 & 20 & Cohesive & & 1520 \\
\hline HDPE & UHMWPE & Decalin & none & 20 & 121 & 90 & 20 & Cohesive & & 1280 \\
\hline HDPE & HDPE & Decalin & none & 75 & 121 & 90 & 20 & Adhesive & Pretest fail & 0 \\
\hline HDPE & HDPE & Decalin & none & 75 & 121 & 90 & 20 & Adhesive & & 375 \\
\hline HDPE & HDPE & Decalin & none & 75 & 121 & 90 & 20 & Adhesive & & 440 \\
\hline HDPE & HDPE & Decalin & none & 60 & 121 & 90 & 20 & Adhesive & & 430 \\
\hline HDPE & HDPE & Decalin & none & 60 & 121 & 90 & 20 & Adhesive & & 460 \\
\hline HDPE & HDPE & Decalin & none & 60 & 121 & 90 & 20 & Cohesive & & 600 \\
\hline HDPE & HDPE & Decalin & none & 40 & 121 & 90 & 20 & $A-C$ & & 860 \\
\hline HDPE & HDPE & Decalin & none & 40 & 121 & 90 & 20 & $A-C$ & & 960 \\
\hline HDPE & HDPE & Decalin & none & 40 & 121 & 90 & 20 & $A-C$ & & 780 \\
\hline HDPE & HDPE & Decalin & none & 20 & 121 & 90 & 20 & Cohesive & & 1240 \\
\hline HDPE & HDPE & Decalin & none & 20 & 121 & 90 & 20 & Cohesive & & 1390 \\
\hline HDPE & HDPE & Decalin & none & 20 & 121 & 90 & 20 & Cohesive & & 1240 \\
\hline HDPE & HDPE & Decalin & none & 30 & 121 & 90 & 20 & Adhesive & & 500 \\
\hline HDPE & HDPE & Decalin & none & 30 & 121 & 90 & 20 & Adhesive & & 1020 \\
\hline HDPE & HDPE & Decalin & none & 30 & 121 & 90 & 20 & Adhesive & & 550 \\
\hline
\end{tabular}

